\title{
CONSUMERS' CHOICE FACTORS OF AN UPSCALE ETHNIC RESTAURANT
}

\author{
A thesis \\ submitted in partial fulfilment \\ of the requirements for the Degree of \\ Master of Commerce and Management
}

at

Lincoln University

by

Chirawan Sriwongrat

Lincoln University

2008 


\title{
ABSTRACT
}

\author{
Abstract of a thesis submitted in partial fulfilment of the \\ requirements for the Degree of M.C. M.
}

\section{CONSUMERS' CHOICE FACTORS OF AN UPSCALE ETHNIC RESTAURANT}

\author{
By Chirawan Sriwongrat
}

Globally, there is a growing demand for food away from home as a result of higher incomes, changes in consumption patterns, changes in household composition, and the time pressures created by dual-working families. The foodservice industry has become highly competitive as the number of foodservice outlets has increased to meet the demand. In order to succeed in such a competitive industry, restaurant operators need to understand the factors (and their relative importance) that influence restaurant patrons' decision when selecting a restaurant.

The demand for ethnic foods has also increased, in New Zealand and worldwide, due to the influences of ethnic diversity, overseas food and cultural experiences, and media exposure. Despite the importance of restaurant choice criteria and a growth in popularity of ethnic foods, published research on consumers' restaurant selection behaviour that focuses on the ethnic segment is relatively limited. Furthermore, there are no published empirical studies on ethnic restaurant choice behaviour in New Zealand. This research aims to fill these gaps in the literature by empirically identifying the factors that influence a decision to dine at an upscale ethnic restaurant, their relative importance, as well as their relationships with dining occasion and consumer characteristics.

Focus group discussions and the literature review helped identify a set of restaurant choice factors. A mail survey was used to collect the data. Factor analysis was used to refine the restaurant choice factors, and logistic regression analysis identified the five 
significant factors that influence consumers' decision. These are: Dining Experience, Social Status, Service Quality, Food Quality, and Value for Money, listed in order of their importance. The results of t-tests and ANOVA suggested that consumers perceived the restaurant choice factors differently based on their demographic characteristics.

The results of this study contribute to the marketing theory by providing an empirical framework of consumer selection behaviour in New Zealand upscale ethnic dining establishments. The study will also assist marketing practitioners and operators of ethnic restaurants to develop their strategies and offer the attributes that attract and retain customers.

Key words: Upscale Ethnic Restaurant, Ethnic Foods, Foodservice Industry, Restaurant Choice Factor, Consumer Selection Behaviour, Logistic Regression. 


\section{ACKNOWLEDGEMENTS}

Thank all the people who helped me to achieve this research. Especially thank my supervisor, Mike Clemes, for his valuable guidance and insights, and dedication to work hard with me throughout this research. I am greatly indebted to his contributions and his great sense of humour, which certainly helped me passed through some of those tough moments. Furthermore, I would like to express my gratitude to my associate supervisor, Dr Zhaohua Li, for her assistance and advice especially in the statistical analysis process, and Dr Christopher Gan for his statistical advice and input.

My sincere thanks go to respondents who filled out the survey and samples who were involved in the focus groups and pre-test process. Thanks for comments and input from postgraduate students and the individuals whom I discussed my work with. My appreciation also goes to the staff at the Commerce Division for their help and assistance. Thanks to P' Yao for helping me setting up my statistical data analysis and providing comments and input, Brenda for assisting me with the document formatting, and Susie for being so helpful at times.

Thank my friends and family for their love and support. A great appreciation goes to my auntie and uncle, Na Pen and Simon, who provided much support throughout the years of my study in New Zealand, particularly Simon who helped commented and edited this paper. Also, special thanks to my boyfriend, Hayden, for his ongoing care and support throughout, for understanding and tolerance, during those times when this thesis was my top priority.

Finally, I would like to thank my mum, Praewta, and my sister, Meaw, for their love and continuous support. The utmost gratitude goes to my mum for her financial and emotional support. I would not have come this far without her encouragement, and for that I am deeply grateful, and thus this thesis is especially dedicated to her. 


\section{TABLE OF CONTENTS}

$\begin{array}{ll}\text { ABSTRACT } & 2\end{array}$

ACKNOWLEDGEMENTS

TABLE OF CONTENTS 5

LIST OF TABLES 9

$\begin{array}{ll}\text { LIST OF FIGURES } & 11\end{array}$

CHAPTER 1 INTRODUCTION 1

1.1 Problem Setting 1

1.2 New Zealand Foods 2

1.3 The New Zealand Dining Out Market 4

1.4 Definitions of Ethnic Food and Upscale Ethnic Restaurants 5

1.5 Research Objectives 6

$\begin{array}{lll}1.6 & \text { Research Contribution } & 7\end{array}$

$\begin{array}{lll}1.7 & \text { Thesis Overview } & 7\end{array}$

$\begin{array}{lr}\text { CHAPTER } 2 \text { LITERATURE REVIEW } & 8\end{array}$

$\begin{array}{llr}2.1 & \text { Introduction } & 8\end{array}$

2.2 Consumers and Services $\quad 8$

2.2.1 Intangibility 8

2.2.2 Variability 9

2.2.3 Inseparability 9

2.2.4 Perishability 9

2.2.5 Lack of Ownership 10

$\begin{array}{lll}2.3 & \text { The Consumer Decision-Making Process Model } & 10\end{array}$

$\begin{array}{ll}2.3 .1 \text { Need Recognition } & 10\end{array}$

2.3.2 Information Search 11

2.3.3 Evaluation of Alternatives 11

2.3.4 Service Purchase and Consumption 11

2.3.5 Postpurchase Evaluation 12

2.4 Studies on Consumers' Restaurant Selection Behaviour 12

2.5 Food Quality, Service Quality, Customer Satisfaction, and Behavioural Intentions 
2.6 Factors Influencing Restaurant Decisions 14

2.6.1 Food Quality 14

$\begin{array}{ll}\text { 2.6.2 Service Quality } & 16\end{array}$

$\begin{array}{ll}2.6 .3 \text { Word of Mouth (Reputation) } & 16\end{array}$

$\begin{array}{ll}\text { 2.6.4 Marketing Communications } & 17\end{array}$

$\begin{array}{ll}2.6 .5 \text { Cultural Learning } & 18\end{array}$

2.6.6 Image and Social Status 19

2.6.7 Different Experience 20

$\begin{array}{ll}2.6 .8 \text { Value for Money } & 20\end{array}$

2.7 Dining Occasion 20

2.8 Demographic Characteristics 21

2.9 Relative Importance of Restaurant Choice Factors 22

2.10 Chapter Summary 22

$\begin{array}{lr}\text { CHAPTER } 3 \text { MODEL AND HYPOTHESES } & 23\end{array}$

3.1 Introduction 23

3.2 Conceptual Gaps 23

3.3 The Conceptual Research Model 24

3.4 The Research Model Based on the Factor Analysis 26

3.5 Hypothesis Development 28

3.6 Hypotheses Relating to Research Objective One 28

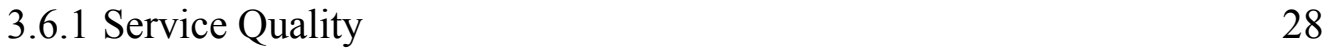

3.6.2 Food Quality 28

3.6.3 Dining Experience 29

3.6.4 Social Status $\quad 29$

3.6.5 Marketing Communications $\quad 30$

$\begin{array}{ll}3.6 .6 \text { Religious Food Options } & 30\end{array}$

3.6.7 Restaurant Décor 31

3.6.8 Value for Money 31

3.7 Hypotheses Relating to Research Objective Two and Three 31

3.8 Chapter Summary 32 
4.1 Introduction 33

4.2 Sampling Method 33

4.3 Sample Size 33

4.4 Questionnaire Development 34

4.4.1 Construct Operationalisation 34

4.4.2 Questionnaire Format 35

4.4.3 Pre-testing Procedures 36

4.5 Data Collection Procedures 36

$\begin{array}{lll}\text { 4.6 Data Analysis Techniques } & 37\end{array}$

4.6.1 Factor Analysis 37

4.6.2 Summated Scale $\quad 44$

4.6.3 Logistic Regression Analysis $\quad 45$

4.6.4 T-test and Analysis of Variance (ANOVA) 55

$\begin{array}{lll}4.7 & \text { Chapter Summary } & 57\end{array}$

$\begin{array}{lr}\text { CHAPTER } 5 \text { RESULTS AND DISCUSSION } & 58\end{array}$

$\begin{array}{llr}5.1 & \text { Introduction } & 58\end{array}$

5.2 Sample and Response Rate 58

5.3 Descriptive Statistics $\quad 58$

5.4 Assessment of the Data Set 59

5.4.1 Statistical Assumptions for Factor Analysis: Goer Group 59

5.4.2 Factor Analysis Results $\quad 61$

5.4.3 Assessment of Summated Scales 63

5.4.4 Statistical Assumptions for Logistic Regression 64

5.4.5 Cross-Tabulation and Chi-square Tests 65

5.5 Results Relating to Research Objective One 66

5.6 Results Relating to Research Objective Two 68

5.6.1 Interpretation of the Marginal Effect 68

5.7 Results Relating to Research Objective Three 69

5.7.1 Gender Relating to Consumers' Restaurant Selection Behaviour $\quad 70$

5.7.2 Ethnicity Relating to Consumers' Restaurant Selection Behaviour $\quad 70$

5.7.3 Age Relating to Consumers' Restaurant Selection Behaviour $\quad 70$

5.7.4 Qualification Relating to Consumers' Restaurant Selection Behaviour 71 
5.7.5 Occupation Relating to Consumers' Restaurant Selection Behaviour 71

5.7.6 Household Composition Relating to Consumers' Restaurant Selection Behaviour

5.7.7 Household Income Relating to Consumers' Restaurant Selection Behaviour

5.8 Chapter Summary

CHAPTER 6 CONCLUSIONS AND IMPLICATIONS

$\begin{array}{lll}6.1 & \text { Introduction } & 73\end{array}$

6.2 Conclusions Relating to Research Objective One 73

6.3 Conclusions Relating to Research Objective Two 74

6.4 Conclusions Relating to Research Objective Three 75

$\begin{array}{lll}6.5 & \text { Theoretical Implications } & 77\end{array}$

6.6 Managerial Implications $\quad 78$

$\begin{array}{lll}6.7 & \text { Limitations } & 81\end{array}$

6.8 Avenues for Future Research 82

$\begin{array}{lr}\text { REFERENCES } & \mathbf{8 3}\end{array}$

$\begin{array}{lr}\text { APPENDICES } & 128\end{array}$ 


\section{LIST OF TABLES}

Table 4.1: Modes of Factor Analysis

Table 4.2: Guidelines for Identifying Significant Factor Loadings Based on Sample Size

Table 5.1: Descriptive Statistics of the Segmentation Characteristics

Table 5.2: Profile of Consumer Segmentation Characteristics

Table 5.3: The Correlation Matrix for Goer

Table 5.4: The Anti-Image Correlation Matrix for Goer

Table 5.5: Factor Extraction

Table 5.6: VARIMAX Rotation Results (Goer) 101

Table 5.7: OBLIMIN Rotation Results (Goer) 102

Table 5.8: VARIMAX Rotation with Descriptions of Variables 103

Table 5.9: The Reliability Test for the Upscale Ethnic Restaurant Goer 104

Table 5.10: The Reliability Test for the Upscale Ethnic Restaurant Non-goer 106

Table 5.11: Pearson Correlation Matrix (Goer) 108

Table 5.12: Chi-square Tests for Demographic Characteristics and a Choice of an Upscale Ethnic Restaurant 109

Table 5.13: Cross-tabulation for Gender $\quad 110$

Table 5.14: Cross-tabulation for Age 111

Table 5.15: Cross-tabulation for Ethnicity 112

Table 5.16: Cross-tabulation for Qualification 113

$\begin{array}{ll}\text { Table 5.17: Cross-tabulation for Occupation } & 114\end{array}$

Table 5.18: Cross-tabulation for Household Composition 115

Table 5.19: Cross-tabulation for Household Income 116

Table 5.20: Classification Table for Choice of Upscale Ethnic Restaurant 66

Table 5.21: Hypotheses 1 through 11 Test Results Summary 66

Table 5.22: The Significant Logistic Regression Results 67

Table 5.23: Marginal Effects of Consumers' Choice of an Upscale Ethnic Restaurant

Table 5.24: T-tests Results Relating to Gender 117

Table 5.25: T-tests Results Relating to Ethnicity 117 
Table 5.26: ANOVA (F-tests) Results Relating to Age 118

Table 5.27: ANOVA (F-tests) Results Relating to Qualification 119

Table 5.28: ANOVA (F-tests) Results Relating to Occupation 120

Table 5.29: ANOVA (F-tests) Results Relating to Household Composition 121

Table 5.30: ANOVA (F-tests) Results Relating to Household Income 122

Table 5.31: The Scheffe Output for Age 123

Table 5.32: The Scheffe Output for Qualification 124

$\begin{array}{ll}\text { Table 5.33: The Scheffe Output for Occupation } & 125\end{array}$

Table 5.34: The Scheffe Output for Household Composition 126

Table 5.35: The Scheffe Output for Household Income 127 


\section{LIST OF FIGURES}

Figure 3.1: The Conceptual Research Model 25

Figure 3.2: The Consumers' Upscale Ethnic Restaurant Choice Factors Model 27

Figure 5.1: The Scree Plot $\quad 62$ 


\section{CHAPTER 1 \\ INTRODUCTION}

\subsection{Problem Setting}

The demand for food away from home is dramatically increasing. According to the 2003/04 New Zealand Household Economic Survey, the average weekly household expenditure on meals away from home increased from $\$ 13.80$ in 2000/01 to $\$ 19.20$ in 2003/04 (Ministry of Health, 2006). The growth of demand for food has prompted an expansion of the New Zealand foodservice industry. The national foodservice industry annual sales rose from $\$ 3,176$ million in 2002 to $\$ 4,800$ million in 2007 - a nominal growth of 51 percent. There was also an analogous trend from 2002 to 2006 in the increase of the number of food service outlets and employees from 8,368 to 10,681 and 59,700 to 78,540 respectively (Restaurant Association of New Zealand, 2007). The expansion of the number of foodservice outlets has lead to an intensely competitive foodservice industry in New Zealand (Restaurant Association of New Zealand, 2006).

Restaurant operators must understand and satisfy consumers' needs, wants, and demands to be successful in the competitive foodservice industry (Gregoire, Shanklin, \& Greathouse, 1995; Kotler, Bowen, \& Makens, 1998). The findings from several studies show that restaurant consumers use different criteria when making restaurant decisions (Johns \& Pine, 2002; Koo, Tao, \& Yeung, 1999). Examples of these criteria are: food quality, service quality, restaurant physical settings, and variety of choice on the menu. The criteria also vary according to the type of restaurant (Elder et al., 1999; Heung, Wong, \& Qu, 2000; Lewis, 1981) and dining occasion (Auty, 1992; June \& Smith, 1987; Koo et al., 1999). In addition, a number of studies suggest that restaurant diners often view a restaurant meal as only a part of the total package of a dining experience, and that diners use a bundle of attributes, rather than a single attribute, when making restaurant decisions (Campbell-Smith, 1967; Kivela, 1997; Koo et al., 1999; Lewis, 1981; Pun \& Ho, 2001). 
There is a need to understand the choice factors and their relative importance that influence restaurant patrons' decision so that restaurateurs can supply their offerings and develop strategies accordingly (Elder et al., 1999). It is also crucial that restaurant operators understand the effects of consumer characteristics on restaurant choice behaviour as this information can guide them in their target marketing (Goldman, 1993).

Previous studies have highlighted the growing interest in ethnic food trends worldwide. The expansion of interest and acceptance of ethnic foods reflect the increasing diversity of contemporary society (Josiam \& Monteiro, 2004). Ethnic restaurants are facing increasingly sophisticated consumers and an intensely competitive restaurant industry. Consumers who go to upscale dining establishments do not only demand good food but also a complete dining experience (Yüksel \& Yüksel, 2002). A deeper understanding of consumers' selection criteria will provide ethnic restaurant operators with valuable information and insights which enable them to attract and retain more consumers $(\mathrm{Qu}, 1997)$.

However, there is only limited published research available on the consumer decisionmaking process and restaurant choice behaviour that focuses on the ethnic segment. For example, see Qu (1997) and Josiam and Monteiro (2004). Despite the importance of restaurant choice criteria and a growth in popularity of ethnic foods in New Zealand, there are no published empirical studies on ethnic restaurant choice behaviour in New Zealand. The findings of studies on the ethnic restaurant choice factors conducted in other countries may not be directly applicable to New Zealand. This study aims to contribute to the limited research in this area and provide insights into the consumer decision-making process specifically for the New Zealand foodservice industry.

\subsection{New Zealand Foods}

The major influence on New Zealand foods has come from Europe, especially from the British settlers, as they were the first group of European immigrants who brought with them their conventional foods of meat, potatoes and dairy (Ray Bailey \& Earle, 
1993). D. Burton (1982, p. xii) commented, "New Zealand cooking is, after all, the cookery of immigrants, beginning with the first Māori canoes. However, it was undoubtedly the nineteenth-century immigrants from England, Ireland, Scotland and Wales who have most influenced our eating patterns."

A typical meal for New Zealanders introduced by the British food culture was meat and a lot of potatoes with limited types of other vegetables (Ray Bailey \& Earle, 1993). Traditionally, the most popular New Zealand takeaway meal was fish and chips which were available at most neighbourhood food bars and dairy shops (van Ameyde \& Brodie, 1984).

From the outset of European settlers, New Zealand has become a multicultural society with immigrants from different ethnic backgrounds. According to the New Zealand census (2006a), 22.9 percent of New Zealand residents were born overseas, compared with 19.5 percent in 2001 and 17.5 percent in 1991. The ethnic diversity in New Zealand is projected to increase in the future with the Asian population growing at the fastest rate, followed by the Pacific Island and Māori populations. In contrast, the European population is projected to drop from 79 percent in 2001 to 70 percent in 2021 (Statistics New Zealand, 2006b).

Ethnic immigrants generally like to maintain the cooking and eating habits that they had in their home countries (Mennell, Murcott, \& Otterloo, 1992). They often establish their own shops making food or selling food ingredients and other food products imported from their home countries. For example, a group of DutchIndonesian immigrants established their own bakeries making several different types of bread, instead of only the brown and white loaves traditionally made by New Zealanders (D. Burton, 1982).

Contemporary New Zealand cuisine, at the restaurant-industry and the home-cooking levels, has been shaped by the different influences of European food and a mixture of ethnic foods (Ray Bailey \& Earle, 1993; D. Burton, 1982; Simpson, 1999). Ethnic foods have become more widely accepted since 1970 when the cookery books published in New Zealand offering ethnic foods recipes started to grow in popularity (Ray Bailey \& Earle, 1993). 
The trend towards ethnic foods preferences has not only come from the growth of cultural and ethnic diversity but also has been fuelled by the demand of New Zealand tourists who travelled overseas and were exposed to different foods and cultures (D. Burton, 1982; Mitchell, 2003; Nimmo-Bell Company Ltd, 2002). New Zealanders who went overseas and tried the other cuisines brought back with them many new ideas for food preparation (D. Burton, 1982). These diners sometimes choose to go to the restaurants serving cuisines of the countries they have been, as they like those foods and/or to recall their overseas experiences (Monteiro, 2000). Furthermore, worldwide and national media have contributed to a rise in the interest in ethnic foods and this has stimulated the demand (Robinson, 2007).

The New Zealand ethnic food market has expanded considerably in response to the growth in the popularity of ethnic foods. The number of ethnic restaurants has increased remarkably with a greater selection of ethnic restaurants than in the past few decades. A study of ethnic restaurants in Auckland by Withers (2000) showed a considerable increase of ethnic restaurants and their diversified ethnic origins, from 41 restaurants with ten cuisines in 1972 to 281 restaurants with 24 cuisines in 1999. Additionally, the major supermarkets are now stocking ethnic food products and ingredients that once were found only in specialty or ethnic food shops, and extensive collections of cook books are now offering recipes featuring different ethnic cuisines (Withers, 2000).

\subsection{The New Zealand Dining Out Market}

Dining out is an important part of the lifestyles of New Zealanders (Lawson, Todd, \& Evans, 2006). The New Zealand Food Market Monitoring Report 2002/03 showed an increasing trend for dining out as a result of higher incomes, an increase in the number of working women, changes in consumptions patterns, and changes in household size and composition (Nimmo-Bell Company Ltd, 2002). New Zealanders are also facing the pressures of time, particularly in those households with women in the workforce (Nimmo-Bell Company Ltd, 2002). 
van Ameyde and Brodie (1984) reported that New Zealanders who dined out more frequently at restaurants were in the younger age group, had smaller or childless families, and were in the professional, managerial and clerical worker families group. Takeaways were popular among young people and families with young children (van Ameyde \& Brodie, 1984).

Individuals also dine out for different reasons (Lundberg \& Walker, 1993). The findings from a study of Auckland consumers on restaurant selection suggested that the majority of Aucklanders dined out for social and special occasions. The dining out habits of several segments were studied, and the group that dined out most frequently were people in the high income, middle aged group (Rammaniya, 1998).

\subsection{Definitions of Ethnic Food and Upscale Ethnic Restaurants}

The term "ethnic food" has been defined differently in various studies. The Food Marketing Institute (1998) defines ethnic food as a product that a particular ethnic (racial, national) or cultural group favours. Utami (2004) defines ethnic food as a regional specific cuisine that tends to reflect the particular characteristics of its local origin. Food is usually considered ethnic by people who are in a different area from its origin (Utami, 2004). "Ethnic food" can also describe the cuisine of the minority immigrants in multicultural societies (Utami, 2004).

Turgeon and Pastinelli (2002, p. 252) refers "ethnic" to outsiders or people who come from another land and are foreign to the mainstream culture. The authors define "an ethnic restaurant" as "a restaurant whose signboard or publicity clearly promises the national or regional cuisine of another land". Similarly, Olsen, Warde, and Martens (2000) studied the dining out market in the United Kingdom and identified all nonBritish restaurants as "ethnic" restaurants.

Based on the definition by Turgeon and Pastinelli (2002) and the restaurant segmentation concept from Olsen et al. (2000), an "ethnic restaurant" in this study is defined as a full-service restaurant serving dishes of foreign origin rather than typical 
New Zealand food. Examples of ethnic restaurants are: Chinese, Greek, Italian, Indian, Japanese, Thai, Mexican, and Spanish.

Goldman (1993) classifies the upscale restaurant as the restaurant segment that offers a wide variety of restaurant concepts, including an ethnic concept. An upscale restaurant is characterised by offering a full menu, full table service, quality food made with fresh ingredients, and personalised service. The upscale restaurant segment includes not only high-check but also casual-dining and moderate-check restaurants. The upper end of this segment is a fine-dining restaurant which generally offers high quality food, décor and service and charges high prices (Goldman, 1993). For the purpose of this study, upscale ethnic restaurants include both casual and fine dining establishments with a table service provided, which have an average main course of at least $\$ 20.00$.

Several studies suggest that restaurant selection factors differ by the type of restaurant (Elder et al., 1999; Goldman, 1993; Heung et al., 2000; Lewis, 1981). This study aims to identify the factors that specifically influence the selection by consumers of upscale ethnic restaurants. The focus on the upscale restaurant segment in the context of this study is to standardise the factors to only those that apply to a full-service, upscale dining establishment. Fast food, takeaway and low-price ethnic restaurants are not included in this research as these types of restaurants normally focus on convenience, speed and price factors.

\subsection{Research Objectives}

The main objectives of this research are:

1. To identify the factors that influence the decisions of consumers to dine at an upscale ethnic restaurant.

2. To determine the most important factors that affect consumers' choice of an upscale ethnic restaurant.

3. To examine if consumers perceive a difference on upscale ethnic restaurant choice factors based on their demographic characteristics and dinning occasion. 


\subsection{Research Contribution}

This research aims to provide a better understanding of the consumer decision-making process for upscale ethnic restaurants in New Zealand. Understanding restaurant choice behaviour can assist upscale ethnic restaurant marketers and practitioners when they develop marketing strategies and enable them to select the most salient attributes to attract and retain customers. Furthermore, a theoretical model of restaurant selection behaviour in New Zealand developed in this study will help to provide a useful framework for future research regarding consumer behaviour in the restaurant industry. This contribution is particularly important due to the limited empirical studies on consumers' restaurant selection behaviour in New Zealand.

\subsection{Thesis Overview}

This research consists of six chapters in order to meet the research objectives outlined in Section 1.5.

Chapter Two reviews the services marketing literature, the literature on the consumer decision-making process, and the criteria that influence restaurant selection behaviour. Chapter Three presents the conceptual model based on the review of the literature and the focus group discussions, the research model based on the results of the factor analysis, and the development of the eleven hypotheses. Chapter Four details the methodology used to test the hypotheses. Chapter Five presents and discusses the results of the analyses undertaken in this study. Finally, Chapter Six offers conclusions and recommendations based on the results and discussions presented in Chapter Five. 


\section{CHAPTER 2 \\ LITERATURE REVIEW}

\subsection{Introduction}

This research investigates consumer behaviour using the consumer decision-making process as a framework and identifies the factors that influence the decisions of consumers in the upscale, ethnic segment of the foodservice industry. This chapter reviews the relevant literature about consumers and services, the consumer decisionmaking process model, and previous studies in consumers' restaurant selection behaviour. Furthermore, the interrelationships between customer satisfaction, food quality, service quality and behavioural intentions are discussed. Lastly, the restaurant choice factors, dining occasion, and demographic characteristics are reviewed.

\subsection{Consumers and Services}

Service providers need to understand how consumers choose and evaluate their offerings (Zeithaml, 1981). Consumers cannot choose and evaluate services in the same manner they do to physical goods as services have distinctive characteristics and are high in experience quality. Therefore, consumers find it more difficult to evaluate services when compared to physical goods. Several studies (e.g., Kotler et al., 1998; Zeithaml, 1981; 2003) suggest that the main characteristics that make services different from physical goods are: intangibility, variability, inseparability, perishability, and lack of ownership.

\subsubsection{Intangibility}

The intangible quality of services is that services constitute performances and they often cannot be seen, felt, tasted, or touched like physical goods (Zeithaml, 1981). Rammaniya (1998) asserted that, when making restaurant choice decisions, consumers used both tangible and intangible factors. The intangible factors are primarily: food quality, service quality, and value for money (Auty, 1992; Soriano, 
2002). The intangible characteristic of services makes these factors difficult to evaluate prior to the actual purchase. Accordingly, restaurant patrons often rely on tangible clues such as restaurant facilities, décor, and atmosphere to guide them in forming expectations about the restaurants (Bitner, 1990; Wall \& Berry, 2007).

\subsubsection{Variability}

Services are highly variable. The performance of a given service may vary across service providers, service employees, consumers, and service encounters (Zeithaml \& Bitner, 2003). The heterogeneity of services makes it difficult for consumers to frame decision criteria towards one service provider, or from one service provider to another (S. Burton, 1990). Restaurant operators; on the other hand, usually face challenges in maintaining consistent performance levels of food quality and service quality (Cadotte $\&$ Turgeon, 1988). For example, a restaurant waitress may have provided an excellent service until the diners at one table make a destructive complaint. The waitress could then feel pressured and provide a poor service performance thereafter (Kotler et al., 1998).

\subsubsection{Inseparability}

Most services are not produced and consumed until after they are sold. The production and consumption of a service experience is usually a simultaneous process (Zeithaml \& Bitner, 2003). A restaurant service has a high level of contact between diners and service employees. Accordingly, the skills and performance of restaurant staff are vital to diners' perception of restaurant experience (Kotler et al., 1998).

\subsubsection{Perishability}

Services cannot be stored. In contrast to physical goods that can be stored and sold at a later time, services cease to exist if they are not sold when they become available (Hoffman \& Bateson, 2001). For instance, a customer who does not show up for a reserved table in the restaurant will cause the restaurateur to turn down the chance to serve other diners if the restaurant is full (Kotler et al., 1998). Service providers often find it difficult to balance the supply and demand of services, given the unpredictable nature of consumer demand for services (Hoffman \& Bateson, 2001). 


\subsubsection{Lack of Ownership}

Services are an experience. Consumers pay to get access to and experience a service but do not get a tangible ownership of that service (Clemes, Mollenkopf, \& Burn, 2000). Accordingly, consumers may feel a lack of control in the purchase of services (Cowell, 1989).

\subsection{The Consumer Decision-Making Process Model}

There are many different versions of models of the consumer decision-making process. The model discussed in this study illustrates the steps consumers typically use when making purchase decisions for services. Given the unique characteristics of services, the consumer decision-making process for services is different from that for goods. The consumer decision-making process for services consists of five stages: problem recognition, information search, evaluation of alternatives, purchase and consumption, and postpurchase evaluation (Zeithaml \& Bitner, 2003).

\subsubsection{Need Recognition}

The consumer decision-making process starts from the consumers recognising that a need exists. They view this need as a problem and prepare to find a solution to solve the problem (Zeithaml \& Bitner, 2003). The structure of human basic needs is proposed by Abraham Maslow as the motivation theory, ranging in a hierarchical manner in order of importance from least at the bottom to most at the top of the pyramid. These needs include physiological, safety, belongingness, esteem, and selfactualisation needs (Maslow, 1970).

In a restaurant context, Finkelstein (1989) emphasised that contemporary restaurant dining had as much to do with psychological desires as objective desires. Restaurant patrons associated their dining out with the presentation of social status and belongingness. They wanted to be seen dining out in the place that could reflect their self-images and include them as a part of social trends (Finkelstein, 1989). 


\subsubsection{Information Search}

Once the need is recognised, consumers usually search for information about a service that can fill their need. Consumers may seek information from both personal sources (e.g. friends or experts) and nonpersonal sources (e.g. mass or selective media) as a way to reduce the perceived risks that are associated with purchasing services (Zeithaml, 1981).

Zeithaml (1981) noted that restaurant meals were considered to be high in experience qualities as they could not be evaluated prior to the purchase. The risk from the selection of the restaurant was therefore perceived to be high. For this reason, consumers primarily relied on personal sources like word-of-mouth from friends as their source of information for restaurant attributes (Ladhari, Brun, \& Morales, 2008; Sweeney, Johnson, \& Armstrong, 1992).

\subsubsection{Evaluation of Alternatives}

Once the consumers have enough information, they tend to form an evoked set of alternatives. The evoked set of alternatives is the group of options considered acceptable by a consumer in a given category of product or service (Zeithaml, 1981). Consumers evaluate these alternatives by identifying a bundle of attributes relating to their needs. They attach different degrees of importance to each of the attributes and are likely to choose the service provider that offers the attributes that are most important to them (Kotler et al., 1998). For instance, one out of two restaurants offering comparable food and service may get selected only because the restaurant offers a lower price or other extra attributes (Brookes, 2004).

\subsubsection{Service Purchase and Consumption}

After comparing the alternatives in the evoked set, consumers finally decide to make a purchase from their chosen service provider. In the case of a restaurant choice, consumers make a decision to dine at a particular restaurant. This stage of service purchase and the consumption of restaurant service experience happens simultaneously (Zeithaml \& Bitner, 2003). 


\subsubsection{Postpurchase Evaluation}

Consumers tend to evaluate the experience by determining if the service has met their expectations. The marketing literature notes that satisfied consumers are likely to have favourable post-dining behavioural intentions such as loyalty, recommendation, and willingness to pay more (Ladhari et al., 2008).

Understanding the process of consumers' decision-making helps restaurateurs to identify the factors that contribute to consumer behaviour in each stage. Restaurateurs can then use these factors to plan strategies in order to influence the behaviour of their customers (Monteiro, 2000).

\subsection{Studies on Consumers' Restaurant Selection Behaviour}

Previous studies on consumer behaviour in the restaurant context have identified a number of factors that consumers consider important in their restaurant selection. Following are examples of these studies:

Lewis (1981) investigated the influence of the benefit features of advertising on consumers' decision to go to a restaurant. Three types of restaurants: family/popular, atmosphere, and gourmet were analysed. Food quality was found as the most important feature determining patronage intentions to any type of restaurant. However, the range of importance of the other features differed by the type of restaurant.

Auty (1992) identified the choice factors in the restaurant decision process based on four occasions: a celebration, social occasion, convenience/quick meal, and business meal. Food type, food quality and value for money were found as the most important choice variables for consumers when choosing a restaurant. The order of these choice criteria varied according to dining occasions. The author further suggested that if the consumers perceived that restaurants provide comparable food type, food quality and price, they would take image and atmosphere of the restaurants into account when making a final decision. 
Kivela (1997) examined the main choice variables of restaurant selection in four different types of restaurants, including fine dining/gourmet, theme/atmosphere, family/popular, and convenience/fast-food restaurants. The Kivela's (1997) results showed that the relative importance of the restaurant choice factors differed considerably by restaurant type, dining occasion, age, and occupation.

The studies of consumer behaviour in ethnic restaurants are relatively limited. Previous ethnic restaurant studies have focused on consumers' perceptions and attitudes (e.g., Raymond Bailey \& Tian, 2002; Josiam \& Monteiro, 2004; Verbeke \& López, 2005) or on a particular cuisine (e.g., Josiam \& Monteiro, 2004; Qu, 1997; Sukalakamala \& Boyce, 2007). Among these studies, the unique characteristics of ethnic cuisine are commonly discussed. However, ethnic restaurateurs cannot compete simply on the uniqueness of the cuisine. The results of past studies have emphasised that, in order to succeed, restaurant operators need to pay attention to the attributes that have the highest regard in relation to consumers' selection behaviour.

The next section will examine the relationships between important constructs: food quality, service quality, customer satisfaction, and behavioural intentions.

\subsection{Food Quality, Service Quality, Customer Satisfaction, and Behavioural Intentions}

The services marketing literature has shown evidence of interrelationships between food quality, service quality, customer satisfaction and repeat patronage. Overall food quality was found to significantly affect customer satisfaction and behavioural intentions (Namkung \& Jang, 2007). Similarly, it has been well established by a number of studies that service quality is an antecedent of customer satisfaction (Chow, Lau, Lo, Sha, \& Yun, 2007), which in turn leads to favourable behavioural intentions such as repurchase and recommendation to others (Cheng, 2006; Dube, Renaghan, \& Miller, 1994; Ladhari et al., 2008).

Because of the correlations between customer satisfaction and food quality, and between customer satisfaction and service quality, the variable 'customer satisfaction' 
will not be included in the research model developed for this study. High correlations between the independent variables need to be avoided to prevent multicollinearity problem in the data analysis stage. Therefore, this study analyses food quality and service quality separately as factors that have an impact on consumers' decisions when selecting a restaurant.

\subsection{Factors Influencing Restaurant Decisions}

Consumers select their restaurants based on many factors. Several published studies have investigated the key criteria used by consumers in selecting a restaurant and have presented a number of different choice factors. The factors that have been found to influence restaurant decisions are as follows:

\subsubsection{Food Quality}

Food quality is rated as the most important attribute influencing restaurant decisions in many studies on consumers' restaurant selection behaviour (e.g., Auty, 1992; Lewis, 1981; Soriano, 2002; Sulek \& Hensley, 2004). The elements that constitute food quality proposed in this study are unique tastes and ingredients, menu variety, appearance and presentation, healthy food options, and familiar food.

\subsubsection{Unique Tastes and Ingredients}

Tastes and ingredients play an important role for consumers when selecting a restaurant. Food taste is regarded as the most important element of food attributes in several restaurant studies (see Josiam \& Monteiro, 2004; Tunsi, 2000). Unique food tastes and ingredients are particularly important in the case of ethnic restaurant dining as Bannerman (1998, as cited in Robinson, 2007, p. 80) noted, "the obvious attraction of ethnic restaurants was getting food you couldn't cook at home". The results of a study by Sukalakamala and Boyce (2007) indicated that consumers of Thai restaurants considered unique tastes and authentic ingredients as the most important components of their authentic dining experience. 


\subsubsection{Menu Variety}

Restaurateurs frequently develop new menus and offer a selection of different menu items to attract customers (Namkung \& Jang, 2007). Kivela, Inbakaram \& Reece (2000) identified menu variety as a significant attribute of food quality in determining customer satisfaction in theme/atmosphere restaurants.

\subsubsection{Appearance and Presentation}

Appearance and presentation refers to the way food is decorated (Namkung \& Jang, 2007). Namkung and Jang (2007) found that presentation was the most important contributor among food quality attributes in determining customer satisfaction in restaurants.

\subsubsection{Healthy Food Options}

Nowadays, consumers are more concerned with their health and are therefore driving a growing demand for healthy food choices (Sulek \& Hensley, 2004). The findings of Namkung and Jang (2007) showed a significant relationship between healthy food options and behavioural intentions. The National Restaurant Association (USA) reported that a large number of restaurants are adding items and adjusting their menus to accommodate and attract consumers who are concerned about health and nutritional value of a meal (as cited in Mill, 2007).

Previous studies have found evidence of consumers' beliefs that particular ethnic foods are healthy. For example, Bailey and Tian (2002) reported that consumers of Indian restaurant in the United States of America viewed Indian food as much healthier than American food. Similarly, health was the most important value of eating Indian food for English consumers in the United Kingdom (White \& Kokotsaki, 2004).

\subsubsection{Familiar Food}

Tian (2001, p. 127) stated, "food consumption habits and patterns are components of culture that make an important contribution to the food decision consumers make". In some cases, foods of other cultures are accepted if they have familiar ingredients and 
preparation styles (Raymond Bailey \& Tian, 2002). This study proposes that consumers go to an ethnic restaurant that serves food they are familiar with.

\subsubsection{Service Quality}

Service quality is found to be a salient factor of restaurant selection in numerous studies. Previous studies have presented inconsistent sets and number of choice attributes of service quality in the restaurant (Tucci \& Talaga, 2000). The dimensions of service quality proposed in this study are physical environment and service staff behaviour.

\subsubsection{Physical Environment}

The marketing literature has provided evidence of how the physical environment influences consumer behaviour (e.g., Bitner, 1992; Wall \& Berry, 2007). The physical environment of the restaurant such as restaurant's atmosphere, ambience, décor, furniture, and other facilities can have a great impact on the dining experience (Sloan, 2004) and behavioural intentions (Ryu \& Jang, 2007). Previous studies demonstrated that, because of the unique nature of the restaurant service, physical environments could guide consumers in evaluating a restaurant experience (Wall \& Berry, 2007).

\subsubsection{Service Staff Behaviour}

The importance of service staff to the service operators is widely recognised in the service marketing literature (Cowell, 1989). Wall and Berry (2007) indicated that service staff behaviour was particularly important when the other mechanic clues such as restaurant atmosphere were perceived negatively. In this situation, humanic clues such as impressive employee behaviour could help level up consumers' perception of dining experience. Consumers generally expect restaurant service employees to be attentive, courteous and possess a good knowledge of the menu (Heung et al., 2000; Pratten, 2003; Sulek \& Hensley, 2004).

\subsubsection{Word of Mouth (Reputation)}

Word-of-mouth is a critical source of information for a restaurant service if uncertainty and risk are perceived to be high (Sweeney et al., 1992). A 
recommendation from a friend can greatly contribute to a decision to try a restaurant. Unlike advertising, a suggestion from a friend is not usually based on any gain or profit. Thus, consumers place more trust on their friends' recommendation when making a restaurant choice (Mill, 2007). Besides, consumers can find out about restaurant experience qualities, which are usually difficult to judge through the other non-personal sources, from their friends' personal experience (Zeithaml \& Bitner, 2003).

According to Mangold, Miller, and Brockway (1999), satisfied customers tell an average of five people, while dissatisfied customers share their bad experiences with nine other people. Research by Bailey and Tian (2002) also discussed the role of recommendations from friends and family in influencing consumers' decision to dine at an Indian restaurant. Knowing that their peers enjoyed the ethnic food culture at a restaurant helped diners to feel more comfortable when choosing to dine at a restaurant with a culture they are not familiar with (Raymond Bailey \& Tian, 2002).

\subsubsection{Marketing Communications}

Services operators use marketing communications as the way to inform, persuade, and remind customers (Lovelock, Patterson, \& Walker, 1998). The marketing communications employed by restaurateurs are advertising, sales promotion, and publicity (Mill, 2007).

\subsubsection{Advertising}

Advertising includes "any paid form of nonpersonal presentation and promotion of ideas, goods, or services by an identified sponsor" (Mill, 2007, p. 83). Advertising may come in the form of television, newspaper, radio, magazines, yellow pages, and internet (Mill, 2007).

Pedraja and Yague (2001) argued that consumers used information from advertising, and the information provided at the restaurant when searching for external sources of information. The information from the advertising was used as a source to reduce perceived risk and uncertainty (Pedraja \& Yague, 2001). 


\subsubsection{Sales Promotion}

Sales promotions, such as special offers and discounts, can act as short-term incentives motivating consumers to choose a particular service provider (Mill, 2007). According to Jackson, Titz, and DeFranco (2004), high-price restaurants benefited from coupon promotions to a greater extent than lower price restaurants. This finding suggests that patronage of consumers in upscale establishments can be motivated by sales promotions.

\subsubsection{Publicity}

Publicity refers to non-paid communications such as a press release and press conference (Mill, 2007). Publicity provides more credibility for consumers as the company (in this context- a restaurant) does not usually have control over critics like it does with paid advertising (Burnett \& Moriarty, 1998). Therefore, publicity has the advantage of being able to reach consumers who are particularly cynical about advertising (Kotler et al., 1998).

Positive media relations can create a positive image for a restaurant and thus may be used as another effective marketing communications tool (J. Miller, 1993). Robinson (2007) argued that a growth of interest and demand in ethnic cuisines was partly from the influence of the media. This contention implies that publicity is another influential factor of ethnic restaurant patronage.

\subsubsection{Cultural Learning}

Eating in an authentic ethnic restaurant is a way to experience another culture, as Van den Berghe (1984, as cited in Withers, 2000) postulated:

What more accessible and friendlier arena of inter-ethnic contact could be devised than the ethnic restaurant? What easier way to experience vicariously another culture than to share its food? As an outsider consuming an exotic cuisine, one is literally 'taking in' the foreign culture.

The whole experience consumers receive from patronizing an ethnic restaurant, including ethnic wait staff, and flavour of the cuisine, brings them closer to that 
particular culture and helps them recall the memories of their overseas trips to the country (Verbeke \& López, 2005).

Yüksel and Yüksel (2002) studied the segmentation of tourist consumers and their restaurant choice and found that tourists in the adventure seekers group would try local cuisine in order to learn about the traditions and culture of the host country. Similarly, the findings by Tian (2001) and Sukalakamala and Boyce (2007) confirmed that diners viewed an ethnic restaurant patronage as a way to learn about a different culture.

\subsubsection{Image and Social Status}

Finkelstein (1989) claimed that restaurant dining helped to satisfy diners' deeper emotional desires for social status, image, and belongingness. Some restaurants were regarded as higher in status than others, which was reflected through images the restaurateurs try to communicate with their consumers (Finkelstein, 1989). For example, Cheng (2006) investigated the differences in consumer behaviours of diners from different classes of restaurants in Taiwan. Restaurants were classed as "fancy restaurant" and "ordinary restaurant" mainly based on their price level. The findings showed that a fancy restaurant attracted more diners with stable jobs such as government employees and teachers, and an ordinary restaurant's main consumers were students (Cheng, 2006). The patronage of certain groups of consumers at different classes of restaurant implies that consumers may choose a restaurant based on the restaurant image, as they relate the restaurant experience to their social status.

Additionally, Peters (2005) studied the reason and motivation of going to fine restaurants in Sao Paulo, Brazil using face-to-face interviews and found that fine restaurant patrons were of high rank and income whose motives included needs of a social and self-esteem nature. The diners generally felt superior in the fine dining environment as they were well looked after, and they claimed that the ambience and style suited their esteem need (Peters, 2005). 


\subsubsection{Different Experience}

Novelty has specific appeal, and consumers are known to be curious for novelties including experiencing a new food and the new ambience of a restaurant (Peters, 2005). A new experience emerges as a determinant influencing some consumers to dine at an ethnic restaurant, as they consider such variety of experiences a value in itself (Martens \& Warde, 1998). Patrons of ethnic restaurants often seek an authentic experience that is different from their everyday meals at home (Turgeon \& Pastinelli, 2002).

Dining at ethnic restaurants also offers diners the opportunity to have the similar emotional and symbolic experience of a vacation, without even leaving home, as Zelinsky (1987, p. 31) posited:

The diners at ethnic restaurants don't go just for the food. They also hunger for an exotic dining experience. Ethnic restaurants offer an effortless journey to a distant land where the waiter recites a menu of alien delights in charmingly accented English. The patrons of ethnic restaurants are gastronomic tourists.

\subsubsection{Value for Money}

Value for money is another factor restaurant patrons take into account when selecting a restaurant. If they perceive that the value received is less than the price paid, they are likely to evaluate the dining experience negatively (Mill, 2007). Muller and Woods (1994) asserted that restaurant consumers use price as a measure for the quality of the restaurant, assuming that an expensive restaurant serves better food and offers better quality. Similarly, Sweeny et al. (1992) commented that a low price may increase the probability of choosing a particular restaurant, while a low price may also decrease consumer perceptions of restaurant quality.

\subsection{Dining Occasion}

Much research on restaurant consumer behaviour includes dining occasion as one of the variables determining dining behaviour. For example, Kivela, Inbakaran, and Reece (1999a) argued that dining occasion was an important factor that aroused the 
need to dine out and lead to different restaurant behaviours. Sweeney et al. (1992) found different patterns of importance of restaurant selection criteria based on two different dining situations: dinner with a friend and dinner with a group of friends. Similarly, June and Smith (1987) proposed a model of consumers' choice of a restaurant according to four different meal contexts: an intimate dinner, a birthday celebration, a business lunch and a family dinner. The authors found that consumers place different level of importance on each restaurant attribute depending on the dining occasion.

This study does not include dining occasion as an upscale ethnic restaurant choice factor. This is because dining occasion in this study is only applicable to one group of consumers, upscale ethnic restaurant goers, whereas the study collects the data from both upscale ethnic restaurant goers and non-goers. However, the study determines if consumers in the goer group perceive upscale ethnic restaurant choice factors differently.

\subsection{Demographic Characteristics}

Demographic variations are used in numerous studies to differentiate the market segments of consumers. The findings of past research demonstrate how different demographic characteristics affect restaurant patronage behaviours. For example, Olsen et al. (2000) reported evidence of niche markets for ethnic restaurants mainly based on education level, age, and income. The authors stated that the likelihood of attending ethnic restaurants decreased with age (Olsen et al., 2000).

Moreover, the restaurant selection behaviour was found to vary according to gender (Mohsin, 2005); ethnic and cultural groups (Josiam \& Monteiro, 2004; Verma, Pullman, \& Goodale, 1999); age groups (Auty, 1992; Kivela, 1997; Mohsin, 2005); occupation (Kivela, 1997); income (Auty, 1992); and benefit seeking behaviour (Yüksel \& Yüksel, 2002). The common demographic groups that were found to relate to ethnic restaurants patronage behaviour were the well educated and high income groups (Turgeon \& Pastinelli, 2002). 
Based on the review of the literature on the foodservice industry, this study examines if the following demographic characteristics: gender, age, ethnicity, qualification, occupation, household composition, and household income affect restaurant choice.

\subsection{Relative Importance of Restaurant Choice Factors}

Several researchers have explained that it is essential that restaurant operators find out the relative importance of each choice factor as consumers make decisions based on the degree of importance they attach to each choice factor (Kivela et al., 1999a; Koo et al., 1999; Qu, 1997). Several studies suggest that the relative importance of different attributes is subject to the dining situation (Auty, 1992; Dube et al., 1994; Kivela, 1997; Koo et al., 1999; Sweeney et al., 1992) and consumer demographic characteristics (Kivela et al., 2000; Olsen et al., 2000; Soriano, 2002; Yüksel \& Yüksel, 2002).

Given limited resources and an indefinite list of choice factors demanded by consumers, an understanding of the relative importance of factors can guide restaurateurs to prioritise their offerings (Dube et al., 1994; Soriano, 2002). Thus, restaurant managers can pay attention and allocate their resources to the attributes that are most important to restaurant consumers in their dining decisions (Sulek \& Hensley, 2004).

\subsection{Chapter Summary}

This chapter presented the relevant literature regarding consumers and services, the consumer decision-making process model, and the restaurant choice factors. The literature supports the contention that food quality, service quality, word-of-mouth, marketing communications, cultural learning, image and social status, different experience, and value for money influence the restaurant selection behaviour. 


\section{CHAPTER 3}

\section{MODEL AND HYPOTHESES}

\subsection{Introduction}

This chapter discusses the conceptual gaps identified in the literature review presented in Chapter Two. A conceptual model of upscale ethnic restaurant choice factors is presented, and the eleven hypotheses proposed in this study are discussed. The testing of the hypotheses will also address the following three research objectives:

1. To identify the factors that influence the decisions of consumers to dine at an upscale ethnic restaurant.

2. To determine the most important factors that affect consumers' choice of an upscale ethnic restaurant.

3. To examine if consumers perceive a difference on upscale ethnic restaurant choice factors based on their demographic characteristics and dinning occasion.

\subsection{Conceptual Gaps}

By reviewing the literature on consumers' restaurant selection behaviour, the following conceptual gaps have been identified:

Firstly, the topic of consumer behaviour regarding restaurant decision has received relatively little research attention. Additionally, only a limited number of the empirical studies have included or focused on the ethnic restaurant segment. Furthermore, many of the previous studies on ethnic restaurants tend to focus on consumers' perceptions and attitudes towards ethnic foods rather than the restaurant choice factors. 
Secondly, to date, there is no empirical research related to consumer choice factors for the ethnic segment of the restaurant industry conducted specifically in New Zealand. The ethnic restaurant choice factors that have been analysed in other countries may vary from the factors that influence New Zealand consumers due to the differences in consumer characteristics and their decision-making behaviour.

The third gap relates to a lack of research pertaining to the restaurant choice factors that consumers perceive to be more or less important. This gap is important as ethnic restaurant management needs to know how to prioritise their efforts and resources to attract and retain more diners.

\subsection{The Conceptual Research Model}

The conceptual model (see Figure 3.1) developed in this study was based on the review of the literature in Chapter Two and the focus group discussions (see Section 4.4.1). The research model suggests that consumers make a decision on an upscale ethnic restaurant based on nine factors: food quality, service quality, word-of-mouth, marketing communications, cultural learning, image and social status, different experience, value for money, and beverage preference, and demographic characteristics including: gender, age, ethnicity, qualification, occupation, household composition, and household income, when selecting a restaurant. 
Figure 3.1: The Conceptual Research Model

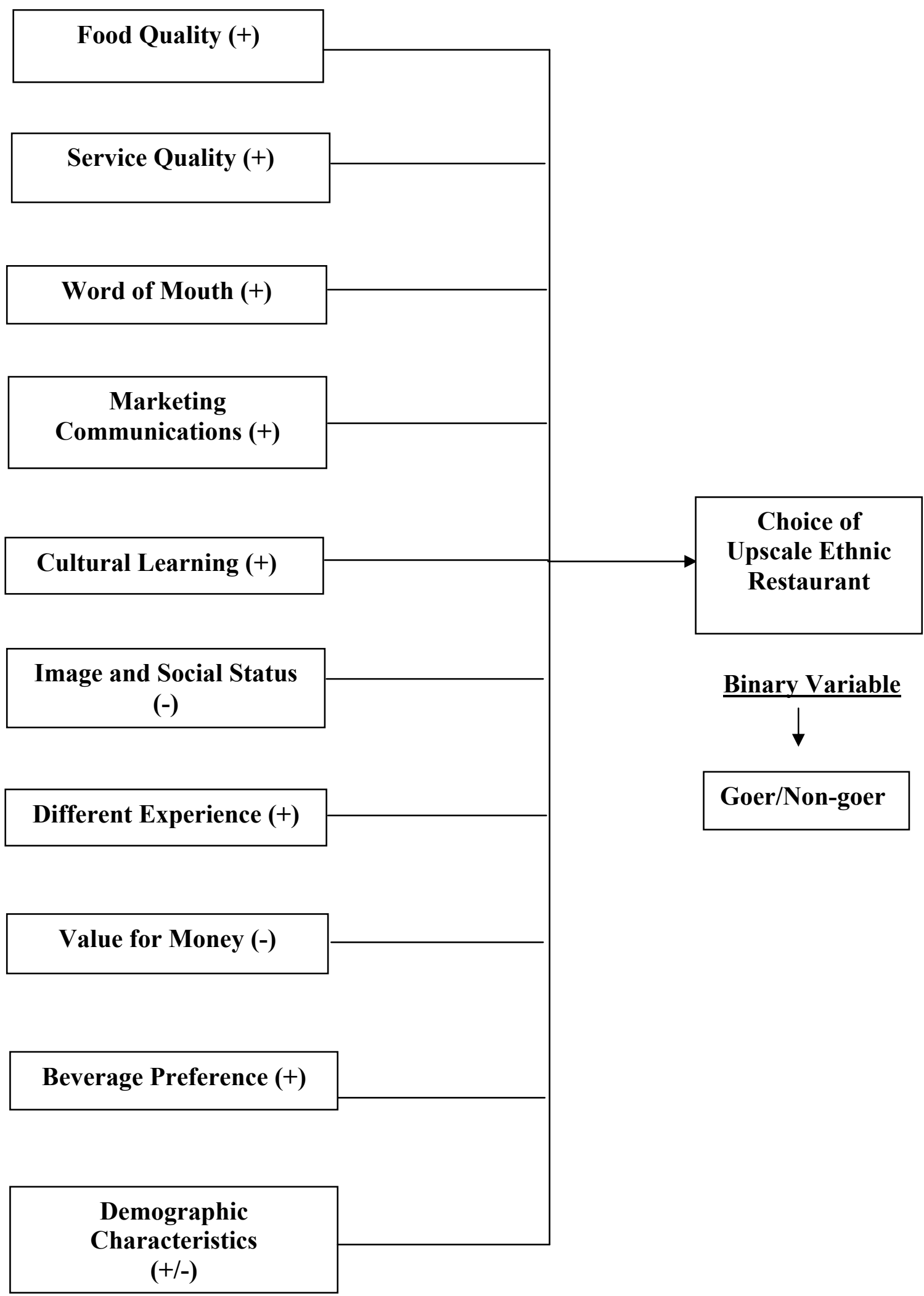

$\underline{\text { Independent Variables }}$ 


\subsection{The Research Model Based on the Factor Analysis}

Due to the exploratory nature of this study, an exploratory factor analysis was performed (see Section 5.4.2) to obtain a robust and reliable factor structure. After deleting one factor which did not meet the reliability measure, eight factors were selected to improve the research model and develop the hypotheses used in this study. The eight factors are service quality, food quality, dining experience, social status, marketing communications, religious food options, restaurant décor, and value for money. Furthermore, the demographic characteristics: gender, age, ethnicity, qualification, occupation, household composition, and household income, are retained in the model. The final version of research model is presented in Figure 3.2. 
Figure 3.2: The Consumers' Upscale Ethnic Restaurant Choice Factors Model

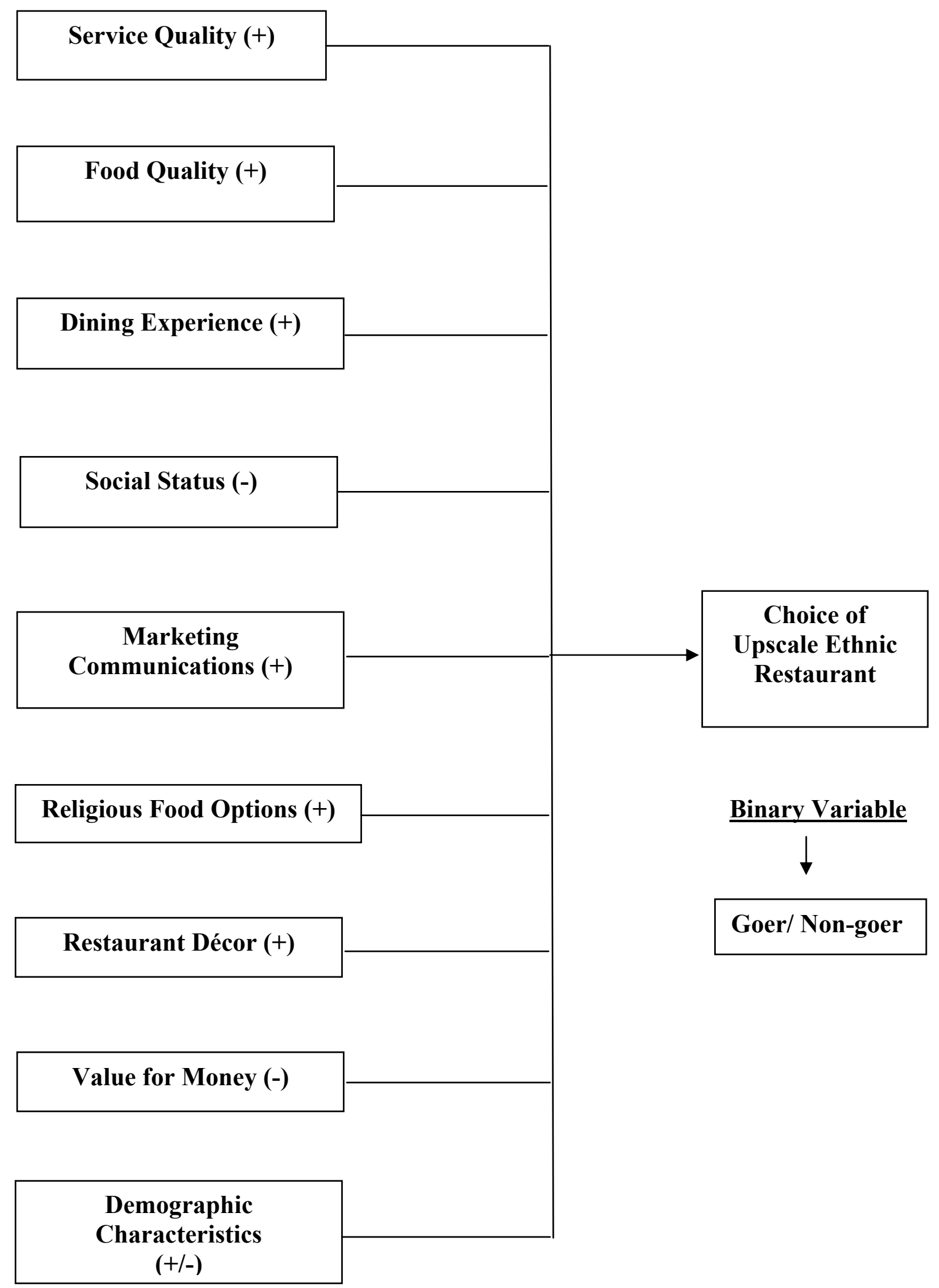

Independent Variables 


\subsection{Hypothesis Development}

The hypotheses developed for this study were based on the factor structure derived from the exploratory factor analysis. Eleven hypotheses are established to satisfy the three research objectives. Hypothesis 1 to Hypothesis 8 address Research Objective One; and Hypothesis 9 to Hypothesis 11 address Research Objective Two and Three.

\subsection{Hypotheses Relating to Research Objective One}

\subsubsection{Service Quality}

Previous studies on consumer behaviour in a restaurant setting (e.g., Chow et al., 2007; Johns \& Pine, 2002; Sweeney et al., 1992) suggest that service quality significantly influences consumers' decision on a restaurant. For example, Sweeny et al. (1992) studied the influence of various cues on the perceptions of service quality for a restaurant and found that manner of staff was the most important cue consumers used in selecting a restaurant. In addition, waiting time (Sulek \& Hensley, 2004) and billing accuracy (Kelly \& Carvell, 1987) can affect the perceived dining experience of restaurant consumers. Thus, the following hypothesis is proposed:

H1: Service quality has a positive effect on consumers' choice of an upscale ethnic restaurant.

\subsubsection{Food Quality}

Food quality is clearly a fundamental element of a restaurant experience (Namkung \& Jang, 2007; Sulek \& Hensley, 2004). Sulek and Hensley (2004) investigated the relative importance of food quality, physical environment, and service quality in a full-service restaurant and found that food quality was the most important determining factor of overall dining experience and repeat patronage. Similarly, Auty (1992) and Kivela (1997) studied the restaurant selection factors for different restaurant types and dining occasions and found that food type and food quality were the most influential factors of a restaurant selection, regardless of restaurant type or occasion. Therefore, the following hypothesis is formulated: 
H2: Food quality has a positive effect on consumers' choice of an upscale ethnic restaurant.

\subsubsection{Dining Experience}

Dining experience, in this study, includes different dining experiences, cultural learning, restaurant atmosphere, and authentic restaurant design. The composition of these elements of a dining experience conforms to the unique aspects of an ethnic restaurant dining experience. Consumers go to an ethnic restaurant not only for food and service but also for a different dining experience and cultural experience (Tian, 2001; Turgeon \& Pastinelli, 2002). This explanation is consistent with the study of Sukalakamala and Boyce (2007) who suggested that authentic ethnic cuisines experience, cultural learning, and different experience were among the main important preferences of consumers' perception of dining at ethnic restaurants. Hence, the following hypothesis is proposed:

H3: Dining experience has a positive effect on consumers' choice of an upscale ethnic restaurant.

\subsubsection{Social Status}

The items that constitute social status in this study are social class, image and beverage preference. The constitution of this variable is unique to this study which may be partly explained by the drinking culture of New Zealand. New Zealand diners may associate their drinking and dining out as being a part of their lifestyle. As Simpson (1999) commented, "New Zealand is a drinking nation". In addition, a study of the Christchurch and New Zealand dining out markets by van Ameyde and Brodie (1984) pointed out that New Zealand patrons dined out more at licensed restaurants than unlicensed restaurants. Further, previous studies have suggested that diners selected a restaurant based on the restaurant image which was often associated with their social status (Cheng, 2006; Peters, 2005). An upscale restaurant, in particular, has been associated with esteem and status (Mill, 2007). Hence, the following hypothesis is proposed: 
H4: Low social status has a negative effect on consumers' choice of an upscale ethnic restaurant.

\subsubsection{Marketing Communications}

As discussed in the literature, marketing communications is used by service firms to inform, persuade and remind consumers (Lovelock et al., 1998). The importance of word-of-mouth for service firms has been well established in the marketing literature (Mangold et al., 1999). Marketing communications, including word-of-mouth, advertising, and promotion was found to be a significant factor influencing customer loyalty for international restaurants in Saudi Arabia (Tunsi, 2000). Additionally, positive publicity can create a positive image for a restaurant and thus may be used as another effective marketing communications tool (J. Miller, 1993). Therefore, the following hypothesis is proposed:

H5: Marketing communications has a positive impact on consumers' choice of an upscale ethnic restaurant.

\subsubsection{Religious Food Options}

Religious beliefs play an important role in food selection for consumers of several religions groups (Asp, 1999; Dugan, 1994). For example, Muslims are forbidden to consume pork and alcohol and only allowed to eat the meat of animals that are slaughtered according to the 'halal' rules of Islam. These religious requirements prevent them from going to restaurants that do not offer 'halal' food (Hassan \& Hall, 2004). Therefore, the restaurants that offer food choices that are prepared according to religious beliefs are likely to attract wider groups of consumers (Dugan, 1994). Thus, the following hypothesis is proposed:

H6: Religious food options have a positive impact on consumers' choice of an upscale ethnic restaurant. 


\subsubsection{Restaurant Décor}

Restaurant décor is also recognised as an important aspect of a dining experience. The decoration in a restaurant including furniture style, lighting, comfort of seating, paintings, and other facilities can have an impact on how diners perceive and rate the restaurant (Sloan, 2004). Ryu and Jang (2007) empirically found a positive relationship between restaurant facility aesthetics, which included restaurant décor, and behavioural intentions, moderated by pleasure. Hence, the following hypothesis is proposed:

H7: An appealing restaurant décor has a positive impact on consumers' choice of an upscale ethnic restaurant.

\subsubsection{Value for Money}

Restaurant consumers consider the value for money of a restaurant by comparing what they get from the restaurant (e.g. food and service) and what they have to sacrifice by patronizing that restaurant (e.g. price) (Oh, 2000). In general, consumers recognise a good value for money when they perceive that the quality of the products and service they receive are worth as much, or more than, the price they pay. Soriano (2002) and Oh (2000) identified value for money as an important variable when consumers make a decision on a restaurant. Therefore, the following hypothesis is proposed:

H8: Low value for money has a negative effect on consumers' choice of an upscale ethnic restaurant.

\subsection{Hypotheses Relating to Research Objective Two and Three}

As discussed in Section 2.6 to Section 2.8, previous research has emphasised that restaurant consumers attached a different level of importance when evaluating restaurant choice factors and the importance of the choice factors varied, depending on dining occasion (e.g., Auty, 1992; Dube et al., 1994; Kivela, 1997; Koo et al., 
1999) and consumers' demographic characteristics (e.g., E. Kim \& Geistfeld, 2003;

Kivela et al., 2000; Koo et al., 1999; Olsen et al., 2000). The following hypotheses are thus proposed:

H9: Consumers attach different degrees of importance to the restaurant choice factors when making a decision to dine at an upscale ethnic restaurant.

H10: Consumers perceive restaurant choice factors differently based on their dining occasion (normal dining out, business- or work-related, gathering with friends/family, special occasion and celebration, and dating/intimate dining).

H11: Consumers perceive restaurant choice factors differently based on their demographic characteristics (gender, age, ethnicity, qualification, occupation, household composition, and household income).

\subsection{Chapter Summary}

This chapter identified three gaps in the literature pertaining to restaurant selection behaviour. A conceptual research model and a research model based on the factor analysis were presented, along with eleven testable hypotheses. 


\section{CHAPTER 4 \\ RESEARCH METHODOLOGY}

\subsection{Introduction}

This chapter outlines the research methodology used to test the eleven hypotheses, stated in Section 3.6 and Section 3.7, and to satisfy the three research objectives, stated in Section 3.1.

The sample derivation and expected sample size are explained, as well as the methods of data collection. Subsequently, the questionnaire design is discussed. Lastly, the data analysis techniques used in this study, such as factor analysis and logistic regression analysis, are discussed.

\subsection{Sampling Method}

The data was collected by a mail survey of Christchurch residents. The data was collected from respondents 18 years and older. A systematic sampling method was employed in this research. The systematic sampling method is common for consumer attitude surveys as the method is suitable when the population frame is large (Sekaran, 2003). First, number 7 was chosen from a list of random numbers that were generated using a Microsoft Excel Spreadsheet. Subsequently, the sample was drawn systematically from the 2007/08 Christchurch Telecom White Pages.

\subsection{Sample Size}

A precise sample size should be met in order to make generalisations with confidence about the constructs under investigation. Therefore, the sample statistics can reflect the population parameters as accurately as possible with only a narrow margin of error (Sekaran, 2003). This study used the Christchurch population as the target population. According to the 2006 New Zealand census, the population of Christchurch city was 
348,435 . The sample size required to achieve a $95 \%$ level of confidence was estimated as $384^{1}$. The expected response rate was 30 percent, thus 1,300 survey questionnaires were mailed out.

\subsection{Questionnaire Development}

The lack of published research relating to ethnic restaurant choice factors in New Zealand made it necessary to collect primary data to test the eleven hypotheses and satisfy the research objectives of this study. The questionnaire was designed specifically for this study. Because this research is exploratory, an extensive review of the literature and focus group discussions were used to help identify the consumer choice criteria for dining at an upscale ethnic restaurant. Initially, the factors derived from the literature review and the focus group discussions were used to assist in developing the questionnaire.

\subsubsection{Construct Operationalisation}

The extensive review of the literature presented in Chapter Two identified the proposed factors that influence a decision to dine at a restaurant. However, only limited studies relate to ethnic restaurants (e.g., Tunsi, 2000; Turgeon \& Pastinelli, 2002; Utami, 2004; Verbeke \& López, 2005; Withers, 2000) and restaurants of particular ethnic cuisine (Raymond Bailey \& Tian, 2002; Josiam \& Monteiro, 2004; Qu, 1997; Sukalakamala \& Boyce, 2007). Therefore, in order to provide additional insights into the factors influencing ethnic restaurant dining and to help develop a questionnaire specifically for the New Zealand foodservice market, it was necessary to conduct focus group interviews.

Focus group research has been used to "reveal consumer's hidden needs, wants, attitudes, feelings, behaviours, perceptions, and motives regarding services, products, or practices" (Hair, Bush, \& Ortinau, 2000, p. 223). In addition, Greenbaum (1998) noted that focus group interviews were most popular with attitude research, such as

\footnotetext{
${ }^{1}$ Sample Size Formula: finite population without replacement: $\mathrm{n}=\frac{N Z^{2} \alpha / 2 \mathrm{pq}}{(\mathrm{N}-1) \mathrm{e}^{2}+\mathrm{Z}^{2} \alpha / 2 \mathrm{pq}}$ (Adapted from Mendenhall, Reinmuth \& Beaver, 1993)
} 
service quality evaluations. When combined with quantitative methods such as questionnaire surveys, focus group interviews are described as critical for developing and creating reliable measurement scales (Hair et al., 2000).

According to Greenbaum (1998), a mini focus group consisting of four to six participants is the most efficient size for focus group research. Two focus groups of six participants were conducted for this study. The participants were randomly selected on a convenience basis. Participants in both groups were males and females 18 years and older, who had or had not dined at an upscale ethnic restaurant in the past twelve months.

The participants were asked to identify the factors that influence their decision to dine at an upscale ethnic restaurant. The groups were encouraged to discuss any factors they could think of and also to comment on any factors mentioned by other participants. Subsequently, the participants were asked to determine the factors that were most important to them when choosing an upscale ethnic restaurant. The focus group discussions lasted for approximately 45 minutes for each group. They were recorded and transcribed.

In addition to the factors derived from the literature review, the focus group discussions have revealed the following factors: religious food options (sub-factor of food quality), waiting time and accuracy of billing (sub-factors of service quality), and beverage preference. These factors and the factors derived from the literature review (see Section 2.6) were used in the analysis.

\subsubsection{Questionnaire Format}

The questionnaire contained four sections. For clarification purposes, the focus and definition of an upscale ethnic restaurant in this study were stated on the first page of the questionnaire. Section One consisted of three questions regarding attendance, frequency of dining, and occasion of dining at an upscale ethnic restaurant. Respondents who had not dined at an upscale ethnic restaurant in the past twelve months were asked to skip the frequency of dining and occasion of dining questions. Section Two was for the respondents who were upscale ethnic restaurant goers. It 
consisted of 37 statements relating to food quality, service quality, word of mouth, marketing communications, cultural learning, image and social status, different experience, value for money, and beverage preference. Likewise, Section Three contained 37 statements for the upscale ethnic restaurant non-goers (respondents who had not dined at an upscale ethnic restaurant in the past twelve months). Section Four contained questions regarding demographic characteristics.

All items in Section Two and Section Three were positively worded. Respondents were asked to express their agreement to the 37 statements in either section, depending if they were an upscale ethnic restaurant goer or non-goer. The statements were measured using a seven-point Likert scale ranging from Strongly Agree (1) to Strongly Disagree (7). The statements were randomly placed in the questionnaire to reduce systematic biases in the responses as recommended by Sekaran (2003).

\subsubsection{Pre-testing Procedures}

To assess the reliability and validity of the questionnaire, a pre-test was conducted. As the questionnaire was developed specifically for this research, pre-testing helped to clarify the questions and statements. 30 questionnaires were randomly distributed to restaurant consumers 18 years and older. The respondents were encouraged to comment on any questions or statements that they thought were ambiguous or unclear. Some minor wording modifications to the questionnaire were made as a result of this process. The final version of the questionnaire is in Appendix B.

\subsection{Data Collection Procedures}

1,300 questionnaires were distributed to the randomly selected respondents. The data collection procedures were based on the guidelines recommended by Dillman (2007). A prepaid self-addressed envelop and a cover letter (see Appendix A) were attached to the survey. Respondents were requested to return the completed surveys within 15 days after receiving them. 


\subsection{Data Analysis Techniques}

Due to the limited empirical studies on ethnic restaurant choice factors, exploratory factor analysis was used to validate the decision factors suggested from the focus group discussions and the literature review. Subsequently, logistic regression analysis was used to identify the significant factors that influence a decision to dine at an upscale ethnic restaurant in order to satisfy Research Objective One. The Sensitivity analysis was used to satisfy Research Objective Two. The marginal effect for each of the estimated coefficients in the model was calculated to determine the most important factors influencing a choice of an upscale ethnic restaurant. Furthermore, T-tests and ANOVA were used to satisfy Research Objective Three.

\subsubsection{Factor Analysis}

Factor analysis is a multivariate statistical technique used to form a structure within a set of observed variables (Stewart, 1981). It is an interdependence technique in which all variables are simultaneously considered (Hair, Anderson, Tatham, \& Black, 1998). Factor analysis has three general functions: (1) minimising the number of variables while the amount of information in the analysis is maximised; (2) searching qualitative and quantitative data distinctions when the data is too large; (3) testing hypotheses about the number of distinctions or factors underlying a set of data (Stewart, 1981).

The following sections will overview different types of factor analysis, assumptions of factor analysis, factor rotation, and interpretation of the resulting factors.

\subsubsection{Modes of Factor Analysis}

There are a number of modes of factor analysis (see Table 4.1) which all provide information about the dimensional structure of data (Stewart, 1981). The appropriate mode of factor analysis depends on the objectives of the research (Hair et al., 1998). In this study, a set of variables were collected at the same time from a number of individuals. Therefore, $\mathrm{R}$ factor analysis was used in this study. 
Table 4.1: Modes of Factor Analysis (Stewart, 1981, p. 53)

[ copyright clearance to reproduce figure not obtained ]

\subsubsection{Types of Factor Analysis}

There are two common types of factor analysis; exploratory factor analysis and confirmatory factor analysis (Stewart, 1981). The selection of either technique depends on the purpose of the analysis. Exploratory factor analysis is used when the underlying structure of a data set are unknown, while confirmatory factor analysis is common for theory building by testing hypotheses about the structure of a data set that has been formed by prior research (Stewart, 1981).

As the underlying structure of the data set is unknown in this exploratory research, exploratory factor analysis was used in this study.

There are two choices of commonly used models to obtain factor solutions; common factor analysis and component analysis (Hair et al., 1998). The exact method is chosen on a basis of the objectives of factor analysis and the amount of prior knowledge about the variance of the variables (Hair et al., 1998).

The common factor model is most appropriate when the objective of the research is to identify the latent dimensions or constructs represented in the original variables, and the researcher has little knowledge regarding either specific or error variances (Hair et al., 1998). However, several problems are associated with the use of common factor analysis, and for this reason, component analysis has become a more widely used technique. Component factor analysis is appropriate if the concern of the research is prediction, or minimum number of factors are needed to account for the maximum portion of the variance, and when prior knowledge suggests that specific and error variance represents a relatively small proportion of the total variance (Hair et al., 
1998). Component factor analysis was considered more appropriate for the data analysis required in this study.

\subsubsection{Statistical Assumptions for Factor Analysis}

Hair et al. (1998) identified several critical conceptual and statistical assumptions for factor analysis. These issues are discussed below:

\section{No Selection Bias/Proper Specification:}

Factor analysis can be used to explore data whose structure is unknown. Factor analysis is not suitable for determining the appropriateness of data other than the correlation among variables (Hair et al., 1998). Garson (2008a) noted that if the relevant variables are excluded and irrelevant variables are included in the correlation matrix, the factors which are uncovered will be affected substantially. Consequently, researchers must ensure that, when using factor analysis, the observed patterns are conceptually valid and appropriate for the study (Hair et al., 1998).

\section{Linearity:}

Factor analysis is a linear procedure, the smaller the sample size, the more important it is to screen the data for linearity (Garson, 2008a).

\section{Normality:}

Screening data for normality is vital if a statistical test is applied to the significance of the factors (Hair et al., 1998). Nevertheless, multicollinearity is also required to some degree, as factor analysis is used to form interrelated sets of variables (Hair et al., 1998).

\section{Homoscedasticity:}

Factor analysis assumes homoscedasticity of the relationship among measured variables. However, this is not considered a critical assumption (Garson, 2008a).

\section{Adequate Sample Size:}

Hair et al (1998) recommended at least 50 and preferably 100 or larger sample for factor analysis. The authors also noted that the highest cases-per-variable ratio is 
desirable to assure that the significance in factor analysis does not happen by chance (Hair et al., 1998).

However, if the data matrix has sufficient correlations to justify the application of factor analysis, the assumptions of linearity, normality, and homoscedasticity do not necessarily have to be met (Hair et al., 1998). The approaches to justify sufficient correlations for factor analysis are discussed in the following section.

\subsubsection{Tests for Determining Appropriateness of Factor Analysis}

Hair et al. (1998) suggested that there are several methods to determine whether factor analysis is appropriate to be applied to a set of data. These are:

(i) Examination of the Correlation Matrix;

(ii) Inspection of the Anti-Image Correlation Matrix

(iii) Bartlett's Test of Sphericity;

(iv) Kaiser-Meyer-Olkin Measure of Sampling Adequacy.

\section{Examination of the Correlation Matrix:}

An examination of the correlation matrix is a simple method of determining the appropriateness of factor analysis. As factor analysis is concerned with the homogeneity of items, low correlations throughout the correlation matrix would suggest the inappropriateness (Stewart, 1981). According to Hair et al. (1998), the values of correlations in the correlation matrix are expected to be greater than .30 for the factor analysis to be appropriate.

\section{Inspection of the Anti-Image Correlation Matrix:}

The correlations among variables in the data matrix can also be determined by inspection of the anti-image correlation matrix. This represents the negative value of the partial correlations (Hair et al., 1998). If variables share common factors, the partial correlation coefficient between pairs of variables should be small, and the correlation matrix should be near diagonal when the linear effects are eliminated. 
Therefore, if the anti-image matrix has many non-zero off-diagonal entries, the correlation matrix is not appropriate for factoring (Stewart, 1981).

\section{Bartlett's Test of Sphericity:}

The Bartlett's test of sphericity is another widely used technique to test the correlations in a data matrix. It provides the statistical probability that the correlation matrix has significant correlations among at least some of the variables (Hair et al., 1998). The correlation matrix is hypothesised to come from a population of variables that are independent. Rejection of the hypothesis indicates that the data are appropriate for factor analysis (Stewart, 1981).

\section{Kaiser-Meyer-Olkin Measure of Sampling Adequacy:}

The Kaiser-Meyer-Olkin measure of sampling adequacy determines the degree of interrelations among the variables (Stewart, 1981). The index ranges from 0 to 1 , reaching 1 when each variable is perfectly predicted without error by the other variables (Hair et al., 1998). Kaiser and Rice (1974, cited in Stewart, 1981) identified the level of appropriateness as: $.90+=$ marvellous, $.80+=$ meritorious, $.70+=$ middling, $.60+=$ mediocre, $.50+=$ miserable, and below $.50=$ unacceptable.

\subsubsection{Factor Extraction in Principal Components Analysis}

For a large set of variables, factor extraction starts by extracting the combinations of variables that explain the greatest amount of variance. The extraction then proceeds to the combinations that account for smaller amounts of variance and so on (Hair et al., 1998). The two criteria, latent root criterion and scree plot, used in determining the number of factors to extract and when to cease extracting are discussed by Stewart (1981) and Hair et al. (1998).

\section{Latent Root Criterion:}

The latent root criterion is the most commonly used technique (Hair et al., 1998). The condition is that a factor should account for the variance of at least a single variable if it is to be retained for interpretation. Each variable contributes a value of 1 to the total eigenvalue (Hair et al., 1998). The factors that have latent roots or eigenvalues greater than 1 are considered significant; other factors with lower eigenvalues can be 
removed (Hair et al., 1998; Stewart, 1981). This method is most reliable when the number of variables in the factor analysis is between 20 and 50 (Hair et al., 1998).

\section{Scree Test Criterion:}

The Scree test can be obtained by plotting the latent roots against the number of factors in their order of extraction, and the shape of the resulting curve can determine the cut off point (Hair et al., 1998). A large break in the plot is taken to indicate the point where factoring should stop (Stewart, 1981). The procedure is as follows:

A straight edge is laid across the bottom portion of the roots to see where they form an approximately straight line. The point where the factors curve above the straight line gives the number of factors, the last factor being the one whose eigenvalue immediately proceeds the straight line (Stewart, 1981, p. 58).

\subsubsection{Factor Rotation}

Factor loadings are used to interpret the role each variable plays in defining each factor (Hair et al., 1998). The loadings indicate the degree of correspondence between the variable and the factor. The higher loadings show the higher degree the variable represents the factor (Hair et al., 1998). Computation of factor matrix can be orthogonally rotated or obliquely rotated.

\section{Orthogonal rotation:}

Orthogonal rotation is the simplest case of rotation which the axes are maintained at 90 degrees (Hair et al., 1998). The orthogonal rotations have three major approaches including VARIMAX, QUARMAX, and EQUIMAX.

VARIMAX is the most common rotation procedure (Hair et al., 1998; Stewart, 1981). VARIMAX method aims to maximise the variance of the squared loadings of a factor on all the variables in a factor matrix which, in return, differentiating the original variables by extracted factor (Garson, 2008a). When the correlation is close to +1 or -1 , it can be interpreted as a high positive or negative association between the variable and the factor; when the correlation is closes to 0 , it indicates a lack of association (Hair et al., 1998). QUARMAX is an alternative orthogonal method which focuses on 
rotating the initial factor so that a variable loads high on one factor and as low as possible on all other factors (Hair et al., 1998).

EQUIMAX method is a combination of both the VARIMAX method, which simplifies the factors, and the QUARTIMAX method, which simplifies the variables. The EQUIMAX method has yet to gain widespread acceptance and is used infrequently (Hair et al., 1998). The VARIMAX rotation was used in this study.

\section{Oblique rotation:}

Oblique rotation is similar to orthogonal rotation, except that oblique rotations allow correlated factors instead of maintaining independence between the rotated factors (Hair et al., 1998). Stewart (1981) found that oblique rotations are particularly useful in theory building, and that they play a significant role in the development of consumer behaviour theories. Two common approaches for oblique rotation are OBLIMIN and PROMAX.

OBLIMIN is the standard method when a non-orthogonal solution is required. This method allows the correlation of the factors. OBLIMIN can produce higher eigenvalues; however, the interpretability of the factors will be lessened (Garson, 2008a). PROMAX can compute faster than OBLIMIN and therefore is sometimes used for datasets that are extensively large (Garson, 2008a).

Realistically, very few factors are uncorrelated (Hair et al., 1998). Correlated factors and hierarchical factor solutions are noted to be intuitively attractive and theoretically justified in many marketing applications (Stewart, 1981). Stewart (1981) recommended that both an oblique rotation and an orthogonal rotation be performed, particularly in exploratory research. Therefore, both the VARIMAX orthogonal rotation and OBLIMIN oblique rotation were conducted in this study.

\subsubsection{Interpretation of Factors}

When interpreting factors, decisions must be made regarding which factor loadings are worth considering. The significance of factor loadings is dependent on the sample size (see Table 4.2). In general, the larger factor loadings are desirable in interpreting 
the factor matrix (Hair et al., 1998). Three criteria are required for identifying the significance of factor loadings (Hair et al., 1998):

(1) The larger the sample size, the smaller the loading to be considered significant.

(2) The larger the number of variables being analysed, the smaller the loading to be considered significant.

(3) The larger the number of factors, the larger the size of the loadings on later factors to be considered significant for interpretation.

\section{Table 4.2: Guidelines for Identifying Significant Factor Loadings Based on Sample Size (Hair et al., 1998, p. 112)}

[ copyright clearance to reproduce figure not obtained ]

As it is common that many variables have moderate-size significant loadings on more than one factor, it becomes difficult to structure a factor matrix (Hair et al., 1998).

The factor solution is obtained when all significant loadings for variables load on a factor (Hair et al., 1998). By examining all the underlined variables for a particular factor, the researcher needs to assign a name or label for a factor, based on the underlying variables for each factor. The variables with the highest factor loadings are also considered more important, and this relationship should be reflected in the process (Hair et al., 1998).

\subsubsection{Summated Scale}

Hair et al. (1998) recommended summated scale as an instrument for decreasing the measurement error from the reliance on a single response. A summated scale is 
formed by combining all the variables loadings highly on a factor and summing or averaging them to create a new variable (Hair et al., 1998). As the summated scale will represent the multiple aspects of concept in a single measure, the requirements of content validity, dimensionality and reliability must be met (Hair et al., 1998).

\subsubsection{Content Validity}

Content validity ${ }^{2}$ is a subjective measurement used to ensure that the summated scales are assessing the correspondence between individual items and the concept (Hair et al., 1998). A display of content validity indicates that the items are adequate and are representative of the concept they are intended to measure (Churchill, 1979).

\subsubsection{Dimensionality}

Each summated scale has a condition to be unidimensional, meaning that they are strongly associated with each other and represent a single concept. The summated scale is unidimensional if its items load highly on a single factor (Hair et al., 1998).

\subsubsection{Reliability}

Reliability scale measures the degree of consistency between multiple measurements of a variable (Hair et al., 1998). A common measure of reliability is internal consistency, which is used to test if the individual items or indicators of the scale measuring the same construct and thus be highly intercorrelated (Hair et al., 1998).

The most widely used measure to assess the internal consistency of the scale is Cronbach's alpha (Churchill, 1979). Churchill (1979) recommended that a Cronbach coefficient alpha of .60 or greater is adequate for a newly developed questionnaire.

\subsubsection{Logistic Regression Analysis}

After performing the factor analysis and creating summated scales, the derived factors can be used for subsequent statistical analyses. Since the dependent variable in this study, choice of upscale ethnic restaurant, is modelled as a discrete variable, the

\footnotetext{
${ }^{2}$ Also known as face validity
} 
following sub-sections overview the model which was designed to explain qualitative choice analysis.

\subsubsection{Qualitative Choice Analysis}

Qualitative choice analysis ${ }^{3}$ is widely used in describing decision-makers' choices in areas such as banking, transportation, housing and telecommunications. Qualitative response models are synonymous with quantal, categorical, qualitative choice or discrete models. The construction of models of qualitative choice in which the dependent variable takes on a dichotomous or polychotomous character is of interest to economic, business and marketing analysis (Greene, 2003). Generally, the purpose of qualitative response models is to determine the probability (or likelihood) that a decision maker, with a given set of attributes, makes one choice rather than the alternative (Liao, 1994).

Amemiya (1981) indicated that qualitative choice modelling has become more important in economic and behavioural studies because they include a number of discrete variables. Economic agents often make a decision between activities rather than choices of levels of participation in markets. As a result, qualitative choice models have been used in analysing participation in a variety of activities (Amemiya, 1981).

For example, Ennew and Binks (1996) used a simple logit model to identify factors affecting bank customer retention and defection. The authors found that functional quality, technical quality, customer relationship, and certain product and firm specific characteristics were important to retain customers' loyalty to a bank.

Hardy and Shuey (2000) utilized two logit models in their study. The two logit models were used to identify (1) if the employees participated in employer-sponsored programs, and (2) whether respondents spent or saved their cash settlement respectively. The findings from the first logit model indicated that women were less likely to have participated in employer-sponsored pension plans. The results from the second logit model identified that women were more likely to save the settlement.

\footnotetext{
${ }^{3}$ Qualitative choice analysis adapted from Ben-Akiva and Lerman (1985) and Train (1986). References were also made from Greene (2003).
} 
Furthermore, Gan, Clemes, Limsombunchai and Weng (2006) used a logit analysis to examine the consumers' choice of banking channels in New Zealand. The authors found that service quality dimensions, perceived risk factors, user input factors, occupation and education significantly affected consumers' choice of electronic or non-electronic banking.

A qualitative choice situation is defined as one in which a decision-maker faces a choice among a set of alternatives which satisfy the following criteria:

a. The number of alternatives in the set is finite;

b. The alternatives are mutually exclusive; that is, the person's choosing one alternative in the set necessarily implies that the person does not choose another alternative; and

c. The set of alternatives is exhaustive: that is, all possible alternatives are included, and so the person necessarily chooses one alternative from the set.

Models for determining discrete choices such as whether to participate or not to participate in state or local government programs, or to favour or not to favour a particular political party are known as qualitative response models. Therefore, the decision to dine or not dine at an upscale ethnic restaurant falls into the realm of qualitative choice. Qualitative response models determine the probability (or likelihood) that a decision-maker, with a given set of attributes, makes one choice rather than the alternative (Liao, 1994).

However, a qualitative choice model cannot be applied to a situation in which a decision or choice is represented by a continuous variable. Generally, qualitative choice models assign a class of models, such as logit and probit, which attempt to relate the probability of making a particular choice to various explanatory factors and calculate the probability that the decision-maker will choose a particular choice or decision from a set of choices or decisions $\left(\mathrm{J}_{\mathrm{n}}\right)$, given data observed by the researcher. This choice probability $\left(\mathrm{P}_{\text {in }}\right)$ depends on the observed characteristics of alternative $i\left(z_{i n}\right)$ compared with all other alternatives $\left(z_{j n}\right.$, for all $j$ in $J_{n}$ and $\left.j \neq i\right)$ and 
on the observed characteristics of the decision-maker $\left(\mathrm{s}_{\mathrm{n}}\right)$. The choice probability can be specified as a parametric function of the general form:

$$
P_{\text {in }}=f\left(z_{\text {in }}, z_{\text {jn }}, s_{n}, \beta\right)
$$

where $\mathrm{f}$ is the function relating the observed data to the choice probabilities specified up to some vector of parameters, $\beta$. By relating qualitative choice models to utility theory, a clear meaning of the choice probabilities emerges from the derivation of probabilities from utility theory. The utility from each alternative depends on various factors, including the characteristics of the decision-maker. By labelling the vector of all relevant characteristics of person $n$ as $r_{n}$ and the vector of all characteristics of alternative $\mathrm{i}$ chosen by person $\mathrm{n}$ as $\mathrm{x}_{\mathrm{in}}$, utility is a function of these factors,

$$
\mathrm{U}_{\text {in }}=\mathrm{U}\left(\mathrm{x}_{\mathrm{in}}, \mathrm{r}_{\mathrm{n}}\right)
$$

for all $i$ in $J_{n}$, the set of alternatives.

Based on Marshall's consumer demand theory of utility maximisation, the decisionmaker therefore chooses the alternative from which he derives the greatest utility. His choice can be said to be deterministic, and he will choose $i\left(i \in J_{n}\right)$ if $U\left(x_{i n}, r_{n}\right) \geq$ $U\left(x_{j n}, r_{n}\right)$, for $\left(i, j \in J_{n}\right.$ and $\left.j \neq i\right)$. To specify the choice probability in qualitative choice models, $U\left(x_{i n}, r_{n}\right)$ for each $i$ in $J_{n}$ can be divided into two sub functions, a systematic component that depends only on factors that the researcher observes and another that represents all factors and aspects of utility that are unknown or excluded by the researcher, labelled $\varepsilon_{\text {in }}$. Thus,

$$
\mathrm{U}_{\mathrm{in}}=\mathrm{U}\left(\mathrm{x}_{\mathrm{in}}, \mathrm{r}_{\mathrm{n}}\right)=\mathrm{V}\left(\mathrm{Z}_{\mathrm{in}}, \mathrm{s}_{\mathrm{n}}\right)+\varepsilon_{\mathrm{in}}
$$

where $Z_{\text {in }}$ are the observed attributes of alternative $i$ and $s_{n}$ are the observable characteristics of decision-maker $n$.

$$
\mathrm{P}_{\text {in }}=\mathrm{P}\left(\mathrm{U}_{\text {in }} \geq \mathrm{U}_{\text {jn }}\right) \quad \forall \quad \mathrm{i}, \mathrm{j} \in \mathrm{J}_{\mathrm{n}} \text { and } \mathrm{i} \neq \mathrm{j},
$$


hence, $\quad \mathrm{P}_{\text {in }}=\mathrm{P}\left(\mathrm{V}_{\text {in }}-\mathrm{V}_{\text {jn }} \geq \varepsilon_{\text {jn }}-\varepsilon_{\text {in }}\right) \quad \forall \quad \mathrm{i}, \mathrm{j} \in \mathrm{J}_{\mathrm{n}}$ and $\mathrm{i} \neq \mathrm{j}$.

Qualitative choice models are used to predict probabilities of choices being made, and they attempt to relate the probability of making a particular choice to various explanatory factors (Sellar, Chavas, \& Stoll, 1982). Probabilities must be between zero and one. Estimation of parameters to maximize the probability of the choice $\mathrm{Y}_{\mathrm{i}}=1$ by use of a linear probability model and ordinary least squares (OLS) is not acceptable due to the return of probabilities outside the unit interval (Stynes \& Peterson, 1984). In addition, the use of a linear probability model results in heteroscedastic errors and as a result, t-tests of significance are not valid (J. R. Miller $\&$ Hay, 1981). For these reasons, it is preferable to use either a logit or probit model.

Different qualitative choice models are obtained by specifying different distributions of the unknown component of utility, $\varepsilon_{\text {in }}$, and deriving functions for the choice probabilities (Ben-Akiva \& Lerman, 1985; Train, 1986). If the error term is assumed to be Gumbel-distributed, then the above represents the standard binary logit model. However, if the error term is assumed to be normally distributed, then the model becomes the binary probit model (Ben-Akiva \& Lerman, 1985; Greene, 2003; Maddala, 1993). The logit model will be used in this research because of the binary nature of the approach, and the differences between the two models are slight (Maddala, 1993). The model will be estimated by the maximum likelihood method used in LIMDEP version 7.0 software.

Thus, the choice probabilities can then be expressed as

$$
\begin{aligned}
& \mathrm{P}_{\text {in }}=\mathrm{e}^{\mu V i n} / \Sigma_{\mathrm{j} \in \mathrm{Jn}} \mathrm{e}^{\mu V \mathrm{jn}} \forall \mathrm{i}, \mathrm{j} \in \mathrm{J}_{\mathrm{n}}, \mu=\text { positive scale parameter, i.e. } \mu>0 \text {. } \\
& \text { or, } \quad \mathrm{P}_{\mathrm{in}}=1 /\left(1+\mathrm{e}^{-\mu[\mathrm{Vin}-\mathrm{Vjn}]}\right)
\end{aligned}
$$

Under relatively general conditions, the maximum likelihood estimator is consistent, asymptotically efficient ${ }^{4}$ and asymptotically normal ${ }^{5}$.

\footnotetext{
${ }^{4}$ Asymptotically efficient means that for large $\mathrm{n}$, no other consistent estimator has a smaller variance.
} 
For example, consumers who are considering an upscale ethnic restaurant are faced with a simple binary choice situation; to dine at an upscale ethnic restaurant, or not to dine at an upscale ethnic restaurant. The consumer's utility associated with dining at an upscale ethnic restaurant is denoted as $U_{1 n}$ and the utility associated with not dining at an upscale ethnic restaurant denoted as $\mathrm{U}_{0 \mathrm{n}}$, which is represented as:

$$
\mathrm{U}_{\text {in }}=\mathrm{V}_{\text {in }}+\varepsilon_{\text {in }} \quad \forall \quad \mathrm{i} \in \mathrm{J}_{\mathrm{n}} \text { and } \mathrm{J}_{\mathrm{n}}=\{0,1\}
$$

The consumer will choose to dine at an upscale ethnic restaurant if $\mathrm{U}_{1 \mathrm{n}}>\mathrm{U}_{0 \mathrm{n}}$, and the utility of each choice depends on the vector of observable attributes of the choices and the vector of observable consumer characteristics, summarized as $V_{\text {in }}$. All unobservable and excluded attributes and consumer characteristics are represented by the error term, $\varepsilon_{\text {in }}$, that is assumed to be independently and identically Gumbeldistributed. The choice probability of $\mathrm{U}_{1 \mathrm{n}}>\mathrm{U}_{0 \mathrm{n}}$ is given as $\mathrm{P}_{1 \mathrm{n}}{ }^{6}=\operatorname{Pr}_{\mathrm{n}}\left(\mathrm{U}_{1 \mathrm{n}}>\mathrm{U}_{0 \mathrm{n}}\right)=$ $1 /\left(1+\mathrm{e}^{-\mu[\mathrm{Vln}-\mathrm{V} 0 \mathrm{n}]}\right)$, where $\mu>0$. In an upscale ethnic restaurant decision, the vector of observable consumer characteristics is represented in parametric functional form.

The choice of an upscale ethnic restaurant in New Zealand is hypothesised to be a function of eight variables and demographic characteristics. The eight variables are: service quality, food quality, dining experience, social status, marketing communications, religious food options, restaurant décor, and value for money. The demographic characteristics are: gender, age, ethnicity, qualification, occupation, household composition, and household income. The proposed empirical model can be written under the general form:

\footnotetext{
$\mathrm{UETNRCH}=f(\mathrm{SQ}, \mathrm{FQ}, \mathrm{DE}, \mathrm{ST}, \mathrm{MC}, \mathrm{RF}, \mathrm{RD}, \mathrm{VM}, \mathrm{GEN}, \mathrm{AGE}, \mathrm{ETH}, \mathrm{QUA}, \mathrm{OCC}$, $\mathrm{HC}, \mathrm{HI}, \varepsilon)$

\footnotetext{
${ }^{5}$ Asymptotically normal means that for large $\mathrm{n}$, they closely approximate the normal distribution, even if the distribution from which the observations were drawn was not normal (Ramanathan, 1992).

${ }^{6} \mathrm{P}_{\mathrm{ln}}=$ Estimated probability of alternative 1, that is, dining at an upscale ethnic restaurant.
} 
The discrete dependent variable, UETNRCH, measures a choice of an upscale ethnic restaurant. The dependent variable is based on the question asked in the mail survey: "Have you dined at an upscale ethnic restaurant in the past twelve months?"

UETNRCH $=\quad 1$ if the respondent is an upscale ethnic restaurant non-goer; 0 otherwise

$\mathrm{SQ}(+) \quad=\quad$ Service Quality

FQ $(+)=$ Food Quality

$\mathrm{DE}(+) \quad=\quad$ Dining Experience

ST $(-) \quad=\quad$ Social Status

$\mathrm{MC}(+)=$ Marketing Communications

$\mathrm{RF}(+) \quad=\quad$ Religious Food Options

$\mathrm{RD}(+) \quad=\quad$ Restaurant Décor

$\mathrm{VM}(-) \quad=\quad$ Value for Money

Demographic Characteristics:

GEN $(+/-)=\quad$ Dummy variables for gender

Gender 1; 1 if respondent is a male; 0 otherwise

$\operatorname{AGE}(+/-)=\quad$ Dummy variables for age group

Age group 1; 1 if respondent is between 18 to 35 years old; 0 otherwise

Age group 2; 1 if respondent is between 36 to 55 years old; 0 otherwise

Age group 3; 1 if respondent is 56 years old and over; 0 otherwise

ETH $(+/-)=\quad$ Dummy variables for ethnicity

Ethnicity 1; 1 if respondent is New Zealand European; 0 otherwise

Ethnicity 2; 1 if respondent is Others (e.g. New Zealand Māori, Pacific Islander, European, Asian); 0 otherwise 
QUA $(+/-)=$

$\operatorname{OCC}(+/-)=$

$\mathrm{HC}(+/-)=$
Dummy variables for qualification

Qualification 1; 1 if respondent completed low-level qualification (up to high school certificate, seventh form certificate); 0 otherwise

Qualification 2; 1 if respondent completed medium-level qualification (diploma, trade qualification); 0 otherwise Qualification 3; 1 if respondent completed high-level qualification (bachelors degree, postgraduate degree); 0 otherwise

Dummy variables for occupation

Occupation 1; 1 if respondent is white-collar (professional, tradesperson, clerical, sales/service, self-employed, management); 0 otherwise

Occupation 2; 1 if respondent is retired; 0 otherwise Occupation 3; 1 if respondent is others (student, farmer, labourer, unemployed, community worker, other); 0 otherwise

Dummy variables for household composition Household composition 1; 1 if respondent's household composition is couple without children at home (married without children at home, partner without children at home); 0 otherwise

Household composition 2; 1 if respondent's household composition is couple with child(ren) at home [married with child(ren) at home, partner with child(ren) at home]; 0 otherwise

Household composition 3; 1 if respondent's household composition is others (single-person household, singleparent family, living with flatmate, living with parents, other); 0 otherwise 
HI $(+/-)=\quad$ Dummy variables for household income

Household income 1; 1 if respondent has low-level income (under \$25,000 - \$49,999); 0 otherwise

Household income 2; 1 if respondent has middle-level income $(\$ 50,000$ - $\$ 99,999) ; 0$ otherwise

Household income 3; 1 if respondent has high-level income (\$100,000 and over); 0 otherwise

$\varepsilon=$

Error term

\subsubsection{Statistical Assumptions for Logistic Regression}

\section{Outliers:}

A few extreme observations or outliers can potentially influence the estimates of the regression parameters (Maddala, 2001). Outliers are observations that have large residual values, or an observation that is far removed from the rest of the observations (Hair et al., 1998). Therefore, the outliers should be identified and removed from the analysis.

\section{Linearity:}

Logistic regression does not assume linear relationships between the dependent and the independent factors as in the other multivariate techniques based on correlational measures of association. However, it assumes a linear relationship between the independents and the log odds (logit) of the dependent (Garson, 2008b). If this assumption is violated, the logistic regression will underestimate the degree of relationship between the dependent and the independent (Garson, 2008b; Hair et al., 1998). Type II errors (showing no relation when there actually is) may be found (Garson, 2008b).

\section{Multicollinearity:}

Multicollinearity occurs when the explanatory variables are highly intercorrelated, making the separate effects of each of the explanatory variables on the explained variable difficult to disentangle (Maddala, 2001). Multicollinearity is not allowed in 
the logistic regression because the high interrelationship of the independent variables can cause the inflation of standard errors of the logit coefficients (Garson, 2008b). The simplest means of identifying the collinearity between variables is to examine the correlation matrix for the independent variables (Hair et al., 1998). Bryman and Cramer (1999) recommended the acceptable level of correlation between each pair of the independent variables at 0.80 or less.

\section{Data Level:}

Garson (2008b) highlighted that dependent variable needs to be dichotomous for binary logistic regression and polytomous for multinominal logistic regression, and independent variables may be either interval or categorical. The categorical independent variables need to be coded as dummy variables before being included in the analysis (Garson, 2008b).

\subsubsection{Sensitivity Analysis}

The empirical estimation of the logit model is Maximum Likelihood Estimates (MLE), which assumes large sample properties of consistency, efficiency, normality of parameter estimates and validity of the t-test significance (Greene, 2003; Studenmund, 2001). Given these properties, the logit model avoids the major problem associated with Ordinary Least Square (OLS) estimation of the standard linear probability model (Hair et al., 1998; Judge, Hill, Griffiths, Lutkepohl, \& Lee, 1982). The MLE coefficient estimates from the logit analysis have no direct interpretation with respect to the probability of the dependent variable $(\mathrm{Y}=1)$ other than indicating a direction of influence of probability. Maddala (1992) and Liao (1994) recommended calculating changes in probabilities to indicate the magnitude of the marginal effect. This represents the partial derivatives of the non-linear probability function evaluation at each variable's sample mean (Liao, 1994; Pindyck \& Rubinfeld, 1991).

The marginal effect determines the marginal change in the dependent variable, given a unit change in a selected independent variable, holding other variables constant (Liao, 1994). Therefore, in order to identify the most important variables that influence consumers' decision to dine at an upscale ethnic restaurant, the marginal effect for each of the estimated coefficients in the empirical model were calculated. The 
marginal effect reveals the level of importance for the estimated coefficients in the empirical model.

\subsubsection{T-test and Analysis of Variance (ANOVA)}

T-test and Analysis of Variance (ANOVA) are two of the most widely used univariate measures for assessing group means. A t-test is normally applied to compare a dependent variable between two groups, while ANOVA is used when there are three or more groups (Hair et al., 1998).

\subsubsection{Analysis of Variance (ANOVA)}

Hair et al. (1998) suggested two assumptions need to be satisfied for the application of ANOVA.

(1) The data is assumed to be from a normally distributed population. The variances in each experimental condition are reasonably similar, and outliers and high multicollinearity should not be present.

(2) The independent and dependent variables should be measured on an interval scale.

The univariate ANOVA could be applied when two independent estimates of the variance for the dependent variable are compared. One reflects the general variability of the respondents within the group $\left(M S_{w}\right)$; and the other represents the different groups attributes to the treatment effects $\left(M S_{B}\right)$ (Hair et al., 1998):

1. $M S_{w}$ : Mean square within groups

2. $M S_{B}$ : Mean square between groups

Given that the null hypothesis of no group difference is not rejected, $M S_{w}$ and $M S_{B}$ represents the independent estimates of the population variance. As a result, the ratio of $M S_{B}$ to $M S_{w}$ measures how much variance is attributable to different treatments versus the variance expected from random samplings, and is calculated as the following (Hair et al., 1998):

F statistic $=\frac{M S_{B}}{M S_{W}}$ 
Although the F-tests of ANOVA assess the null hypothesis of equal means between groups, the results cannot specify where the significant differences lie if there are more than two groups. Hair et al. (1998) pointed out five common post hoc procedures: the Scheffe test, the Turkey's honestly significant difference test, the Turkey's extension of the Fisher least significant approach, the Duncan's multiplerange test, and the Newman-Kules test, to test each combination of groups in order to identify the significant differences among groups. Of the five post hoc test procedures, the Scheffe test is the most conservative method with regard to a Type I error.

\subsubsection{T-test}

T-test requires the same assumptions as of ANOVA to be met. The parametric two independent sample t-tests provide a rational way to determine if the difference between the two sample means occurred by chance (Hair et al., 1998; Hair et al., 2000). The test of differences between two group means can be conceptualised as the difference between the means divided by the variability of random means. Hence, the $t$ statistic is a ratio of the difference between the two sample means and the standard error. In the case of the means for two independent samples, the hypotheses can be written in following form:

$\mathrm{H} 0: \mu_{1}=\mu_{2}$

$\mathrm{H} 1: \mu_{1} \neq \mu_{2}$

The formula for calculating the $\mathrm{t}$-statistic value is:

T statistic $=\frac{\mu_{1}-\mu_{2}}{\mathrm{SE} \mu_{1} \mu_{2}}$

where: $\mu_{1}=$ Mean of Group 1

$\mu_{2}=$ Mean of Group 2

$\mathrm{SE} \mu_{1} \mu_{2}=$ Standard error of the difference in group means. 


\subsubsection{Statistical Analysis for Research Objective Three}

The univariate ANOVA and t-test are the appropriate methods by which to test the hypotheses regarding the demographic characteristics and the dining occasion because the upscale ethnic restaurant choice factors are measured on an interval scale. The other assumption made in Section 4.6.4.1 is also satisfied.

The demographic characteristics consisting of three or more groups including age, qualification, occupation, household composition, and household income, and the dining occasion will be measured using ANOVA. The Scheffe test is the most appropriate procedure to test for significant differences among these groups. Additionally, the results of t-tests will demonstrate whether or not the mean scores of two groups including male and female, and New Zealand European and Others, are significantly different with respect to their perceptions of the upscale ethnic restaurant choice factors.

\subsection{Chapter Summary}

This chapter outlined the research methodology used to test the eleven hypotheses, stated in Chapter Three, and to satisfy the three research objectives stated in Chapter One and Three. The expected sample size and sampling method were explained, as well as the methods of data collection. The questionnaire design, format, pre-testing, and data analysis techniques were also discussed. 


\section{CHAPTER 5 \\ RESULTS AND DISCUSSION}

\subsection{Introduction}

This chapter presents the results and analysis of the statistical methodology outlined in Chapter Four. The data set is examined to ensure the statistical assumptions of factor analysis and logistic regression analysis are met. The results of the factor analysis, logistic regression analysis, T-tests, and ANOVA are presented, and the eleven hypotheses tested. The results are discussed in terms of their relation to each of the relevant research objectives.

\subsection{Sample and Response Rate}

A total of 461 questionnaires were returned from the 1,300 questionnaires distributed through the mail. Of these, 35 were returned to the sender because the addressees were no longer current, 7 were not filled out, and 17 were partly filled out and not suitable for use. This resulted in 402 usable responses, or a $30.9 \%$ usable response rate. The questionnaires were all returned within 15 days of being mailed out.

The usable questionnaires were above the minimum sample size of 384 as recommended by Mendenhall et al. (1993). Therefore, the sample size was deemed to be acceptable for the purposes of this research.

\subsection{Descriptive Statistics}

The descriptive statistics were obtained from the frequency analysis using SPSS version 15.0. From the total of 402 usable questionnaires, $80.8 \%$ (325) of respondents have dined at an upscale ethnic restaurant in the past twelve months, while 19.2\% (77) of the respondents have not dined at one. Among the upscale ethnic restaurant goers, $42.2 \%$ (137) have dined at an upscale ethnic restaurant three to six times a year, 
$24.6 \%(80)$ once or twice a year, $13.2 \%$ (43) once a month, $12.9 \%(42)$ seven to eleven times a year, 4\% (13) twice to three times a month, and 3.1\% (10) more than three times a month. The main dining occasion was gathering with friends/family which accounted for $41.2 \%$ (134), followed by normal dining out 31.7\% (103). Other occasions of dining at an upscale ethnic restaurant included special occasion and celebration $21.2 \%$ (69), business- or work-related 3.7\% (12), and dating/intimate dining $2.2 \%(7)$.

The salient aspects of the demographic characteristics of the sample are as follows. The total sample respondents consisted of 53\% females and $47 \%$ males. The dominant age groups were 46 to 55 years $(24.6 \%)$ and 56 to 65 years $(24.6 \%)$. New Zealand European made up the major ethnic group, accounting for $81.8 \%$ of the respondents. $20.4 \%$ and $19.7 \%$ of the respondents reported their highest qualification as diploma and up to high school certificate levels, respectively. The dominant groups of the respondents worked as professionals $(27.9 \%)$ and were married without children at home (40.3\%). The dominant annual household income levels included $\$ 50,000$ to $\$ 74,999(21.9 \%)$ and $\$ 25,000$ to $\$ 49,999$ (21.6\%) (see Table 5.1, page 91 and Table 5.2 , page 92 , for the complete descriptive statistics of the demographic characteristics).

\subsection{Assessment of the Data Set}

The data set collected from respondents was tested to verify whether the statistical assumptions of factor analysis and logistic regression analysis had been met. The data set consisted of two distinctive groups of respondents: upscale ethnic restaurant goers and non-goers. The statistical assumptions were conducted separately for each group for factor analysis.

\subsubsection{Statistical Assumptions for Factor Analysis: Goer Group}

As discussed in Section 4.6.1.3, if the statistical assumptions of normality, homoscedasticity and linearity for factor analysis are not met, the observed correlations between variables may be diminished. Therefore, the data matrix was tested in order to ensure its appropriateness for factor analysis. The testing methods as 
recommended by Hair et al. (1998) included examination of the correlation matrix, inspection of the anti-image correlation matrix, Bartlett's test of sphericity, and the Kaiser-Meyer-Olkin measure of sampling adequacy.

\subsubsection{Examination of the Correlation Matrix}

The correlation matrix (as shown in Table 5.3, page 95 [the complete descriptions of the variables are in Table 5.8, page 103]) showed a number of substantial correlations above .30 as recommended by Hair et al. (1998). These correlations justified that the items share common factors and were therefore suitable for factor analysis.

\subsubsection{Inspection of the Anti-Image Correlation Matrix}

The anti-image correlation matrix (as shown in Table 5.4, page 97 [the complete descriptions of the variables are in Table 5.8, page 103]), which represented the negative value of the partial correlations, showed that the majority of the off diagonal values were low. This result indicated that the correlation matrix was appropriate for factor analysis.

\subsubsection{Bartlett's Test of Sphericity}

Bartlett's test of sphericity was conducted in order to assess whether the correlation matrix came from a population of variables that were independent ${ }^{7}$. The test value was high at 5368.09 and was significant at 0.000 . The null hypothesis was therefore rejected, indicating that the data was appropriate for factor analysis.

\subsubsection{The Kaiser-Meyer-Olkin Measure of Sampling Adequacy}

As discussed in Section 4.6.1.4, the index of the Kaiser-Meyer-Olkin measure ranged from 0 to 1 , with 1 indicating a perfect prediction. The test result was 0.863 . Kaiser and Rice (1974, as cited in Stewart, 1981) defined the value of $0.80+$ as meritorious level of appropriateness. Therefore, these variables were deemed appropriate for factor analysis.

\footnotetext{
${ }^{7}$ The null hypothesis.
} 


\subsubsection{Factor Analysis Results}

The test results satisfied the assumptions of factor analysis, and principal components factor analysis was conducted on all of the 37 items representing restaurant choice factors. The following results were based on respondents in the upscale ethnic restaurant Goer Group because the factor rotation for this group produced the best structure in terms of content validity, when compared to the factor structure of the combined Groups and of only the Non-goer Group. The sample size for the Non-goer Group was under 85 and required a cut off point for factor loadings of at least 0.65 (Hair et al., 1998). A VARIMAX factor rotation was also performed on the Non-goer Group, and the rotations produced a similar factor structure to the Goer Group. However, Hair et al. (1998) recommended that factor results based on sample sizes that are less than 100 must be interpreted with caution.

\subsubsection{The Roots Criterion}

Results of the latent root criterion ${ }^{8}$ indicated that nine factors should be extracted from the 37 variables submitted for factor analysis (see Table 5.5, page 100). These nine factors explained $62.87 \%$ of the variation in the data.

\subsubsection{The Scree Test}

By laying a straight edge across the bottom portion of the roots, the point at which the factors curve above the straight line indicated that the extraction of nine factors was suitable for this analysis.

\footnotetext{
${ }^{8}$ Where the eigenvalues are greater than 1 .
} 


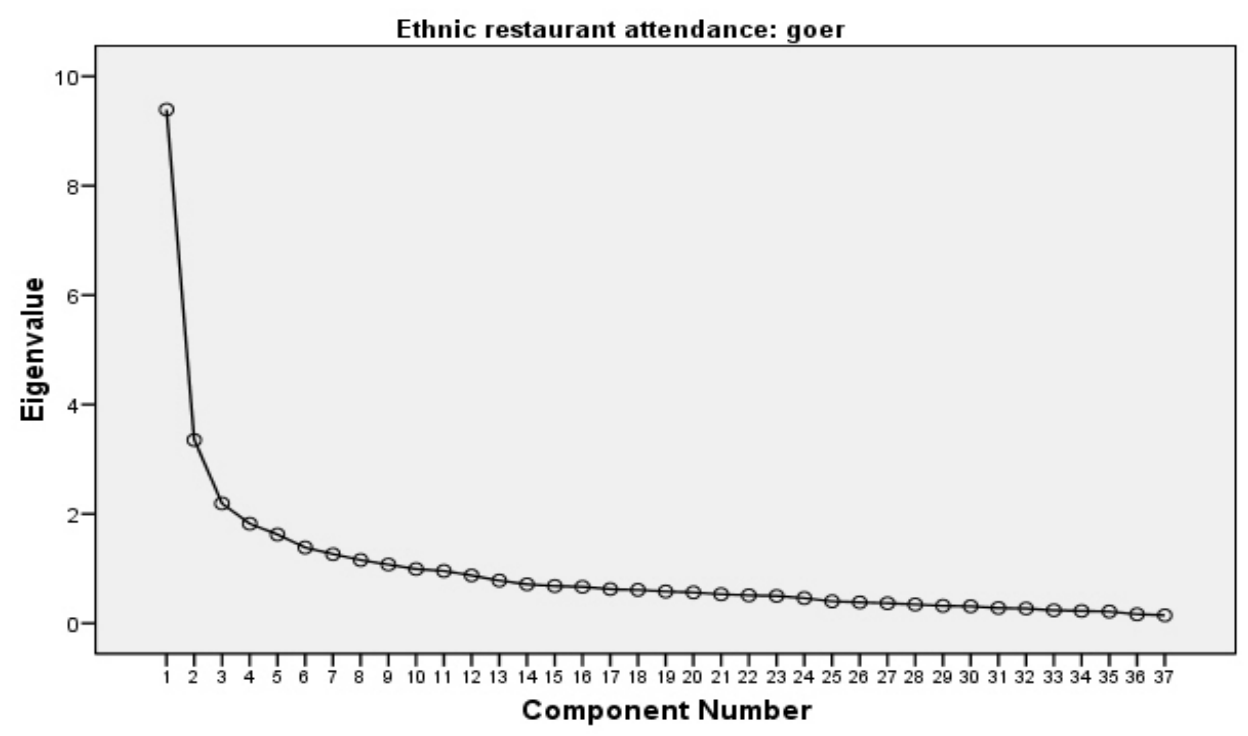

Figure 5.1: The Scree Plot

\subsubsection{Rotation Results}

Both the VARIMAX (see Table 5.6, page 101) and the oblique rotations (see Table 5.7, page 102 [the complete descriptions of the variables are in Table 5.8, page 103]) displayed a similar structure of factor loadings. However, the VARIMAX rotation produced a better structure in terms of content validity of the factors. Therefore, the final factor structure was based on the factor loadings from the VARIMAX rotation.

\subsubsection{Factor Interpretation}

Hair et al. (1998) suggested a significant factor loading at least 0.35 for a sample size of 250. However, 0.40 was used as a cut-off point of factor loading as it produced a clearer structure and helped increase the robustness of the factor rotation. All of the rotated items had significant loadings above \pm .40 . One variable (UF1) was deleted from the matrix as it loaded negatively with other variables on Factor 7. Four variables (VM2, AP1, VM1, CL2 [the complete descriptions of the variables are in Table 5.8, page 103]) had significant cross loadings on two separate factors. The remaining 32 variables loaded cleanly on one factor (see Table 5.6, page 101, for details of the variable loadings).

The four variables that had significant cross loadings on two separate factors were grouped with the variables that represented the constructs as suggested in the 
literature review. In addition, the Cronbach's Coefficient Alpha for the re-grouped variables was higher than those without the variables included to measure the latent constructs.

Each factor was subsequently named according to the construct they represented (see Table 5.8, page, 103 for the complete descriptions of the variables). The nine factors were named: (1) Service Quality; (2) Food Quality; (3) Dining Experience; (4) Social Status; (5) Marketing Communications; (6) Religious Food Options; (7) Familiar Food; (8) Restaurant Décor; (9) Value for Money.

\subsubsection{Assessment of Summated Scales}

Before summation of the items, the content validity, dimensionality, and reliability of the scales were assessed.

\subsubsection{Content Validity}

All of the items in the final VARIMAX factor rotation did not load exactly on the constructs as proposed in the development of the questionnaire items, based on the results from the focus group discussions and the literature review. The variables comprising each factor were inspected by the researcher and three marketing experts familiar with scale development to ensure that the variables were an adequate and a thorough representation of the construct under investigation. Following this assessment, all nine factors were considered to have adequate content validity.

\subsubsection{Dimensionality}

As noted in Section 5.4.2.4, four variables had two significant cross loadings, indicating that these variables were associated with two factors. Variable AP1 loaded highly on Factor 2 and only moderately loaded on Factor 8. This variable was therefore considered to represent the most highly loaded factor, which was Factor 2. The remaining three variables, VM1, VM2 and CL2, exhibited similar loading power on the two factors they loaded on. They were subsequently chosen to represent only one factor, using content validity as a criterion. VM1 and VM2 were grouped together representing Factor 9 (Value for Money), and CL2 was grouped with Factor 3 (Dining Experience). 


\subsubsection{Reliability}

The remaining 36 items were subjected to reliability tests, except for item PE1, which consisted of only one item representing Factor 8. Cronbach's Coefficient Alpha was used to measure reliability, and as recommended by Churchill (1979), a Cronbach's Coefficient Alpha of 0.60 or above was deemed to produce a reliable measure. Factor 7 (Familiar Food) had a Cronbach's Coefficient Alpha of less than 0.60 for both Goer and Non-goer Groups and was not included in the analysis. Factor 4 (Social Status) had a Cronbach's Coefficient Alpha of above 0.60 for the Goer Group but less than 0.60 for the Non-goer Group. Therefore, Factor 4 was retained for further analysis.

The structure from the results of VARIMAX factor rotation of the Goer Group was used to form the summated scales for this study. The Cronbach's Coefficient Alpha was; however, calculated for both the Goer and the Non-goer Groups using the VARIMAX factor structure of the Goer group. The variables used in the summated scales and their Cronbach's Coefficient Alpha are presented in Table 5.9, page 104, for the Goer Group. Table 5.10, page 106, presents the Cronbach's Coefficient Alpha for the Non-goer Group.

All of the remaining eight summated scales were judged to demonstrate sufficient content validity, dimensionality, and reliability for a newly developed questionnaire. The mean of each of the scales was then used to represent each one of the upscale ethnic restaurant choice factors for further analysis.

\subsubsection{Statistical Assumptions for Logistic Regression}

A series of statistical tests were conducted to ensure that the data met the assumptions for logistic regression.

\subsubsection{Outliers}

The outliers were examined and removed from the analysis to reduce the effects of their influence. 


\subsubsection{Multicollinearity}

The Pearson Correlation Matrix was inspected for the correlations between the independent variables. As shown in Table 5.11, page 108, no correlations exceeded 0.80 . As a result, the assumption of multicollinearity was satisfied.

\subsubsection{Data Level}

As postulated by Garson (2008b), the dependent variable was dichotomous for the binary logistic regression. The independent variables were measured at interval level using a Likert scale, except for the demographic characteristics, which were categorical. These categorical independent variables were coded as dummy variables in the logistic regression analysis.

\subsubsection{Cross-Tabulation and Chi-square Tests}

The chi-square statistic was used to test the statistical significance of the association of the demographic characteristics as recommended by Malhotra (2004).

From the output of cross-tabulation of the original Groups of the demographic characteristics and choice of an upscale ethnic restaurant (see Table 5.12, page 109), only Age, Occupation and Household Income were significant at .05 level. Regrouping some of the demographic characteristics into fewer categories provided an improved interpretation of the data set. Re-grouping Age resulted in 3 Groups, Ethnicity 2 Groups, Qualification 3 Groups, Occupation 3 Groups, Household Composition 3 Groups, and Household Income 3 Groups. The Household Income Groups were re-grouped into similar groups of the Annual Family Income ranged by the 2006 New Zealand census (Statistics New Zealand, 2006c). The Gender Groups remained unchanged.

The chi-square tests were further used to test the significance of the new groups. In addition to the three significant demographic variables, Household Composition was found significant. The cross-tabulation results of the demographic characteristics are in Table 5.13 (page 110) for Gender, Table 5.14 (page 111) for Age, Table 5.15 (page 112) for Ethnicity, Table 5.16 (page 113) for Qualification, Table 5.17 (page 114) for 
Occupation, Table 5.18 (page 115) for Household Composition, and Table 5.19 (page 116) for Household Income.

\subsection{Results Relating to Research Objective One}

Research Objective One is to identify the factors that influence a decision to dine at an upscale ethnic restaurant. Logistic regression analysis was used to satisfy Research Objective One. Logistic regression analysis was conducted to test Hypotheses 1 through 8, relating to Factor 1 to Factor 8, respectively. The classification table for the choice of an upscale ethnic restaurant is presented in Table 5.20. The summary results of Hypothesis 1 to Hypothesis 11 are shown in Table 5.21, and the results for the significant factors are shown in Table 5.22.

Table 5.20: Classification Table for Choice of Upscale Ethnic Restaurant

\begin{tabular}{|l|c|c|c|}
\hline & \multicolumn{2}{|c|}{ Predicted } & $\begin{array}{c}\text { Percentage } \\
\text { Correct }\end{array}$ \\
\hline Actual & Goer & Non-goer & \\
Goer & 322 & 3 & 99.08 \\
Non-goer & 1 & 76 & 98.70 \\
Overall Percentage & & & 99.00 \\
\hline
\end{tabular}

The full logistic regression model containing all predictors is statistically significant $($ Chi-Square $=369.71, \mathrm{p}$ value $=0.000$, degrees of freedom $=14)$. The HosmerLemeshow Goodness of Fit Test of value at $0.195(\mathrm{p}$ value $=0.996)$ indicates a good fit of the model. The model explains $94.10 \%$ (Pseudo R-squared) of the variance in a choice of upscale ethnic restaurant, and correctly classifies $99.00 \%$ of cases (see Table 5.20).

Table 5.21: Hypotheses 1 through 11 Test Results Summary

\begin{tabular}{|l|c|c|c|}
\hline \multicolumn{1}{|c|}{ Hypotheses } & Supported & $\begin{array}{c}\text { Partially } \\
\text { Supported }\end{array}$ & $\begin{array}{c}\text { Not } \\
\text { Supported }\end{array}$ \\
\hline $\begin{array}{l}\text { H1: Service quality has a positive effect on } \\
\text { consumers' choice of an upscale ethnic } \\
\text { restaurant. }\end{array}$ & $\sqrt{ }$ & & \\
\hline
\end{tabular}




\begin{tabular}{|l|c|c|c|}
\hline \multicolumn{1}{|c|}{ Hypotheses } & Supported & $\begin{array}{c}\text { Partially } \\
\text { Supported }\end{array}$ & $\begin{array}{c}\text { Not } \\
\text { Supported }\end{array}$ \\
\hline $\begin{array}{l}\text { H2: Food quality has a positive effect on } \\
\text { consumers' choice of an upscale ethnic } \\
\text { restaurant. }\end{array}$ & $\sqrt{ }$ & & \\
\hline $\begin{array}{l}\text { H3: Dining experience has a positive effect on } \\
\text { consumers' choice of an upscale ethnic } \\
\text { restaurant. }\end{array}$ & $\sqrt{ }$ & & \\
\hline $\begin{array}{l}\text { H4: Low social status has a negative effect on } \\
\text { consumers' choice of an upscale ethnic } \\
\text { restaurant. }\end{array}$ & & $\sqrt{ }$ \\
\hline $\begin{array}{l}\text { H5: Marketing communications has a positive } \\
\text { impact on consumers' choice of an upscale } \\
\text { ethnic restaurant. }\end{array}$ & & $\sqrt{ }$ \\
\hline $\begin{array}{l}\text { H6: Religious food options have positive } \\
\text { impact on consumers' choice of an upscale } \\
\text { ethnic restaurant. }\end{array}$ & & $\sqrt{ }$ \\
\hline $\begin{array}{l}\text { H7: Appealing restaurant décor has a positive } \\
\text { impact on consumers' choice of an upscale } \\
\text { ethnic restaurant. }\end{array}$ & & $\sqrt{ }$ \\
\hline $\begin{array}{l}\text { H8: Low value for money has a negative effect } \\
\text { on consumers' choice of an upscale ethnic } \\
\text { restaurant. }\end{array}$ & $\sqrt{ }$ & & \\
\hline $\begin{array}{l}\text { H9: Consumers attach different degrees of } \\
\text { importance to the restaurant choice factors } \\
\text { when making a decision to dine at an upscale } \\
\text { ethnic restaurant. }\end{array}$ & $\sqrt{ }$ & & \\
\hline $\begin{array}{l}\text { H10: Consumers perceive restaurant choice } \\
\text { factors differently based on their dining } \\
\text { occasion. }\end{array}$ & & & \\
\hline $\begin{array}{l}\text { H11: Consumers perceive restaurant choice } \\
\text { factors differently based on their demographic } \\
\text { characteristics. }\end{array}$ & & & \\
\hline
\end{tabular}

Table 5.22: The Significant Logistic Regression Results

\begin{tabular}{|l|l|l|l|}
\hline \multicolumn{1}{|c|}{ Factors } & \multicolumn{1}{|c|}{ B } & \multicolumn{1}{c|}{ S.E. } & \multicolumn{1}{c|}{ Sig. } \\
\hline Service Quality & 3.424 & 1.184 & $0.004^{*}$ \\
Food Quality & 2.782 & 1.025 & $0.007^{*}$ \\
Dining Experience & 5.269 & 2.381 & $0.027^{*}$ \\
Social Status & -4.868 & 2.220 & $0.028^{*}$ \\
Value for Money & -1.829 & 0.898 & $0.042^{*}$ \\
\hline
\end{tabular}

* Significant at .05 level 
The results presented in Table 5.22 show that Service Quality, Food Quality and Dining Experience positively influence a decision to dine at an upscale ethnic restaurant. Therefore, Hypothesis 1, Hypothesis 2, and Hypothesis 3 are supported. A significant negative relationship between Social Status and choice of an upscale ethnic restaurant confirms the hypothesised negative relationship. Thus, Hypothesis 4 is supported. Similarly, a significant negative relationship between Value for Money and choice of an upscale ethnic restaurant supports Hypothesis 8.

The results do not show significant relationships between Marketing Communications, Religious Food Options, and Restaurant Décor and consumers' choice of an upscale ethnic restaurant. Hence, Hypothesis 5, Hypothesis 6, and Hypothesis 7 are rejected.

\subsection{Results Relating to Research Objective Two}

Research Objective Two is to determine the most important factors that affect consumers' choice of an upscale ethnic restaurant. Marginal effect analysis was used to satisfy Research Objective Two (see Table 5.23).

Table 5.23: Marginal Effects of Consumers' Choice of an Upscale Ethnic Restaurant

\begin{tabular}{|l|c|c|}
\hline \multicolumn{1}{|c|}{ Factors } & Marginal Effect & Ranking \\
\hline Dining Experience & 0.0004277 & 1 \\
\hline Social Status & -0.0003951 & 2 \\
\hline Service Quality & 0.0002779 & 3 \\
\hline Food Quality & 0.0002258 & 4 \\
\hline Value for Money & -0.0001485 & 5 \\
\hline
\end{tabular}

\subsubsection{Interpretation of the Marginal Effect}

From the results of the marginal effect, Dining Experience is the most important factor that influences consumers' choice of an upscale ethnic restaurant when compared to all of the marginal effects for the other factors listed in Table 5.23. The 
marginal effect of Dining Experience indicates that a unit increase in Dining Experience results in an estimated $0.043 \%$ increase in the probability of choosing an upscale ethnic restaurant.

Social Status has the second highest impact on an upscale ethnic restaurant dining decision. A unit decrease in Social Status results in an estimated $0.040 \%$ probability that consumers in the Goer Group will choose to be in the Non-goer Group, in other words, not to dine at an upscale ethnic restaurant. Further, the marginal effect of Service Quality suggests a unit increase in Service Quality results in an estimated $0.028 \%$ increase in the probability that consumers will choose an upscale ethnic restaurant. Likewise, a unit increase in Food Quality also results in an estimated $0.023 \%$ increase in the probability of selecting an upscale ethnic restaurant.

In addition, the marginal effect of Value for Money suggests that a unit decrease in Value for Money leads to an estimated $0.015 \%$ of probability that the Goer Group will become a Non-goer Group, or choose not to dine at an upscale ethnic restaurant. Value for money ranks the fifth most important factor that influences an upscale ethnic restaurant choice.

The results of the marginal effects supports Hypothesis 9 (see Table 5.21) that consumers attach different degrees of importance to the restaurant choice factors when making a decision to dine at an upscale ethnic restaurant.

\subsection{Results Relating to Research Objective Three}

Research Objective Three aims to examine if consumers perceive a difference on upscale ethnic restaurant choice factors based on their demographic characteristics and dining occasion. ANOVA and T-tests were used to test Hypothesis 10 and Hypothesis 11 to satisfy Research Objective Three.

The results of ANOVA between the dining occasion and the upscale ethnic restaurant choice factors do not show any statistical significance. Thus, Hypothesis 10 proposing that consumers perceive a difference on upscale ethnic restaurant choice factors based on the dining occasion is rejected (see Table 5.21). 
The results from Table 5.24 to Table 5.30 (pages 117-122) indicate that consumers with different gender, age, ethnicity, qualification, occupation, household composition, and household income attribute different amounts of importance to the restaurant choice factors when they consider dining at an upscale ethnic restaurant. The choice factors that are perceived differently are: Service Quality, Food Quality, Dining Experience, Social Status, Marketing Communications, Religious Food, and Restaurant Décor. Value for Money is not considered differently by consumers with different demographic characteristics. Therefore, Hypothesis 11 is partially supported (see Table 5.21).

\subsubsection{Gender Relating to Consumers' Restaurant Selection Behaviour}

The results in Table 5.24 (page 117) show that Marketing Communications is perceived as a more important choice factor by Female than Male.

\subsubsection{Ethnicity Relating to Consumers' Restaurant Selection Behaviour}

The results in Table 5.25 (page 117) reveal that diners in the Others Ethnic Group (e.g. New Zealand Māori, Pacific Islander, Asian) perceive Dining Experience, Religious Food, and Restaurant Décor as more important in their restaurant decision process than diners in the New Zealand European Group.

\subsubsection{Age Relating to Consumers' Restaurant Selection Behaviour}

Marketing Communications and Restaurant Décor are more important to the Youngage Group than the Middle-age and the Old-age Groups. In addition, the Young-age Group view Religious Food as more important, compared to the Middle-age Group (See Table 5.31, page 123). 


\subsubsection{Qualification Relating to Consumers' Restaurant Selection Behaviour}

The results in Table 5.32 (page 124) illustrate that consumers in the Medium-level Qualification Group consider Dining Experience as a more important choice factor than consumers in the Low-level Qualification Group. Moreover, the Medium-level Qualification Group considers Social Status as more important, when compared to the High-level Qualification Group.

\subsubsection{Occupation Relating to Consumers' Restaurant Selection Behaviour}

The results presented in Table 5.33 (page 125) indicate that Service Quality, Food Quality, Dining Experience, and Marketing Communications are perceived as more important by consumers in the White-collar and the Others (e.g. student, farmer, unemployed) Groups than the Retired Group. Furthermore, consumers from the Others Group consider Restaurant Décor as more important than consumers in the White-collar and the Retired Groups. Consumers in the Others Group also consider Religious Food as more important than consumers in the Retired Group.

\subsubsection{Household Composition Relating to Consumers' Restaurant Selection Behaviour}

Diners in the 'Couple with Child(ren) at Home' Household Group and the 'Others' Household Group (e.g. Single-person Household, Single-parent Family) perceive Marketing Communications as a more important choice factor, compared to diners in the 'Couple without Child(ren) at Home' Household Group (see Table 5.34, page 126).

\subsubsection{Household Income Relating to Consumers' Restaurant Selection Behaviour}

Service Quality and Food Quality are more important choice factors for diners in the Middle Income and the High Income Groups than diners in the Low Income Group (see Table 5.35, page 127). 


\subsection{Chapter Summary}

This chapter presented the results based on the research methods outlined in Chapter Four. The results from factor analysis formed a valid and reliable factor structure with eight factors in the consumers' upscale ethnic restaurant choice factors model. The logistic regression results indicated five significant choice factors. The marginal effects identified the most important choice factors that influenced restaurant decisions. Additionally, the ANOVA, and T-tests results revealed that consumers perceived restaurant choice factors differently based on their demographic characteristics but not on the dining occasion. 


\title{
CHAPTER 6 \\ CONCLUSIONS AND IMPLICATIONS
}

\subsection{Introduction}

This chapter reviews the research findings and reports several conclusions based on the results of the statistical analysis and discussion presented in Chapter Five. Subsequently, the theoretical and managerial contributions, limitations, and avenues for future research are discussed.

\subsection{Conclusions Relating to Research Objective One}

\author{
Research Objective 1: To identify the factors that influence the decisions of \\ consumers to dine at an upscale ethnic restaurant.
}

Hypotheses 1 through 8 were formulated to satisfy Research Objective 1. Hypotheses 1 through 8 propose relationships between the following factors; Service Quality, Food Quality, Dining Experience, Social Status, Marketing Communications, Religious Food Options, Restaurant Décor, Value for Money, and a decision to dine at an upscale ethnic restaurant.

The results of logistic regression analysis show that the factors: Service Quality, Food Quality, Dining Experience, Social Status, and Value for Money influence consumers' decision to dine at an upscale ethnic restaurant. Consequently, Hypothesis 1, 2, 3, 4, and 8 are supported, while Hypothesis 5, 6, and 7 are rejected (see Table 5.21 and Table 5.22, pages 66-67).

The support for Hypothesis 1 confirms that Service Quality influences restaurant selection behaviour. This result is consistent with the findings of Chow et al. (2007), Dube et al. (1994), Kivela et al. (2000), Soriano (2002), Sulek and Hensley (2004), and Wall and Berry (2007). The support for Hypothesis 2 confirms that Food Quality influences restaurant selection behaviour. This result is consistent with the findings of 
Auty (1992), Clark and Wood (1998), Dube et al.(1994), Josiam and Monteiro (2004), Kivela et al. (2000), Lewis (1981), Namkung and Jang (2007), Soriano (2002), and Sulek and Hensley (2004). The finding of the influence of Dining Experience on a decision to dine at an upscale ethnic restaurant as proposed in Hypothesis 3 supports the findings of Turgeon and Pastinelli (2002), Tian (2001), and Sukalamala and Boyce (2007). In addition, the support for Hypothesis 4 confirms that Social Status influences restaurant selection. This result is in accordance with the findings of Cheng (2006) and Peters (2005). Further, the support for Hypothesis 8, that Value for Money is an influential factor for a restaurant decision, is in agreement with the findings of Auty (1992), Myung, McCool, and Feinstein (2008), Oh (2000), Rammaniya (1998), and Soriano (2002).

However, the rejection of Hypothesis 5 does not support the findings of Tunsi (2000) regarding the influence of Marketing Communications on restaurant selection behaviour. Similarly, the rejection of Hypothesis 6 does not support the findings of Dugan (1994) who found that Religious Food influenced restaurant choice. Finally, the rejection of Hypothesis 7 does not support the findings of Ryu and Jang (2007) who found that Restaurant Décor influenced restaurant selection behaviour.

\subsection{Conclusions Relating to Research Objective Two}

Research Objective 2: To determine the most important factors that affect consumers' choice of an upscale ethnic restaurant.

The results from the marginal effect (see Table 5.23, page 68) show that Dining Experience is the most important factor that influences consumers to dine at an upscale ethnic restaurant, when compared to all of the other factors. Social Status is ranked the second most important factor. The third and fourth most important factors are Service Quality and Food Quality. Value for Money ranks the fifth most important factor. 


\subsection{Conclusions Relating to Research Objective Three}

Research Objective 3: To examine if consumers perceive a difference on restaurant choice factors based on their demographic characteristics and dinning occasion.

The results from ANOVA between the dining occasion and the upscale ethnic restaurant choice factors do not show any statistical significance, indicating that consumers did not perceive restaurant choice factors differently. Therefore, Hypothesis 10 is rejected. The rejection of Hypothesis 10 does not support the findings of June and Smith (1987) and Sweeny et al. (1992).

The results from ANOVA and T-tests (see Table 5.24 to Table 5.30, pages 117-122) demonstrate that consumers perceive a difference on restaurant choice factors based on their demographic characteristics: including gender, ethnicity, age, qualification, occupation, household composition, and household income, which supports Hypothesis 11. These results are in accordance with the findings of Josiam and Monteiro (2004), Kivela (1997), and Mohsin (2005).

The results indicate that Female consumers perceive Marketing Communications as a more important choice factor than Male consumers. This finding suggests that Female diners rely on marketing communications including word-of-mouth, advertising, sales promotion, and publicity more than Male diners when considering an upscale ethnic restaurant. This may be attributed to the general role of female in the food preparation in the household. It may be that females are more selective and want to be better informed when making a decision to purchase food when compared to males, so it is natural for females to seek information about a restaurant from marketing communications and/or word-of-mouth before making a decision on a restaurant.

The results further reveal that Dining Experience, Religious Food, and Restaurant Décor are perceived as more important choice factors by diners from the Others Ethnic Group than the New Zealand European Group. This result suggests that diners from the Others Ethnic Group are more demanding than diners from the New Zealand European Group in terms of dining experience, religious food, and restaurant décor. 
Diners with other ethnic origins may have certain expectations about ethnic restaurants that they have visited in their home countries. When dining at an ethnic restaurant of their own or similar ethnicity, they are therefore likely to be more critical of the dining experience and restaurant décor.

The results regarding age group indicate that the Young-age Group view Marketing Communications and Restaurant Décor as more important, when compared to the Middle-age and the Old-age Groups, and also view Religious Food as more important, when compared to the Middle-age Group. It may be that young consumers cannot afford to dine at an upscale ethnic restaurant as frequently as older groups of consumers, and thus make more effort to gather information about the restaurant. Young-age consumers are also generally more exposed to marketing communications via media such as TV, internet and magazines and place greater emphasis on trends and fashion (Story, Neumark-Sztainer, \& French, 2002). Therefore, it is likely that young diners are deeply influenced by the way something (e.g. the décor of the restaurant) appeals to their sense of fashion.

Diners from the Medium-level Qualification Group consider Dining Experience as a more important choice factor than diners from the Low-level Qualification Group, and consider Social Status as a more important choice factor than those diners from the High-level Qualification Group. It can be argued that the highly educated diners are likely to earn more than the medium educated diners and thus can express their status in alternative ways such as expensive cars, luxurious outfit and accessories, in addition to dining out at an upscale restaurant.

The results suggest that the White-collar and the Others Occupation Groups perceive Service Quality, Food Quality, Dining Experience, and Marketing Communications as more important than the Retired Group. In addition, consumers in the Others Occupation Group perceive Restaurant Décor as more important than consumers in the White-collar Group, and the Others Occupation Group perceive Religious Food as more important than the Retired Group. These results imply that the White-collar and the Others Occupation Groups are more demanding consumers than the Retired Group. 
Furthermore, the results show that restaurant patrons who are in the 'Couple with Child(ren) at Home' and the 'Others' Household Groups consider Marketing Communications as more important than the 'Couple without Child(ren) at Home' Group. This may be attributed to the fact that diners who do not have living-at-home children generally have more disposable income to spend on dining out, compared to the other two household groups. For this reason, diners who do not have children at home do not have the need to use friends' recommendations, advertising, or sales promotion as a means to search for a good deal or bargain as much as the other two household groups.

Lastly, the results regarding Household Income reveal that Service Quality and Food Quality are perceived as more important choice factors by consumers in the Middle Income and the High Income Groups than consumers in the Low Income Group. This may be because the more affluent consumers demand a higher level of service quality and food quality and can afford to pay for them, compared to consumers with low incomes.

\subsection{Theoretical Implications}

This research makes several contributions to the existing body of knowledge about the consumers' selection behaviour in the foodservice industry. Firstly, this study contributes to the limited empirical studies currently available on consumers' decision-making behaviour and the ethnic restaurant, especially in a New Zealand context. The study provides a more comprehensive understanding of the consumer decision-making process and upscale ethnic restaurant choice in New Zealand by empirically identifying the choice factors that influence a decision to dine at an upscale ethnic restaurant.

Secondly, this research used the consumers' decision-making process as a theoretical framework to examine consumers' choice factors of an upscale ethnic restaurant. The results of the study provide support for the contention that the consumer decisionmaking process is an appropriate framework to apply in examining consumers' restaurant selection behaviour. 
Thirdly, the research model developed in this study provides a framework for future research. Future researchers can apply this model for an empirical study regarding consumer behaviour in the foodservice industry, especially in the upscale ethnic restaurant segment.

Fourthly, this research has analysed and ranked the factors in a New Zealand context that have been previously identified as important to consumers when selecting a restaurant. These factors are Service Quality, Food Quality, Dining Experience, Social Status, and Value for Money. The findings of significant relationships between these factors and a choice of an upscale ethnic restaurant provide empirical support for other international studies (see for example Auty, 1992; Josiam \& Monteiro, 2004; Kivela et al., 2000; Lewis, 1981; Peters, 2005; Soriano, 2002; Sulek \& Hensley, 2004; Turgeon \& Pastinelli, 2002).

Finally, apart from providing empirical support for the choice factors that have been identified in previous studies, this study also identifies a factor that is unique to the New Zealand foodservice market. The Social Status factor in this study is comprised of: social class and image, and beverage preference. This factor may be appropriate as a choice factor for other international studies on restaurant selection behaviour.

\subsection{Managerial Implications}

The findings from this research offer ethnic restaurant operators valuable information and insights with which to assess their operation, improve their competitiveness and assist them in developing more efficient marketing and operational strategies to attract and retain customers. The results identify Dining Experience, Social Status, Service Quality, Food Quality, and Value for Money as the significant factors that influence consumers to dine at an upscale ethnic restaurant.

Moreover, the results of the study indicate that certain factors are more important than others in influencing consumers' decision on an upscale ethnic restaurant. The results have implications for determining how restaurant management should allocate their efforts and resources. Resource allocation can be prioritised based on the relative importance of the choice factors. For example, the results show that Dining 
Experience is the most important choice factor in influencing consumers' decision. Ethnic restaurant operators should therefore pay extra attention to create a pleasurable dining experience for their existing and potential customers.

This study clearly identifies Dining Experience, which includes different dining experiences, cultural learning, restaurant atmosphere, and authentic restaurant design. These factors can be controlled to a large extent by restaurant management. Ethnic restaurants have the advantage of offering exotic dining experiences which can satisfy consumers who want to escape from their ordinary routines (H. Kim, 2000). Ethnic restaurant operators can design their restaurants to reflect and maintain the ethnic authenticity in order to give diners the impression that they have been exposed to the different dining experience. The whole restaurant experience including settings, atmosphere, and restaurant staff can be designed to boost the ethnic theme. The incorporation of traditional artwork, music, staff dress and/or other ethnic features is a way to communicate ethnic and cultural identity, which may also provide the additional benefit of making diners feel as if they were transformed into another exotic land.

The findings of Social Status as an influential factor are consistent with the study of Peters (2005) and Cheng (2006) who highlighted that restaurant patrons associated their dining out with social status and esteem. Restaurant management can opt for a trendy and classy image to attract consumers who are concerned about their personal image when dining out. For example, a restaurant that has stylish furnishing and interior design, professional-looking wait staff, and quality tableware may attract diners who are looking for a fine dining environment that can boost their self-esteem. Further, the restaurant should offer a wide range of beverages as many diners view drinking as an important part of their dining out experience. An extensive wine list, especially one that includes mid- to higher-range vintages, is another feature restaurants can use to attract classy and sophisticated consumers who seek extraordinary dining choices. Ethnic restaurants may also offer imported drinks to attract consumers who look for specialty beverages that are not commonly found in conventional restaurants in order to add an additional level of exclusivity to the dining experience. 
In addition, the results indicate that Service Quality significantly influences a choice of an upscale ethnic restaurant. The literature review and results of factor analysis identified service staff behaviour, waiting time, and accuracy of billing as components of Service Quality in this study. Restaurant staff who are well-trained, have a good knowledge of the menu, and possess excellent interpersonal skills are vital for customers' perceptions of restaurant dining experience (Pratten, 2003; Sulek \& Hensley, 2004). Therefore, restaurateurs should place a strong emphasis on staff training to ensure they have a service mind and are willing to deliver high-quality service. The standard performance assessment of staff can be set with these qualities in mind and reviewed regularly. It is particularly important for ethnic restaurants that wait staff have a good knowledge of the menu items, so that they are able to clarify any unfamiliar menu items or ingredients to consumers.

Another aspect of service quality that restaurateurs should not overlook is the accuracy of the billing process. An accurate check is among the most critical servicerelated factors that diners use in their evaluation of dining experience (Heung et al., 2000; Kelly \& Carvell, 1987). Staff who are responsible for billing should be trained to take extra care when calculating the total bill by rechecking the diners' list of orders and prices. In addition, restaurants need to supply a sufficient number of staff to ensure a prompt and efficient service, especially during busy times, and have an effective reservation system to reduce waiting times.

The results also indicate that ethnic restaurant patrons prefer restaurants that prepare tasty dishes of high quality with fresh ingredients and appealing presentation and also offer a variety of choices on the menu including healthy food choices. Ethnic restaurants have the advantage of offering exotic dishes with distinctive flavours, as opposed to the conventional restaurants that serve dishes which can usually be prepared at home. The ethnic restaurateurs should emphasise their usage of authentic ingredients on the menu. However, these ingredients need to be described clearly (e.g. written on the menu or verbally by the wait staff), so that consumers do not shy away from the meals that they know nothing about, especially for the dishes that have foreign names. Additionally, to meet the current trends and demand of a healthy lifestyle, ethnic restaurants should offer healthy food choices such as vegetarian, gluten-free or low-fat meals. Ethnic restaurants can also offer special dishes and 
change the specials regularly to satisfy adventurous diners who like to try new flavours.

Furthermore, upscale ethnic restaurant management needs to ensure consumers perceive that they have a good value from dining at their restaurants. Unlike consumers of the lower-price restaurants, it is not just the price of the meal that reflects the value at upscale restaurants. Instead, upscale restaurant goers are likely to perceive value for money from the combination of other offerings such as specialty meals, a high level of service quality, and a pleasant atmosphere (Oh, 2000). Again, upscale restaurant management needs to make sure consumers perceive a pleasurable experience. For example, consumers should be accommodated for their special needs such as food allergies and the preferred level of spiciness. Any service-related or food-related defects should be resolved promptly and with care as dissatisfied customers are likely to spread negative word-of-mouth (Mangold et al., 1999; Susskind, 2002).

\subsection{Limitations}

While this study offers a number of contributions to the marketing literature and restaurateurs, there are also some limitations.

As this research focus solely on the upscale ethnic segment, the results of this study may not be applied conclusively to the other segments of the restaurant industry or other types of restaurants. Consumers may take different factors into account when considering different types of restaurants.

The samples of this study were drawn from a limited group of consumers who were living in the Christchurch area. The likelihood of having eaten at an upscale ethnic restaurant and the profile of consumers may vary if the survey is expanded to other cities.

In addition, different restaurants of different ethnic cuisines have different characteristics and attributes. The respondents in this study may have a particular 
restaurant in mind when filling the survey, and thus their responses may be biased to that restaurant.

\subsection{Avenues for Future Research}

Future research may extend the focus of the study to other segments and types of restaurants. Additionally, rather than including the whole ethnic segment, future research may focus on particular ethnic cuisine(s).

Future studies can collect data from different cities or different countries and/or use a different data collection approach such as face-to-face interviews, or only focus on a particular segment of consumers. Further, future researchers can undertake a comparative study between two different cuisines or between two different groups of consumers such as Eastern versus Western.

Future research may extend the study to include other influential factors that were not included in this study such as past experience, perceptions, and attitudes. In addition, future research may examine the restaurant choice factors from the viewpoints of restaurant operators and employees, instead of consumers.

Moreover, because the foodservice industry is dynamic, the factors that influence consumers' restaurant selection behaviour may vary over time. Future research can conduct a longitudinal study to compare changes in restaurant choice factors that influence consumers' decision at different times. 


\section{REFERENCES}

Amemiya, T. (1981). Qualitative response model: A survey. Journal of Economic Literature, 19, 1485-1536.

Asp, E. H. (1999). Factors affecting food decisions made by individual consumers. Food Policy, 24(2-3), 287-294.

Auty, S. (1992). Consumer choice and segmentation in the restaurant industry. The Service Industries Journal, 12(3), 324-339.

Bailey, R., \& Earle, M. (1993). Home cooking to takeaways: Changes in food consumption in New Zealand during 1880-1990. Palmerston North, New Zealand: Massey University.

Bailey, R., \& Tian, R. G. (2002). Cultural understanding and consumer behavior: A case study of Southern American perception of Indian food. Journal of American Academy of Business, 2(1), 58-65.

Ben-Akiva, M., \& Lerman, S. R. (1985). Discrete choice analysis: Theory and application to travel demand. Cambridge: MIT press.

Bitner, M. J. (1990). Evaluating service encounters: The effects of physical surroundings and employee responses. Journal of Marketing, 54(2), 69-82.

Bitner, M. J. (1992). Servicescapes: The impact of physical surroundings on customers and employees. Journal of Marketing, 56(2), 57-71.

Brookes, M. (2004). Shaping culinary taste: the influence of commercial operators (We are what we eat, or what we are persuaded to eat?). In D. Sloan (Ed.), Culinary taste: Consumer behaviour in the international restaurant sector. Oxford: Elsevier Butterworth-Heinemann.

Bryman, A., \& Cramer, D. (1999). Quantitative data analysis with SPSS release 8 for Windows: A guide for social scientists. London: Routledge.

Burnett, J., \& Moriarty, S. (1998). Introduction to marketing communications: An integrated approach. Upper Saddle River, NJ: Prentice-Hall.

Burton, D. (1982). Two hundred years of New Zealand food \& cookery. Wellington, New Zealand: Reed.

Burton, S. (1990). The framing of purchase for services. The Journal of Services Marketing, 4(4), 55-66.

Cadotte, E. R., \& Turgeon, N. (1988). Key factors in guest satisfaction. Cornell Hotel and Restaurant Administration Quarterly, 28(4), 44-51.

Campbell-Smith, G. (1967). The marketing of the meal experience. Guildford, UK: Surrey University Press.

Cheng, K. (2006). What consumers need from restaurants: An empirical study on different classes of restaurants in Taiwan and their customer service. Journal of American Academy of Business, 8(1), 156-162. 
Chow, I. H., Lau, V. P., Lo, T. W., Sha, Z., \& Yun, H. (2007). Service quality in restaurant operations in China: Decision- and experiential-oriented perspectives. International Journal of Hospitality Management, 26(3), 698710.

Churchill, G. A. (1979). A paradigm for developing better measures of marketing constructs. Journal of Marketing Research, 16(1), 64-73.

Clark, M. A., \& Wood, R. C. (1998). Consumer loyalty in the restaurant industry: A preliminary exploration of the issues. International Journal of Contemporary Hospitality Management, 10(4), 139-144.

Clemes, M., Mollenkopf, D., \& Burn, D. (2000). An investigation of marketing problems across service typologies. Journal of Services Marketing, 14(7), 573594.

Cowell, D. W. (1989). The marketing of services. Oxford: Heinemann.

Dillman, D. A. (2007). Mail and internet surveys: The tailored design method (2nd ed.). Hoboken, NJ: Wiley.

Dube, L., Renaghan, L. M., \& Miller, J. M. (1994). Measuring customer satisfaction for strategic management. Cornell Hotel and Restaurant Administration Quarterly, 35(1), 39-47.

Dugan, B. (1994). Religion and food service. Cornell Hotel and Restaurant Administration Quarterly, 35(6), 80-85.

Elder, J., Sallis, J. F., Zive, M. M., Hoy, P., McKenzie, T. L., Nader, P. R., et al. (1999). Factors affecting selection of restaurants by Anglo- and MexicanAmerican families. Journal of the American Dietetic Association, 99(7), 856858.

Ennew, C. T., \& Binks, M. R. (1996). The impact of service quality and service characteristics on customer retention: Small business and their banks in the UK. British Journal of Management, 7(3), 219-230.

Finkelstein, J. (1989). Dining out: A sociology of modern manners. Cambridge: Polity.

Food Marketing Institute. (1998). Language of the food industry. Retrieved from http://www.fmi.org/glossary_search.cfm?keyword=ethnic\% $\% 20$ foods

Gan, C., Clemes, M., Limsombunchai, V., \& Weng, A. (2006). A logit analysis of electronic banking in New Zealand. International Journal of Bank Marketing, 24(6), 60-83.

Garson, G. D. (2008a, September 27). "Factor Analysis", from Statnotes: Topics in multivariate analysis. Retrieved from http://faculty.chass.ncsu.edu/garson/pa765/factor.htm

Garson, G. D. (2008b, May 21). "Logistic Regression", from Statnotes: Topics in multivariate analysis. Retrieved from http://faculty.chass.ncsu.edu/garson/pa765/logistic.htm

Goldman, K. L. (1993). Concept selection for independent restaurants. Cornell Hotel and Restaurant Administration Quarterly, 34(6), 59-72. 
Greenbaum, T. L. (1998). The handbook for focus group research (2nd ed.). London: Sage.

Greene, W. H. (2003). Econometric Analysis. Upper Saddle River, NJ: Prentice Hall.

Gregoire, M. B., Shanklin, C. W., \& Greathouse, K. R. (1995). Factors influencing restaurant selection by travelers who stop at visitor information centers. Journal of Travel \& Tourism Marketing, 4(2), 41-49.

Hair, J. F., Anderson, R. E., Tatham, R. L., \& Black, W. C. (1998). Multivariate data analysis (5th ed.). New Jersey: Prentice Hall.

Hair, J. F., Bush, R. P., \& Ortinau, D. J. (2000). Marketing research: A practical approach for the new millenium. Boston: McGraw Hill.

Hardy, M. A., \& Sheuy, K. (2000). Pension decision in changing economy: Gender, structure, and choice. Journal of Gerontology, 55B(5), S271-S277.

Hassan, M. W., \& Hall, C. M. (2004). The demand for halal food among Muslim travellers in New Zealand. In C. M. Hall, L. Sharples, R. Mitchell, N. Macionis \& B. Cambourne (Eds.), Food tourism around the world (pp. 81101). Oxford: Elsevier Butterworth-Heinemann.

Heung, V. C., Wong, M. Y., \& Qu, H. (2000). Airport-restaurant service quality in Hong Kong. Cornell Hotel and Restaurant Administration Quarterly, 41(3), 86-96.

Hoffman, K. D., \& Bateson, J. E. (2001). Essentials of services marketing: Concepts, strategies, and cases (2nd ed.). Ohio: South-Western.

Jackson, F. H., Titz, K., \& DeFranco, A. L. (2004). Frequency of restaurant advertising and promotion strategies: Exploring an urban market. Journal of Food Products Marketing, 10(2), 17-32.

Johns, N., \& Pine, R. (2002). Consumer behaviour in the food service industry: A review. International Journal of Hospitality Management, 21(2), 119-134.

Josiam, B. M., \& Monteiro, P. A. (2004). Tandori tastes: Perceptions of Indian restaurants in America. International Journal of Contemporary Hospitality Management, 16(1), 18-26.

Judge, G. G., Hill, R. C., Griffiths, W. E., Lutkepohl, H., \& Lee, T. (1982). Introduction to the theory and practice of econometrics. New York: Wiley.

June, L. P., \& Smith, S. L. (1987). Service attributes and situational effects on customer preferences for restaurant dining. Journal of Travel Research, 26(2), 20-27.

Kelly, T. J., \& Carvell, S. (1987). Checking the checks: A survey of guest-check accuracy. Cornell Hotel and Restaurant Administration Quarterly, 28(3), 6366.

Kim, E., \& Geistfeld, L. V. (2003). Consumers' restaurant choice behaviour and the impact of socio-economic and demographic factors. Journal of Foodservice Business Research, 6(1), 3-24.

Kim, H. (2000). Ethnicity in the design of ethnic food outlets. Unpublished master's thesis, Victoria University of Wellington, Wellington, New Zealand. 
Kivela, J. (1997). Restaurant marketing: Selection and segmentation in Hong Kong. International Journal of Contemporary Hospitality Management, 9(3), 116123.

Kivela, J., Inbakaran, R., \& Reece, J. (1999a). Consumer research in the restaurant environment, part 1: A conceptual model of dining satisfaction and return patronage. International Journal of Contemporary Hospitality Management, $11(5), 205-222$.

Kivela, J., Inbakaran, R., \& Reece, J. (2000). Consumer research in the restaurant environment, part 3: Analysis, findings and conclusions. International Journal of Contemporary Hospitality Management, 12(1), 13-30.

Koo, L. C., Tao, F. K., \& Yeung, J. H. (1999). Preferential segmentation of restaurant attributes through conjoint analysis. International Journal of Contemporary Hospitality Management, 11(5), 242.

Kotler, P., Bowen, J., \& Makens, J. (1998). Marketing for hospitality and tourism (2nd ed.). Upper Saddle River, NJ: Prentice-Hall.

Ladhari, R., Brun, I., \& Morales, M. (2008). Determinants of dining satisfaction and post-dining behavioral intentions. International Journal of Hospitality Management, 27(4), 563-573. doi:10.1016/j.ijhm.2007.07.025

Lawson, R., Todd, S., \& Evans, S. (2006). New Zealand in the 21st century: A consumer lifestyles study. Dunedin, New Zealand: University of Otago.

Lewis, R. C. (1981). Restaurant advertising: Appeals and consumers' intentions. Journal of Advertising Research, 21(5), 69-74.

Liao, T. F. (1994). Interpreting probability models: Logit, probit, and other genelaized linear models: Sage Publication.

Lovelock, C. H., Patterson, P. G., \& Walker, R. H. (1998). Services marketing: Australia and New Zealand. New South Wales: Prentice-Hall.

Lundberg, D. E., \& Walker, J. R. (1993). The restaurant: From concept to operation (2nd ed.). New York: John Wiley \& Sons.

Maddala, G. S. (1992). Introduction to econometrics (2nd ed.). New York: Macmillan Publishing Company.

Maddala, G. S. (1993). The econometrics of panel data. Aldershot, Hants, England; Brookfield: Vt: Elgar.

Maddala, G. S. (2001). Introduction to econometrics (3rd ed.). West Sussex: Wiley.

Malhotra, N. K. (2004). Marketing research: An applied orientation (4th ed.): Pearson Education.

Mangold, W. G., Miller, F., \& Brockway, G. R. (1999). Word-of-mouth communication in the service marketplace. The Journal of Services Marketing, 13(1), 73-89.

Martens, L., \& Warde, A. (1998). The social and symbolic significance of ethnic cuisine in England: New cosmopolitanism and old xenophobia? Sosiologisk årbok, 1, 111-146.

Maslow, A. H. (1970). Motivation and personality (3rd ed.). New York: Harper Collins. 
Mendenhall, W., Reinmuth, J. E., \& Beaver, R. J. (1993). Statistics for management and economics. California: Duxbury Press.

Mennell, S., Murcott, A., \& Otterloo, A. H. (1992). The sociology of food: Eating, diet and culture. London: Sage.

Mill, R. C. (2007). Restaurant management: Customers, operations, and employees (3rd ed.). Upper Saddle River, NJ: Pearson Prentice Hall.

Miller, J. (1993). Marketing communications. Cornell Hotel and Restaurant Administration Quarterly, 34(5), 48-53.

Miller, J. R., \& Hay, M. J. (1981). Determinants of hunter participation: Duck hunting in the Mississippi Flyway. Southern Journal of Agricultural Economics, 63(4), 677-684.

Ministry of Health. (2006). Food and nutrition monitoring report 2006. Wellington, New Zealand: Ministry of Health.

Mitchell, J. (2003). Institutional recipes as a source of information about food habits. Food Service Technology, 3(3-4), 157-165. doi:10.1111/j.14715740.2003.00076.x

Mohsin, A. (2005). Service quality perceptions: An assessment of restaurant and cafe visitor in Hamilton, New Zealand. The Business Review, 3(2), 51-57.

Monteiro, P. A. (2000). Factors that influence the decision of patrons to dine at selected Indian restaurants in the twin cities. Unpublished master's thesis, University of Wisconsin-Stout, Wisconsin.

Muller, C. C., \& Woods, R. H. (1994). An expanded restaurant typology. Cornell Hotel and Restaurant Administration Quarterly, 35(3), 27-37.

Myung, E., McCool, A. C., \& Feinstein, A. H. (2008). Understanding attributes affecting meal choice decisions in a bundling context. International Journal of Hospitality Management, 27(1), 119-125. Retrieved from http://www.sciencedirect.com/science/article/B6VBH-4PMT5WB1/2/239fdd0cc273a1ca1226de0da9a91a3a

Namkung, Y., \& Jang, S. (2007). Does food quality really matter in restaurants? Its impact on customer satisfaction and behavioral intentions. Journal of Hospitality \& Tourism Research, 31(3), 387-410.

Nimmo-Bell Company Ltd. (2002). New Zealand food market monitoring report 2002/03. Wellington, New Zealand.

Oh, H. (2000). Diners' perceptions of quality, value, and satisfaction: A practical viewpoint. Cornell Hotel and Restaurant Administration Quarterly, 41(3), 5866.

Olsen, W. K., Warde, A., \& Martens, L. (2000). Social differentiation and the market for eating out in the UK. International Journal of Hospitality Management, 19(2), 173-190.

Pedraja, M., \& Yague, J. (2001). What information do customers use when choosing a restaurant? International Journal of Contemporary Hospitality Management, 13(6), 316-318. 
Peters, T. (2005). Understanding consumer involvement influence on consumer behavior in fine restaurants. The Business Review, 3(2), 155-160.

Pindyck, R. S., \& Rubinfeld, D. L. (1991). Econometric models and economic forecasts (3rd ed.). New York: McGraw Hill.

Pratten, J. D. (2003). The importance of waiting staff in restaurant service. British Food Journal, 105(11), 826-834.

Pun, K. F., \& Ho, K. Y. (2001). Identification of service quality attributes for restaurant operations: A Hong Kong case. Managing Service Quality, 11(4), 233-240.

Qu, H. (1997). Determinant factors and choice intention for Chinese restaurant dining: A multivariate approach. Journal of Restaurant \& Foodservice Marketing $2(2), 35-49$.

Ramanathan, R. (1992). Introductory econometrics with applications (2nd ed.). London: Fort Worth.

Rammaniya, S. (1998). Exploratory study into the purchase decision criteria used by Auckland consumers in restaurant selection. Unpublished master's thesis, Massey University, Palmerston North, New Zealand.

Restaurant Association of New Zealand. (2006). Restaurant industry forecast 2006: Executive summary. Auckland, New Zealand: Restaurant Association of New Zealand.

Restaurant Association of New Zealand. (2007). Foodservice facts 2007. Auckland, New Zealand: Restaurant Association of New Zealand

Robinson, R. S. (2007). Plain fare to fusion: Ethnic impacts on the process of maturity in Brisbane's restaurant sector. Journal of Hospitality and Tourism Management, 14(1), 70-84.

Ryu, K., \& Jang, S. S. (2007). The effect of environmental perceptions on behavioral intentions through emotions: The case of upscale restaurants. Journal of Hospitality \& Tourism Research, 31(1), 56-72. doi:10.1177/1096348006295506

Sekaran, U. (2003). Research methods for business: A skill building approach (4th ed.). NJ: John Wiley \& Sons.

Sellar, C., Chavas, J. P., \& Stoll, J. R. (1982). Specification of the logit model: The case of valuation of nonmarket goods. Natural Resources Working Paper Series, $T A-18178$

Simpson, T. (1999). A distant feast: The origins of New Zealand's cuisine. Auckland: Random House.

Sloan, D. (2004). Culinary taste: Consumer behaviour in the international restaurant sector. Oxford: Elsevier Butterworth-Heinemann.

Soriano, D. R. (2002). Customers' expectations factors in restaurants: The situation in Spain. The International Journal of Quality \& Reliability Management, 19(8/9), 1055-1067. 
Statistics New Zealand. (2006a). 2006 Census of population and dwellings: Regional summary tables by territorial authority. Retrieved December 6, 2007. from http://www.stats.govt.nz/NR/rdonlyres/C9A86DBD-5B34-402D-89477F705104026B/0/RegionalSummaryTablesTerritorialAuthority.xls.

Statistics New Zealand. (2006b). Demographic trends 2006. Retrieved November 8 , 2007. from http://www.stats.govt.nz/NR/rdonlyres/A052992C-A2C6-4DD197D5-74908FE3B3CA/0/Chapter8.pdf.

Statistics New Zealand. (2006c). Quick stats about incomes. Retrieved March 9, 2009. from http://www.stats.govt.nz/census/2006-census-data/quickstats-aboutincomes/quickstats-about-incomes.htm?page=para028Master.

Stewart, D. W. (1981). The application and misapplication of factor analysis in marketing research. Journal of Marketing Research, 18(1), 51-62.

Story, M., Neumark-Sztainer, D., \& French, S. (2002). Individual and environmental influences on adolescent eating behaviors. Journal of the American Dietetic Association, 102(3), S40-S51.

Studenmund, W. H. (2001). Econometric analysis (2nd ed.): Macmillan Publishing Company.

Stynes, D. J., \& Peterson, G. L. (1984). A review of logit models with implications for modelling recreation choices. Journal of Leisure Research, 16(4), 295-310.

Sukalakamala, P., \& Boyce, J. B. (2007). Customer perceptions for expectations and acceptance of an authentic dining experience in Thai restaurants. Journal of Foodservice, 18(2), 69-75. doi:10.1111/j.1745-4506.2007.00048.x

Sulek, J. M., \& Hensley, R. L. (2004). The relative importance of food, atmosphere, and fairness of wait: The case of a full-service restaurant. Cornell Hotel and Restaurant Administration Quarterly, 45(3), 235-247.

Susskind, A. M. (2002). I told you so!: Restaurant customers' word-of-mouth communication patterns. Cornell Hotel and Restaurant Administration Quarterly, 43(2), 75-85.

Sweeney, J. C., Johnson, L. W., \& Armstrong, R. W. (1992). The effect of cues on service quality expectations and service selection in a restaurant setting. The Journal of Services Marketing, 6(4), 15-22.

Tian, R. G. (2001). Cultural awareness of the consumers at a Chinese restaurant: An antropological descriptive analysis. Journal of Food Products Marketing, $7(1 / 2), 111-130$.

Train, K. (1986). Qualitative choice analysis: Theory, econometrics, and an application to automobile demand. Cambridge: MIT press.

Tucci, L. A., \& Talaga, J. A. (2000). Determinants of consumer perceptions of service quality in restaurants. Journal of Food Products Marketing, 6(2), 3-13.

Tunsi, A. M. (2000). Factors associated with customer loyalty for international dining restaurants located in Jeddah, Saudi Arabia. Unpublished doctoral dissertation, The Ohio State University, Ohio.

Turgeon, L., \& Pastinelli, M. (2002). "Eat the world": Postcolonial encounters in Quebec City's ethnic restaurants. Journal of American Folklore, 115(456), 247-268. 
Utami, H. D. (2004). Consumer behaviour and food processor response towards ethnic food in East Java, Indonesia. Unpublished doctoral thesis, Massey University, Palmerston North, New Zealand.

van Ameyde, A., \& Brodie, R. J. (1984). The Christchurch and New Zealand eating out markets. Canterbury, New Zealand: Agricultural Economics Research Unit, Lincoln College, Report no. 148.

Verbeke, W., \& López, G. P. (2005). Ethnic food attitudes and behaviour among Belgians and Hispanics living in Belgium. British Food Journal, 107(10/11), 823-840.

Verma, R., Pullman, M. E., \& Goodale, J. C. (1999). Designing and positioning food services for multicultural markets. Cornell Hotel and Restaurant Administration Quarterly, 40(6), 76-87.

Wall, E. A., \& Berry, L. L. (2007). The combined effects of the physical environment and employee behaviour on customer perception of restaurant service quality. Cornell Hotel and Restaurant Administration Quarterly, 48(1), 59-69.

White, H., \& Kokotsaki, K. (2004). Indian food in the UK: Personal values and changing patterns of consumption. International Journal of Consumer Studies, 28(3), 284-294.

Withers, R. (2000). Eating out: A global experience: A study of Auckland's ethnic restaurants, 1972-1999. Unpublished master's thesis, University of Auckland, Auckland, New Zealand.

Yüksel, A., \& Yüksel, F. (2002). Market segmentation based on tourists' dining preferences. Journal of Hospitality \& Tourism Research, 26 (4), 315-331.

Zeithaml, V. A. (1981). How consumer evaluation process differ between goods and services. In J. H. Donnelly \& W. R. George (Eds.), Marketing of services. Chicago: American Marketing Association.

Zeithaml, V. A., \& Bitner, M. J. (2003). Services marketing: Integrating customer focus across the firm (3rd ed.). New York: McGraw-Hill.

Zelinsky, W. (1987). You are where you eat. American Demographics, 9(7), 30. 
Table 5.1: Descriptive Statistics of the Segmentation Characteristics

\begin{tabular}{|c|c|c|c|c|c|c|c|c|}
\hline \multirow[t]{2}{*}{ Groups } & \multirow[t]{2}{*}{ Variables } & \multicolumn{2}{|r|}{$\mathbf{N}$} & \multicolumn{5}{|c|}{ Statistics } \\
\hline & & Valid & Missing & Min & Max & Mean & Median & Std. Dev \\
\hline \multirow{9}{*}{\begin{tabular}{|l|} 
Total \\
Respondents
\end{tabular}} & Frequency of Dining & 325 & 77 & 1 & 6 & 2.39 & 2 & 1.27 \\
\hline & Occasion of Dining & 325 & 77 & 1 & 5 & 2.58 & 3 & 1.20 \\
\hline & Gender & 402 & 0 & 1 & 2 & 1.53 & 2 & 0.50 \\
\hline & Age & 402 & 0 & 1 & 6 & 4.23 & 4 & 1.36 \\
\hline & Ethnicity & 402 & 0 & 1 & 8 & 1.63 & 1 & 1.52 \\
\hline & Qualification & 397 & 5 & 1 & 7 & 3.49 & 3 & 1.78 \\
\hline & Occupation & 400 & 2 & 1 & 13 & 6.24 & 7 & 4.14 \\
\hline & Household Composition & 401 & 1 & 1 & 9 & 2.36 & 2 & 1.68 \\
\hline & Household Income & 388 & 14 & 1 & 9 & 3.81 & 3 & 2.05 \\
\hline \multirow{9}{*}{$\begin{array}{l}\text { Upscale Ethnic } \\
\text { Restaurant } \\
\text { Goers }\end{array}$} & Frequency of Dining & 325 & 0 & 1 & 6 & 2.39 & 2 & 1.27 \\
\hline & Occasion of Dining & 325 & 0 & 1 & 5 & 2.58 & 3 & 1.20 \\
\hline & Gender & 325 & 0 & 1 & 2 & 1.54 & 2 & 0.50 \\
\hline & Age & 325 & 0 & 1 & 6 & 4.14 & 4 & 1.33 \\
\hline & Ethnicity & 325 & 0 & 1 & 8 & 1.63 & 1 & 1.51 \\
\hline & Qualification & 320 & 5 & 1 & 7 & 3.57 & 3 & 1.77 \\
\hline & Occupation & 323 & 2 & 1 & 13 & 5.98 & 7 & 4.12 \\
\hline & Household Composition & 324 & 1 & 1 & 9 & 2.37 & 2 & 1.64 \\
\hline & Household Income & 316 & 9 & 1 & 9 & 4.02 & 4 & 2.08 \\
\hline \multirow{9}{*}{$\begin{array}{l}\text { Upscale Ethnic } \\
\text { Restaurant } \\
\text { Non-goers }\end{array}$} & Frequency of Dining & N/A & N/A & N/A & $\mathrm{N} / \mathrm{A}$ & N/A & $\mathrm{N} / \mathrm{A}$ & N/A \\
\hline & Occasion of Dining & N/A & N/A & N/A & $\mathrm{N} / \mathrm{A}$ & N/A & N/A & N/A \\
\hline & Gender & 77 & 0 & 1 & 2 & 1.51 & 2 & 0.50 \\
\hline & Age & 77 & 0 & 1 & 6 & 4.64 & 5 & 1.41 \\
\hline & Ethnicity & 77 & 0 & 1 & 8 & 1.64 & 1 & 1.57 \\
\hline & Qualification & 77 & 0 & 1 & 7 & 3.17 & 3 & 1.78 \\
\hline & Occupation & 77 & 0 & 1 & 13 & 7.34 & 9 & 4.06 \\
\hline & Household Composition & 77 & 0 & 1 & 7 & 2.32 & 1 & 1.85 \\
\hline & Household Income & 72 & 5 & 1 & 7 & 2.89 & 2 & 1.58 \\
\hline
\end{tabular}


Table 5.2: Profile of Consumer Segmentation Characteristics

\begin{tabular}{|c|c|c|c|c|c|c|c|c|}
\hline \multirow[t]{2}{*}{ Variables } & \multirow[t]{2}{*}{$\mathbf{N}$} & & \multicolumn{2}{|c|}{ Total Respondents } & \multicolumn{2}{|c|}{$\begin{array}{c}\text { Upscale Ethnic } \\
\text { Restaurant Goers }\end{array}$} & \multicolumn{2}{|c|}{$\begin{array}{c}\text { Upscale Ethnic } \\
\text { Restaurant Non- } \\
\text { goers } \\
\end{array}$} \\
\hline & & & $\begin{array}{c}\text { Frequency } \\
\text { (No. of } \\
\text { respondents } \\
\text { per option) }\end{array}$ & $\%$ & \begin{tabular}{|c|}
$\begin{array}{c}\text { Frequency } \\
\text { (No. of } \\
\text { respondents } \\
\text { per option) }\end{array}$ \\
\end{tabular} & $\%$ & \begin{tabular}{|c|} 
Frequency \\
(No. of \\
respondents \\
per option)
\end{tabular} & $\%$ \\
\hline $\begin{array}{l}\text { Frequency } \\
\text { of Dining }\end{array}$ & $\begin{array}{l}\text { Valid } \\
\\
\\
\\
\text { Missing } \\
\text { Total } \\
\end{array}$ & \begin{tabular}{|l|}
$1-2$ times a year \\
$3-6$ times a year \\
$7-11$ times a year \\
once a month \\
$2-3$ times a \\
month \\
more than 3 \\
times a month \\
Total N/A
\end{tabular} & $\begin{array}{r}80 \\
137 \\
42 \\
43 \\
\\
13 \\
\\
10 \\
325 \\
77 \\
402 \\
\end{array}$ & $\begin{array}{r}19.9 \\
34.1 \\
10.4 \\
10.7 \\
\\
3.2 \\
\\
2.5 \\
80.8 \\
19.2 \\
100.0 \\
\end{array}$ & $\begin{array}{r}80 \\
137 \\
42 \\
43 \\
\\
13 \\
10 \\
325 \\
0 \\
325 \\
\end{array}$ & $\begin{array}{r}24.6 \\
42.2 \\
12.9 \\
13.2 \\
4.0 \\
\\
3.1 \\
100.0 \\
0.0 \\
100.0 \\
\end{array}$ & $\begin{array}{l}\text { N/A } \\
\text { N/A } \\
\text { N/A } \\
\text { N/A } \\
\text { N/A } \\
\text { N/A } \\
\text { N/A } \\
\text { N/A } \\
\text { N/A }\end{array}$ & $\begin{array}{l}\mathrm{N} / \mathrm{A} \\
\mathrm{N} / \mathrm{A} \\
\mathrm{N} / \mathrm{A} \\
\mathrm{N} / \mathrm{A} \\
\\
\mathrm{N} / \mathrm{A} \\
\\
\mathrm{N} / \mathrm{A} \\
\mathrm{N} / \mathrm{A} \\
\mathrm{N} / \mathrm{A} \\
\mathrm{N} / \mathrm{A}\end{array}$ \\
\hline $\begin{array}{l}\text { Dining } \\
\text { Occasion }\end{array}$ & \begin{tabular}{|l} 
Valid \\
\\
\\
Missing \\
Total \\
\end{tabular} & \begin{tabular}{|l|} 
Normal dining \\
out \\
Business- or \\
Work-related \\
Gathering with \\
friends/family \\
Special occasion \\
$\&$ celebration \\
Dating/Intimate \\
dining \\
Total
\end{tabular} & $\begin{array}{r}12 \\
134 \\
69 \\
\\
7 \\
325 \\
77 \\
402 \\
\end{array}$ & \begin{tabular}{|r}
25.6 \\
3.0 \\
33.3 \\
\\
17.2 \\
\\
1.7 \\
80.8 \\
19.2 \\
100.0
\end{tabular} & $\begin{array}{r}12 \\
134 \\
69 \\
7 \\
725 \\
0 \\
325\end{array}$ & \begin{tabular}{|r}
31.7 \\
3.7 \\
41.2 \\
\\
21.2 \\
\\
2.2 \\
100.0 \\
0.0 \\
100.0
\end{tabular} & $\begin{array}{l}\text { N/A } \\
\text { N/A } \\
\text { N/A } \\
\text { N/A } \\
\text { N/A } \\
\text { N/A } \\
\text { N/A }\end{array}$ & $\begin{array}{l}\text { N/A } \\
\text { N/A } \\
\text { N/A } \\
\text { N/A }\end{array}$ \\
\hline Gender & $\begin{array}{l}\text { Valid } \\
\text { Total } \\
\end{array}$ & $\begin{array}{l}\text { Male } \\
\text { Female }\end{array}$ & $\begin{array}{l}189 \\
213 \\
402 \\
\end{array}$ & \begin{tabular}{|r|}
47.0 \\
53.0 \\
100.0 \\
\end{tabular} & $\begin{array}{l}151 \\
174 \\
325 \\
\end{array}$ & $\begin{array}{r}46.5 \\
53.5 \\
100.0 \\
\end{array}$ & $\begin{array}{l}38 \\
39 \\
77 \\
\end{array}$ & $\begin{array}{r}49.4 \\
50.6 \\
100.0 \\
\end{array}$ \\
\hline Age & Valid & $\begin{array}{l}18-25 \\
26-35 \\
36-45 \\
46-55 \\
56-65 \\
66+\end{array}$ & $\begin{array}{r}10 \\
40 \\
68 \\
99 \\
99 \\
86 \\
402 \\
\end{array}$ & \begin{tabular}{|r|}
2.5 \\
10.0 \\
16.9 \\
24.6 \\
24.6 \\
21.4 \\
100.0 \\
\end{tabular} & $\begin{array}{r}9 \\
31 \\
63 \\
83 \\
82 \\
57 \\
325 \\
\end{array}$ & \begin{tabular}{|r|}
2.8 \\
9.5 \\
19.4 \\
25.5 \\
25.2 \\
17.5 \\
100.0 \\
\end{tabular} & $\begin{array}{r}1 \\
9 \\
5 \\
16 \\
17 \\
29 \\
77\end{array}$ & $\begin{array}{r}1.3 \\
11.7 \\
6.5 \\
20.8 \\
22.1 \\
37.7 \\
100.0 \\
\end{array}$ \\
\hline
\end{tabular}


Table 5.2: Profile of Consumer Segmentation Characteristics (Continued)

\begin{tabular}{|c|c|c|c|c|c|c|c|c|}
\hline \multirow[t]{2}{*}{ Variables } & \multirow[t]{2}{*}{$\mathbf{N}$} & & \multicolumn{2}{|c|}{ Total Respondents } & \multicolumn{2}{|c|}{$\begin{array}{c}\text { Upscale Ethnic } \\
\text { Restaurant Goers }\end{array}$} & \multicolumn{2}{|c|}{$\begin{array}{l}\text { Upscale Ethnic } \\
\text { Restaurant Non- } \\
\text { goers }\end{array}$} \\
\hline & & & \begin{tabular}{|c|} 
Frequency \\
(No. of \\
respondents \\
per option)
\end{tabular} & $\%$ & $\begin{array}{c}\text { Frequency } \\
\text { (No. of } \\
\text { respondents } \\
\text { per option) }\end{array}$ & $\%$ & \begin{tabular}{|c|} 
Frequency \\
(No. of \\
respondents \\
per option)
\end{tabular} & $\%$ \\
\hline \multirow[t]{9}{*}{ Ethnicity } & Valid & NZ European & 329 & 81.8 & 268 & 82.5 & 61 & \begin{tabular}{|l|}
79.2 \\
\end{tabular} \\
\hline & & NZ Maori & 13 & 3.2 & 7 & 2.2 & 6 & 7.8 \\
\hline & & Pacific Islander & 3 & 0.7 & 2 & 0.6 & 1 & 1.3 \\
\hline & & European & 21 & 5.2 & 18 & 5.5 & 3 & 3.9 \\
\hline & & Asian & 22 & 5.5 & 19 & 5.8 & 3 & 3.9 \\
\hline & & Australian & 3 & 0.7 & 3 & 0.9 & 0 & 0.0 \\
\hline & & North American & 7 & 1.7 & 6 & 1.8 & 1 & 1.3 \\
\hline & & Other & 4 & 1.0 & 2 & 0.6 & 2 & 2.6 \\
\hline & Total & & 402 & 100.0 & 325 & 100.0 & 77 & 100.0 \\
\hline \multirow[t]{13}{*}{ Qualification } & Valid & $\begin{array}{l}\text { Up to high school } \\
\text { certificate }\end{array}$ & 79 & 19.7 & 60 & 18.5 & 19 & $|24.7|$ \\
\hline & & Seventh form & & & & & & \\
\hline & & certificate & 47 & 11.7 & 34 & 10.5 & 13 & 16.9 \\
\hline & & Diploma & 82 & 20.4 & 69 & 21.2 & 13 & $\mid 16.9$ \\
\hline & & Trade & & & & & & \\
\hline & & qualification & 53 & 13.2 & 41 & 12.6 & 12 & 15.6 \\
\hline & & Bachelors degree & 65 & 16.2 & 56 & 17.2 & 9 & 11.7 \\
\hline & & Postgraduate & & & & & & \\
\hline & & degree & 67 & 16.7 & 57 & 17.5 & 10 & 13.0 \\
\hline & & Other & 4 & 1.0 & 3 & 0.9 & 1 & 1.3 \\
\hline & & Total & 397 & 98.8 & 320 & 98.5 & 77 & 100.0 \\
\hline & Missing & -999 & 5 & 1.2 & 5 & 1.5 & 0 & 0.0 \\
\hline & Total & & 402 & 100.0 & 325 & 100.0 & 77 & 100.0 \\
\hline \multirow[t]{16}{*}{ Occupation } & Valid & Professional & 112 & 27.9 & 99 & 30.5 & 13 & 16.9 \\
\hline & & Tradesperson & 14 & 3.5 & 11 & 3.4 & 3 & 3.9 \\
\hline & & Student & 20 & 5.0 & 14 & 4.3 & 6 & 7.8 \\
\hline & & Clerical & 28 & 7.0 & 24 & 7.4 & 4 & 5.2 \\
\hline & & Labourer & 4 & 1.0 & 3 & 0.9 & 1 & 1.3 \\
\hline & & Sales/Service & 23 & 5.7 & 19 & 5.8 & 4 & 5.2 \\
\hline & & Unemployed & 13 & 3.2 & 12 & 3.7 & 1 & 1.3 \\
\hline & & Self-employed & 61 & 15.2 & 50 & 15.4 & 11 & \begin{tabular}{|l|}
14.3 \\
\end{tabular} \\
\hline & & Management & 38 & 9.5 & 33 & 10.2 & 5 & 6.5 \\
\hline & & Retired & 79 & 19.7 & 52 & 16.0 & 27 & 35.1 \\
\hline & & Community & & & & & & \\
\hline & & worker & 4 & 1.0 & 3 & 0.9 & 1 & 1.3 \\
\hline & & Other & 4 & 1.0 & 3 & 0.9 & 1 & 1.3 \\
\hline & & Total & 400 & 99.5 & 323 & 99.4 & 77 & 100.0 \\
\hline & Missing & -999 & 2 & 0.5 & 2 & 0.6 & 0 & 0.0 \\
\hline & Total & & 402 & 100.0 & 325 & 100.0 & 77 & 100.0 \\
\hline
\end{tabular}


Table 5.2: Profile of Consumer Segmentation Characteristics (Continued)

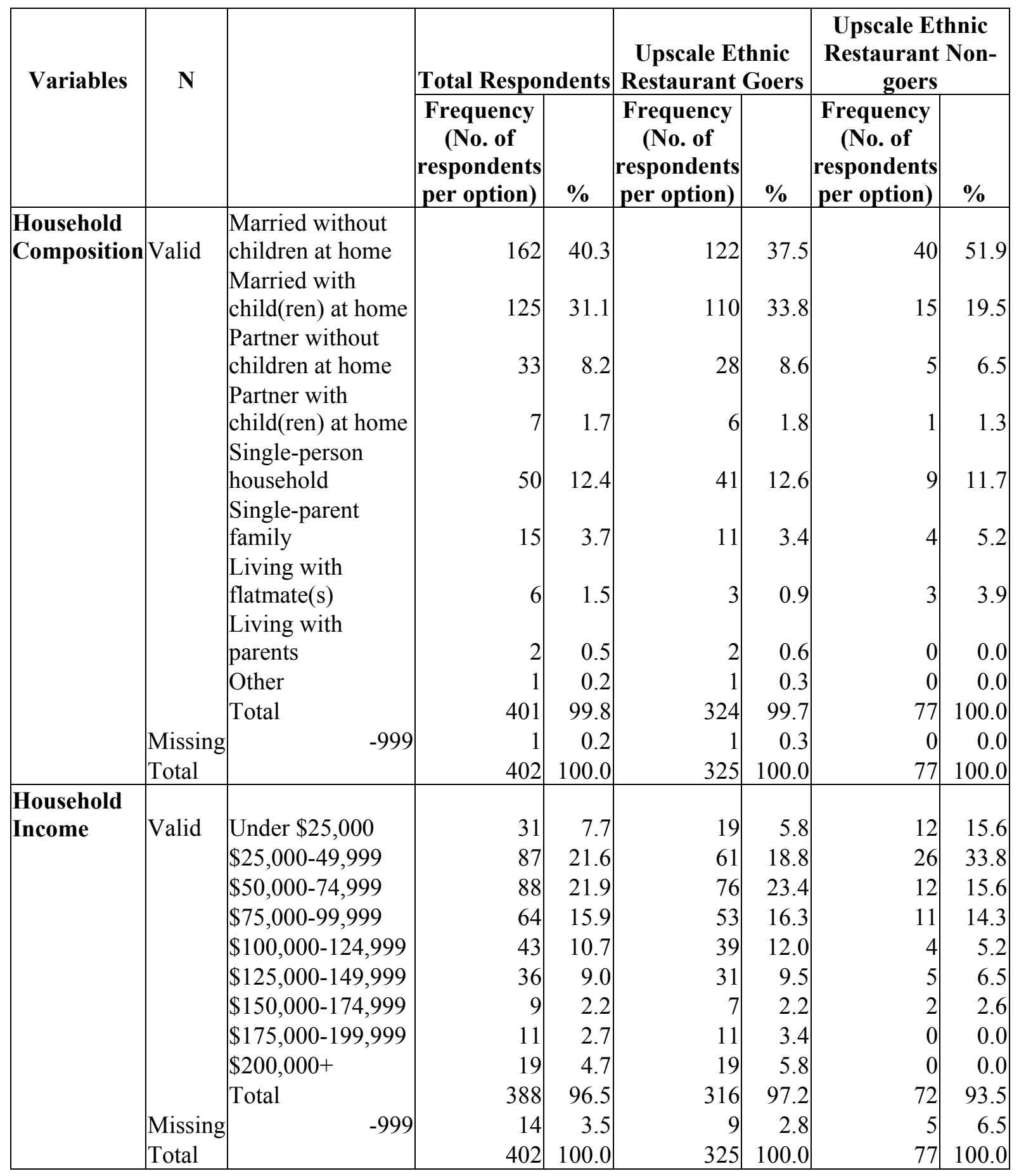


Table 5.3: The Correlation Matrix for Goer

\begin{tabular}{|c|c|c|c|c|c|c|c|c|c|c|c|c|c|c|c|c|c|c|c|}
\hline & UF1 & UF2 & MV1 & MV2 & AP1 & AP2 & HF1 & HF2 & FF1 & FF2 & RF1 & RF2 & PE1 & PE2 & PE3 & SB1 & SB2 & SB3 & WT1 \\
\hline UF1 & 1.00 & 0.28 & 0.11 & 0.22 & 0.25 & 0.26 & 0.28 & 0.16 & -0.03 & -0.30 & 0.15 & 0.13 & 0.19 & 0.16 & 0.14 & 0.19 & 0.24 & 0.19 & 0.22 \\
\hline UF2 & 0.28 & 1.00 & 0.29 & 0.35 & 0.42 & 0.37 & 0.40 & 0.34 & 0.07 & -0.01 & 0.04 & 0.00 & 0.24 & 0.26 & 0.08 & 0.32 & 0.31 & 0.29 & 0.26 \\
\hline MV1 & 0.11 & 0.29 & 1.00 & 0.39 & 0.38 & 0.45 & 0.38 & 0.44 & 0.23 & 0.15 & 0.15 & 0.13 & 0.30 & 0.17 & 0.13 & 0.28 & 0.19 & 0.35 & 0.29 \\
\hline MV2 & 0.22 & 0.35 & 0.39 & 1.00 & 0.37 & 0.35 & 0.33 & 0.35 & 0.06 & -0.09 & 0.02 & 0.07 & 0.12 & 0.19 & 0.13 & 0.31 & 0.29 & 0.25 & 0.28 \\
\hline AP1 & 0.25 & 0.42 & 0.38 & 0.37 & 1.00 & 0.62 & 0.50 & 0.42 & 0.09 & -0.01 & 0.05 & 0.07 & 0.48 & 0.20 & 0.22 & 0.48 & 0.42 & 0.41 & 0.36 \\
\hline AP2 & 0.26 & 0.37 & 0.45 & 0.35 & 0.62 & 1.00 & 0.37 & 0.28 & 0.19 & 0.03 & 0.10 & 0.08 & 0.43 & 0.27 & 0.25 & 0.36 & 0.32 & 0.36 & 0.33 \\
\hline HF1 & 0.28 & 0.40 & 0.38 & 0.33 & 0.50 & 0.37 & 1.00 & 0.65 & 0.16 & 0.01 & 0.15 & 0.13 & 0.24 & 0.12 & 0.16 & 0.39 & 0.32 & 0.33 & 0.31 \\
\hline HF2 & 0.16 & 0.34 & 0.44 & 0.35 & 0.42 & 0.28 & 0.65 & 1.00 & 0.19 & 0.16 & 0.20 & 0.25 & 0.20 & 0.21 & 0.19 & 0.26 & 0.23 & 0.27 & 0.25 \\
\hline FF1 & -0.03 & 0.07 & 0.23 & 0.06 & 0.09 & 0.19 & 0.16 & 0.19 & 1.00 & 0.39 & 0.19 & 0.12 & 0.05 & 0.06 & 0.12 & 0.15 & 0.11 & 0.09 & 0.12 \\
\hline FF2 & -0.30 & -0.01 & 0.15 & -0.09 & -0.01 & 0.03 & 0.01 & 0.16 & 0.39 & 1.00 & 0.14 & 0.18 & 0.16 & 0.11 & 0.06 & -0.03 & -0.02 & -0.01 & 0.02 \\
\hline RF1 & 0.15 & 0.04 & 0.15 & 0.02 & 0.05 & 0.10 & 0.15 & 0.20 & 0.19 & 0.14 & 1.00 & 0.77 & 0.18 & 0.14 & 0.17 & 0.09 & 0.10 & 0.08 & 0.09 \\
\hline RF2 & 0.13 & 0.00 & 0.13 & 0.07 & 0.07 & 0.08 & 0.13 & 0.25 & 0.12 & 0.18 & 0.77 & 1.00 & 0.20 & 0.17 & 0.23 & 0.08 & 0.10 & 0.12 & 0.07 \\
\hline PE1 & 0.19 & 0.24 & 0.30 & 0.12 & 0.48 & 0.43 & 0.24 & 0.20 & 0.05 & 0.16 & 0.18 & 0.20 & 1.00 & 0.29 & 0.33 & 0.33 & 0.30 & 0.37 & 0.25 \\
\hline PE2 & 0.16 & 0.26 & 0.17 & 0.19 & 0.20 & 0.27 & 0.12 & 0.21 & 0.06 & 0.11 & 0.14 & 0.17 & 0.29 & 1.00 & 0.51 & 0.27 & 0.29 & 0.18 & 0.24 \\
\hline PE3 & 0.14 & 0.08 & 0.13 & 0.13 & 0.22 & 0.25 & 0.16 & 0.19 & 0.12 & 0.06 & 0.17 & 0.23 & 0.33 & 0.51 & 1.00 & 0.35 & 0.31 & 0.19 & 0.37 \\
\hline SB1 & 0.19 & 0.32 & 0.28 & 0.31 & 0.48 & 0.36 & 0.39 & 0.26 & 0.15 & -0.03 & 0.09 & 0.08 & 0.33 & 0.27 & 0.35 & 1.00 & 0.71 & 0.63 & 0.56 \\
\hline SB2 & 0.24 & 0.31 & 0.19 & 0.29 & 0.42 & 0.32 & 0.32 & 0.23 & 0.11 & -0.02 & 0.10 & 0.10 & 0.30 & 0.29 & 0.31 & 0.71 & 1.00 & 0.57 & 0.58 \\
\hline SB3 & 0.19 & 0.29 & 0.35 & 0.25 & 0.41 & 0.36 & 0.33 & 0.27 & 0.09 & -0.01 & 0.08 & 0.12 & 0.37 & 0.18 & 0.19 & 0.63 & 0.57 & 1.00 & 0.49 \\
\hline BA1 & 0.13 & 0.26 & 0.23 & 0.24 & 0.34 & 0.27 & 0.36 & 0.22 & 0.06 & -0.02 & 0.02 & 0.04 & 0.27 & 0.16 & 0.17 & 0.58 & 0.59 & 0.56 & 0.57 \\
\hline BA2 & 0.22 & 0.27 & 0.24 & 0.18 & 0.37 & 0.33 & 0.32 & 0.24 & 0.10 & 0.02 & 0.06 & 0.08 & 0.32 & 0.11 & 0.10 & 0.44 & 0.50 & 0.60 & 0.46 \\
\hline WM1 & 0.25 & 0.23 & 0.25 & 0.29 & 0.18 & 0.35 & 0.19 & 0.21 & 0.08 & 0.08 & 0.06 & 0.11 & 0.21 & 0.32 & 0.15 & 0.28 & 0.30 & 0.32 & 0.26 \\
\hline WM2 & 0.09 & 0.18 & 0.22 & 0.23 & 0.19 & 0.27 & 0.19 & 0.22 & 0.15 & 0.13 & 0.13 & 0.16 & 0.20 & 0.25 & 0.17 & 0.21 & 0.27 & 0.22 & 0.21 \\
\hline MC1 & 0.08 & 0.05 & 0.07 & 0.04 & -0.02 & 0.08 & -0.03 & 0.08 & -0.02 & 0.14 & 0.09 & 0.08 & 0.08 & 0.21 & 0.12 & -0.03 & 0.07 & 0.04 & 0.00 \\
\hline MC2 & 0.06 & 0.07 & 0.10 & -0.02 & 0.01 & 0.06 & 0.06 & 0.12 & -0.14 & 0.03 & 0.11 & 0.07 & 0.15 & 0.18 & 0.12 & 0.03 & 0.10 & 0.03 & 0.07 \\
\hline MC3 & 0.24 & 0.27 & 0.17 & 0.26 & 0.22 & 0.29 & 0.16 & 0.20 & 0.03 & 0.04 & 0.01 & 0.01 & 0.15 & 0.33 & 0.19 & 0.27 & 0.26 & 0.18 & 0.21 \\
\hline CL1 & 0.29 & 0.29 & 0.32 & 0.39 & 0.26 & 0.31 & 0.26 & 0.25 & 0.07 & -0.04 & 0.05 & 0.11 & 0.22 & 0.32 & 0.31 & 0.33 & 0.31 & 0.20 & 0.21 \\
\hline CL2 & 0.29 & 0.21 & 0.28 & 0.11 & 0.29 & 0.33 & 0.24 & 0.19 & 0.08 & -0.02 & 0.14 & 0.16 & 0.38 & 0.30 & 0.36 & 0.33 & 0.31 & 0.27 & 0.24 \\
\hline ST1 & 0.17 & 0.00 & 0.27 & 0.09 & 0.11 & 0.14 & 0.11 & 0.16 & 0.14 & 0.14 & 0.23 & 0.21 & 0.17 & 0.26 & 0.25 & 0.10 & 0.16 & 0.10 & 0.16 \\
\hline ST2 & 0.15 & 0.06 & 0.20 & 0.08 & 0.13 & 0.15 & 0.15 & 0.21 & 0.19 & 0.24 & 0.26 & 0.30 & 0.22 & 0.30 & 0.33 & 0.13 & 0.11 & 0.09 & 0.11 \\
\hline DE1 & 0.29 & 0.24 & 0.19 & 0.22 & 0.30 & 0.29 & 0.16 & 0.23 & -0.05 & -0.06 & 0.14 & 0.13 & 0.24 & 0.46 & 0.35 & 0.22 & 0.29 & 0.17 & 0.18 \\
\hline DE2 & 0.29 & 0.22 & 0.26 & 0.25 & 0.27 & 0.35 & 0.16 & 0.18 & -0.03 & -0.06 & 0.11 & 0.16 & 0.26 & 0.43 & 0.33 & 0.19 & 0.15 & 0.17 & 0.16 \\
\hline VM1 & 0.20 & 0.24 & 0.32 & 0.23 & 0.26 & 0.31 & 0.35 & 0.27 & 0.15 & 0.02 & 0.04 & 0.00 & 0.15 & 0.11 & 0.10 & 0.46 & 0.46 & 0.46 & 0.46 \\
\hline VM2 & 0.13 & 0.21 & 0.28 & 0.28 & 0.25 & 0.29 & 0.32 & 0.13 & 0.12 & -0.01 & 0.00 & -0.02 & 0.15 & 0.05 & 0.06 & 0.43 & 0.41 & 0.40 & 0.38 \\
\hline BP1 & 0.11 & 0.06 & 0.27 & 0.15 & 0.22 & 0.22 & 0.11 & 0.16 & 0.09 & 0.16 & 0.07 & 0.09 & 0.29 & 0.27 & 0.21 & 0.24 & 0.23 & 0.25 & 0.22 \\
\hline BP2 & 0.10 & -0.02 & 0.12 & 0.07 & 0.03 & 0.08 & 0.09 & 0.15 & 0.19 & 0.19 & 0.15 & 0.18 & 0.06 & 0.24 & 0.24 & 0.08 & 0.09 & 0.06 & 0.15 \\
\hline
\end{tabular}


Table 5.3: The Correlation Matrix for Goer (Continued)

\begin{tabular}{|c|c|c|c|c|c|c|c|c|c|c|c|c|c|c|c|c|c|c|}
\hline & WT2 & BA1 & BA2 & WM1 & WM2 & MC1 & MC2 & MC3 & CL1 & CL2 & ST1 & ST2 & DE1 & DE2 & VM1 & VM2 & BP1 & BP2 \\
\hline UF1 & 0.24 & 0.13 & 0.22 & 0.25 & 0.09 & 0.08 & 0.06 & 0.24 & 0.29 & 0.29 & 0.17 & 0.15 & 0.29 & 0.29 & 0.20 & 0.13 & 0.11 & 0.10 \\
\hline UF2 & 0.26 & 0.26 & 0.27 & 0.23 & 0.18 & 0.05 & 0.07 & 0.27 & 0.29 & 0.21 & 0.00 & 0.06 & 0.24 & 0.22 & 0.24 & 0.21 & 0.06 & -0.02 \\
\hline MV1 & 0.31 & 0.23 & 0.24 & 0.25 & 0.22 & 0.07 & 0.10 & 0.17 & 0.32 & 0.28 & 0.27 & 0.20 & 0.19 & 0.26 & 0.32 & 0.28 & 0.27 & 0.12 \\
\hline MV2 & 0.30 & 0.24 & 0.18 & 0.29 & 0.23 & 0.04 & -0.02 & 0.26 & 0.39 & 0.11 & 0.09 & 0.08 & 0.22 & 0.25 & 0.23 & 0.28 & 0.15 & 0.07 \\
\hline AP1 & 0.47 & 0.34 & 0.37 & 0.18 & 0.19 & -0.02 & 0.01 & 0.22 & 0.26 & 0.29 & 0.11 & 0.13 & 0.30 & 0.27 & 0.26 & 0.25 & 0.22 & 0.03 \\
\hline AP2 & 0.44 & 0.27 & 0.33 & 0.35 & 0.27 & 0.08 & 0.06 & 0.29 & 0.31 & 0.33 & 0.14 & 0.15 & 0.29 & 0.35 & 0.31 & 0.29 & 0.22 & 0.08 \\
\hline HF1 & 0.40 & 0.36 & 0.32 & 0.19 & 0.19 & -0.03 & 0.06 & 0.16 & 0.26 & 0.24 & 0.11 & 0.15 & 0.16 & 0.16 & 0.35 & 0.32 & 0.11 & 0.09 \\
\hline HF2 & 0.33 & 0.22 & 0.24 & 0.21 & 0.22 & 0.08 & 0.12 & 0.20 & 0.25 & 0.19 & 0.16 & 0.21 & 0.23 & 0.18 & 0.27 & 0.13 & 0.16 & 0.15 \\
\hline FF1 & 0.20 & 0.06 & 0.10 & 0.08 & 0.15 & -0.02 & -0.14 & 0.03 & 0.07 & 0.08 & 0.14 & 0.19 & -0.05 & -0.03 & 0.15 & 0.12 & 0.09 & 0.19 \\
\hline FF2 & 0.01 & -0.02 & 0.02 & 0.08 & 0.13 & 0.14 & 0.03 & 0.04 & -0.04 & -0.02 & 0.14 & 0.24 & -0.06 & -0.06 & 0.02 & -0.01 & 0.16 & 0.19 \\
\hline RF1 & 0.15 & 0.02 & 0.06 & 0.06 & 0.13 & 0.09 & 0.11 & 0.01 & 0.05 & 0.14 & 0.23 & 0.26 & 0.14 & 0.11 & 0.04 & 0.00 & 0.07 & 0.15 \\
\hline RF2 & 0.18 & 0.04 & 0.08 & 0.11 & 0.16 & 0.08 & 0.07 & 0.01 & 0.11 & 0.16 & 0.21 & 0.30 & 0.13 & 0.16 & 0.00 & -0.02 & 0.09 & 0.18 \\
\hline PE1 & 0.51 & 0.27 & 0.32 & 0.21 & 0.20 & 0.08 & 0.15 & 0.15 & 0.22 & 0.38 & 0.17 & 0.22 & 0.24 & 0.26 & 0.15 & 0.15 & 0.29 & 0.06 \\
\hline PE2 & 0.31 & 0.16 & 0.11 & 0.32 & 0.25 & 0.21 & 0.18 & 0.33 & 0.32 & 0.30 & 0.26 & 0.30 & 0.46 & 0.43 & 0.11 & 0.05 & 0.27 & 0.24 \\
\hline PE3 & 0.37 & 0.17 & 0.10 & 0.15 & 0.17 & 0.12 & 0.12 & 0.19 & 0.31 & 0.36 & 0.25 & 0.33 & 0.35 & 0.33 & 0.10 & 0.06 & 0.21 & 0.24 \\
\hline SB1 & 0.58 & 0.58 & 0.44 & 0.28 & 0.21 & -0.03 & 0.03 & 0.27 & 0.33 & 0.33 & 0.10 & 0.13 & 0.22 & 0.19 & 0.46 & 0.43 & 0.24 & 0.08 \\
\hline SB2 & 0.54 & 0.59 & 0.50 & 0.30 & 0.27 & 0.07 & 0.10 & 0.26 & 0.31 & 0.31 & 0.16 & 0.11 & 0.29 & 0.15 & 0.46 & 0.41 & 0.23 & 0.09 \\
\hline SB3 & 0.62 & 0.56 & 0.60 & 0.32 & 0.22 & 0.04 & 0.03 & 0.18 & 0.20 & 0.27 & 0.10 & 0.09 & 0.17 & 0.17 & 0.46 & 0.40 & 0.25 & 0.06 \\
\hline WT1 & 0.50 & 0.57 & 0.46 & 0.26 & 0.21 & 0.00 & 0.07 & 0.21 & 0.21 & 0.24 & 0.16 & 0.11 & 0.18 & 0.16 & 0.46 & 0.38 & 0.22 & 0.15 \\
\hline WT2 & 1.00 & 0.54 & 0.58 & 0.28 & 0.20 & 0.07 & 0.08 & 0.24 & 0.30 & 0.36 & 0.22 & 0.21 & 0.24 & 0.26 & 0.33 & 0.31 & 0.38 & 0.17 \\
\hline BA1 & 0.54 & 1.00 & 0.76 & 0.22 & 0.21 & -0.04 & 0.02 & 0.19 & 0.29 & 0.24 & 0.04 & 0.05 & 0.13 & 0.13 & 0.47 & 0.51 & 0.21 & 0.07 \\
\hline BA2 & 0.58 & 0.76 & 1.00 & 0.22 & 0.16 & 0.03 & 0.02 & 0.21 & 0.22 & 0.25 & 0.06 & 0.02 & 0.07 & 0.09 & 0.44 & 0.42 & 0.24 & 0.07 \\
\hline WM1 & 0.28 & 0.22 & 0.22 & 1.00 & 0.42 & 0.25 & 0.19 & 0.38 & 0.30 & 0.16 & 0.12 & 0.16 & 0.33 & 0.22 & 0.18 & 0.19 & 0.22 & 0.16 \\
\hline WM2 & 0.20 & 0.21 & 0.16 & 0.42 & 1.00 & 0.26 & 0.16 & 0.23 & 0.26 & 0.14 & 0.26 & 0.23 & 0.19 & 0.22 & 0.23 & 0.16 & 0.16 & 0.19 \\
\hline MC1 & 0.07 & -0.04 & 0.03 & 0.25 & 0.26 & 1.00 & 0.32 & 0.37 & 0.18 & 0.22 & 0.24 & 0.30 & 0.25 & 0.23 & 0.13 & 0.00 & 0.18 & 0.22 \\
\hline MC2 & 0.08 & 0.02 & 0.02 & 0.19 & 0.16 & 0.32 & 1.00 & 0.13 & 0.17 & 0.17 & 0.20 & 0.14 & 0.26 & 0.22 & 0.05 & -0.02 & 0.21 & 0.20 \\
\hline MC3 & 0.24 & 0.19 & 0.21 & 0.38 & 0.23 & 0.37 & 0.13 & 1.00 & 0.31 & 0.27 & 0.15 & 0.26 & 0.30 & 0.37 & 0.22 & 0.23 & 0.17 & 0.12 \\
\hline CL1 & 0.30 & 0.29 & 0.22 & 0.30 & 0.26 & 0.18 & 0.17 & 0.31 & 1.00 & 0.47 & 0.18 & 0.18 & 0.51 & 0.45 & 0.24 & 0.18 & 0.33 & 0.11 \\
\hline CL2 & 0.36 & 0.24 & 0.25 & 0.16 & 0.14 & 0.22 & 0.17 & 0.27 & 0.47 & 1.00 & 0.27 & 0.33 & 0.40 & 0.47 & 0.36 & 0.25 & 0.25 & 0.18 \\
\hline ST1 & 0.22 & 0.04 & 0.06 & 0.12 & 0.26 & 0.24 & 0.20 & 0.15 & 0.18 & 0.27 & 1.00 & 0.65 & 0.18 & 0.26 & 0.18 & 0.12 & 0.31 & 0.36 \\
\hline ST2 & 0.21 & 0.05 & 0.02 & 0.16 & 0.23 & 0.30 & 0.14 & 0.26 & 0.18 & 0.33 & 0.65 & 1.00 & 0.25 & 0.31 & 0.13 & 0.04 & 0.24 & 0.37 \\
\hline DE1 & 0.24 & 0.13 & 0.07 & 0.33 & 0.19 & 0.25 & 0.26 & 0.30 & 0.51 & 0.40 & 0.18 & 0.25 & 1.00 & 0.49 & 0.14 & 0.08 & 0.27 & 0.19 \\
\hline DE2 & 0.26 & 0.13 & 0.09 & 0.22 & 0.22 & 0.23 & 0.22 & 0.37 & 0.45 & 0.47 & 0.26 & 0.31 & 0.49 & 1.00 & 0.16 & 0.07 & 0.21 & 0.17 \\
\hline VM1 & 0.33 & 0.47 & 0.44 & 0.18 & 0.23 & 0.13 & 0.05 & 0.22 & 0.24 & 0.36 & 0.18 & 0.13 & 0.14 & 0.16 & 1.00 & 0.65 & 0.10 & 0.07 \\
\hline VM2 & 0.31 & 0.51 & 0.42 & 0.19 & 0.16 & 0.00 & -0.02 & 0.23 & 0.18 & 0.25 & 0.12 & 0.04 & 0.08 & 0.07 & 0.65 & 1.00 & 0.09 & 0.03 \\
\hline BP1 & 0.38 & 0.21 & 0.24 & 0.22 & 0.16 & 0.18 & 0.21 & 0.17 & 0.33 & 0.25 & 0.31 & 0.24 & 0.27 & 0.21 & 0.10 & 0.09 & 1.00 & 0.33 \\
\hline BP2 & 0.17 & 0.07 & 0.07 & 0.16 & 0.19 & 0.22 & 0.20 & 0.12 & 0.11 & 0.18 & 0.36 & 0.37 & 0.19 & 0.17 & 0.07 & 0.03 & 0.33 & 1.00 \\
\hline
\end{tabular}


Table 5.4: The Anti-Image Correlation Matrix for Goer

\begin{tabular}{|c|c|c|c|c|c|c|c|c|c|c|c|c|c|c|}
\hline & UF1 & UF2 & MV1 & MV2 & AP1 & AP2 & HF1 & HF2 & FF1 & FF2 & RF1 & RF2 & PE1 & PE2 \\
\hline UF1 & $.813(a)$ & -0.13 & 0.10 & -0.02 & 0.00 & 0.00 & -0.16 & 0.06 & -0.04 & 0.35 & -0.05 & -0.05 & -0.10 & 0.04 \\
\hline UF2 & -0.13 & $.918(a)$ & -0.04 & -0.11 & -0.10 & -0.05 & -0.13 & -0.05 & -0.01 & -0.04 & -0.04 & 0.09 & -0.04 & -0.18 \\
\hline MV1 & 0.10 & -0.04 & $.895(a)$ & -0.20 & -0.01 & -0.17 & -0.01 & -0.20 & -0.11 & -0.05 & -0.08 & 0.06 & -0.09 & 0.04 \\
\hline MV2 & -0.02 & -0.11 & -0.20 & $.880(a)$ & -0.09 & -0.03 & 0.03 & -0.13 & 0.06 & 0.11 & 0.05 & -0.05 & 0.08 & -0.01 \\
\hline AP1 & 0.00 & -0.10 & -0.01 & -0.09 & $.883(a)$ & -0.41 & -0.18 & -0.13 & 0.02 & 0.03 & 0.12 & -0.04 & -0.24 & 0.06 \\
\hline AP2 & 0.00 & -0.05 & -0.17 & -0.03 & -0.41 & $.908(a)$ & -0.01 & 0.12 & -0.10 & 0.03 & -0.06 & 0.06 & -0.08 & -0.01 \\
\hline HF1 & -0.16 & -0.13 & -0.01 & 0.03 & -0.18 & -0.01 & $.865(a)$ & -0.51 & 0.02 & 0.00 & -0.10 & 0.09 & 0.05 & 0.08 \\
\hline HF2 & 0.06 & -0.05 & -0.20 & -0.13 & -0.13 & 0.12 & -0.51 & $.828(a)$ & -0.04 & -0.09 & 0.07 & -0.16 & 0.08 & -0.04 \\
\hline FF1 & -0.04 & -0.06 & -0.11 & 0.06 & 0.02 & -0.10 & 0.02 & -0.04 & $.663(a)$ & -0.34 & -0.17 & 0.13 & 0.15 & 0.03 \\
\hline FF2 & 0.35 & -0.04 & -0.05 & 0.11 & 0.03 & 0.03 & 0.00 & -0.09 & -0.34 & $.576(a)$ & 0.06 & -0.13 & -0.22 & -0.07 \\
\hline RF1 & -0.05 & -0.04 & -0.08 & 0.05 & 0.12 & -0.06 & -0.10 & 0.07 & -0.17 & 0.06 & $.611(a)$ & -0.75 & -0.06 & -0.01 \\
\hline RF2 & -0.05 & 0.09 & 0.06 & -0.05 & -0.04 & 0.06 & 0.09 & -0.16 & 0.13 & -0.13 & -0.75 & $.625(a)$ & 0.01 & 0.00 \\
\hline PE1 & -0.10 & -0.04 & -0.09 & 0.08 & -0.24 & -0.08 & 0.05 & 0.08 & 0.15 & -0.22 & -0.06 & 0.01 & $.878(a)$ & -0.04 \\
\hline PE2 & 0.04 & -0.18 & 0.04 & -0.01 & 0.06 & -0.01 & 0.08 & -0.04 & 0.03 & -0.07 & -0.01 & 0.00 & -0.04 & $.899(a)$ \\
\hline PE3 & 0.04 & 0.14 & 0.06 & 0.04 & 0.07 & -0.07 & -0.03 & -0.04 & -0.05 & 0.05 & 0.07 & -0.10 & -0.13 & -0.31 \\
\hline SB1 & 0.07 & -0.03 & 0.01 & 0.00 & -0.17 & 0.06 & -0.04 & 0.05 & -0.03 & 0.04 & -0.10 & 0.08 & 0.03 & -0.02 \\
\hline SB2 & -0.05 & -0.03 & 0.15 & -0.08 & -0.08 & 0.04 & 0.03 & 0.04 & -0.04 & -0.02 & -0.01 & -0.02 & 0.02 & -0.05 \\
\hline SB3 & 0.03 & -0.06 & -0.18 & 0.05 & 0.00 & 0.03 & 0.04 & -0.01 & 0.07 & 0.05 & 0.07 & -0.08 & -0.04 & 0.04 \\
\hline WT1 & -0.12 & -0.04 & -0.09 & -0.04 & -0.05 & -0.01 & 0.06 & 0.00 & 0.04 & -0.08 & -0.05 & 0.05 & 0.08 & 0.04 \\
\hline WT2 & 0.03 & 0.09 & 0.08 & -0.10 & 0.03 & -0.09 & -0.13 & -0.03 & -0.18 & 0.13 & 0.04 & -0.05 & -0.25 & -0.06 \\
\hline BA1 & 0.16 & 0.02 & 0.00 & 0.03 & 0.06 & 0.09 & -0.11 & 0.04 & 0.07 & 0.07 & 0.05 & -0.01 & -0.01 & -0.04 \\
\hline BA2 & -0.15 & -0.05 & 0.04 & 0.08 & -0.07 & -0.07 & 0.07 & -0.05 & 0.00 & -0.07 & -0.03 & -0.02 & -0.02 & 0.05 \\
\hline WM1 & -0.15 & 0.04 & -0.05 & -0.07 & 0.17 & -0.19 & -0.03 & 0.00 & -0.02 & -0.06 & 0.09 & -0.06 & -0.02 & -0.12 \\
\hline WM2 & 0.09 & -0.03 & 0.03 & -0.04 & -0.01 & -0.05 & -0.02 & -0.02 & -0.08 & 0.01 & 0.01 & -0.06 & -0.09 & -0.02 \\
\hline MC1 & 0.02 & 0.00 & 0.02 & 0.00 & 0.03 & 0.02 & 0.07 & 0.00 & 0.08 & -0.09 & -0.04 & 0.05 & 0.04 & 0.02 \\
\hline MC2 & 0.08 & -0.05 & -0.03 & 0.12 & 0.08 & 0.02 & -0.04 & -0.08 & 0.18 & 0.02 & -0.09 & 0.07 & -0.09 & 0.02 \\
\hline MC3 & -0.08 & -0.06 & 0.04 & -0.04 & -0.01 & -0.04 & 0.07 & -0.09 & 0.04 & -0.05 & -0.01 & 0.09 & 0.07 & -0.09 \\
\hline CL1 & -0.08 & -0.07 & -0.10 & -0.22 & 0.12 & -0.01 & -0.04 & 0.02 & -0.07 & 0.00 & 0.11 & -0.08 & 0.05 & 0.05 \\
\hline CL2 & -0.04 & -0.02 & -0.07 & 0.19 & 0.00 & -0.01 & -0.02 & 0.04 & -0.03 & 0.08 & 0.01 & -0.03 & -0.17 & 0.02 \\
\hline ST1 & -0.08 & 0.10 & -0.17 & 0.05 & -0.03 & 0.06 & 0.04 & 0.01 & 0.04 & 0.03 & -0.09 & 0.08 & 0.05 & -0.07 \\
\hline ST2 & -0.03 & -0.03 & 0.05 & -0.02 & 0.00 & 0.01 & -0.04 & -0.01 & -0.06 & -0.13 & 0.03 & -0.12 & -0.05 & 0.02 \\
\hline DE1 & -0.05 & -0.02 & 0.05 & 0.05 & -0.16 & 0.01 & 0.09 & -0.09 & 0.10 & 0.05 & -0.12 & 0.09 & 0.03 & -0.17 \\
\hline DE2 & -0.08 & 0.02 & -0.06 & -0.07 & -0.03 & -0.12 & 0.01 & 0.07 & 0.06 & 0.03 & 0.06 & -0.09 & 0.02 & -0.16 \\
\hline VM1 & -0.06 & 0.04 & -0.02 & 0.03 & 0.11 & -0.08 & -0.03 & -0.14 & -0.04 & -0.02 & -0.01 & 0.09 & 0.06 & -0.02 \\
\hline VM2 & 0.04 & 0.01 & -0.06 & -0.15 & 0.02 & -0.04 & -0.14 & 0.20 & -0.02 & -0.02 & 0.03 & -0.04 & -0.01 & 0.06 \\
\hline BP1 & -0.01 & 0.10 & -0.09 & 0.01 & -0.06 & 0.01 & 0.06 & 0.01 & 0.04 & -0.11 & 0.02 & 0.04 & -0.06 & -0.07 \\
\hline BP2 & -0.07 & 0.06 & 0.03 & -0.06 & 0.05 & 0.00 & -0.03 & -0.01 & -0.12 & -0.06 & 0.04 & -0.05 & 0.12 & -0.04 \\
\hline
\end{tabular}


Table 5.4: The Anti-Image Correlation Matrix for Goer (Continued)

\begin{tabular}{|c|c|c|c|c|c|c|c|c|c|c|c|c|c|c|}
\hline & PE3 & SB1 & SB2 & SB3 & WT1 & WT2 & BA1 & BA2 & WM1 & WM2 & MC1 & MC2 & MC3 & CL1 \\
\hline UF1 & 0.04 & 0.07 & -0.05 & 0.03 & -0.12 & 0.03 & 0.16 & -0.15 & -0.15 & 0.09 & 0.02 & 0.08 & -0.08 & -0.08 \\
\hline UF2 & 0.14 & -0.03 & -0.03 & -0.06 & -0.04 & 0.09 & 0.02 & -0.05 & 0.04 & -0.03 & 0.00 & -0.05 & -0.06 & -0.07 \\
\hline MV1 & 0.06 & 0.01 & 0.15 & -0.18 & -0.09 & 0.08 & 0.00 & 0.04 & -0.05 & 0.03 & 0.02 & -0.03 & 0.04 & -0.10 \\
\hline MV2 & 0.04 & 0.00 & -0.08 & 0.05 & -0.04 & -0.10 & 0.03 & 0.08 & -0.07 & -0.04 & 0.00 & 0.12 & -0.04 & -0.22 \\
\hline AP1 & 0.07 & -0.17 & -0.08 & 0.00 & -0.05 & 0.03 & 0.06 & -0.07 & 0.17 & -0.01 & 0.03 & 0.08 & -0.01 & 0.12 \\
\hline AP2 & -0.07 & 0.06 & 0.04 & 0.03 & -0.01 & -0.09 & 0.09 & -0.07 & -0.19 & -0.05 & 0.02 & 0.02 & -0.04 & -0.01 \\
\hline HF1 & -0.03 & -0.04 & 0.03 & 0.04 & 0.06 & -0.13 & -0.11 & 0.07 & -0.03 & -0.02 & 0.07 & -0.04 & 0.07 & -0.04 \\
\hline HF2 & -0.04 & 0.05 & 0.04 & -0.01 & 0.00 & -0.03 & 0.04 & -0.05 & 0.00 & -0.02 & 0.00 & -0.08 & -0.09 & 0.02 \\
\hline FF1 & -0.05 & -0.03 & -0.04 & 0.07 & 0.04 & -0.18 & 0.07 & 0.00 & -0.02 & -0.08 & 0.08 & 0.18 & 0.04 & -0.07 \\
\hline FF2 & 0.05 & 0.04 & -0.02 & 0.05 & -0.08 & 0.13 & 0.07 & -0.07 & -0.06 & 0.01 & -0.09 & 0.02 & -0.05 & 0.00 \\
\hline RF1 & 0.07 & -0.10 & -0.01 & 0.07 & -0.05 & 0.04 & 0.05 & -0.03 & 0.09 & 0.01 & -0.04 & -0.09 & -0.01 & 0.11 \\
\hline RF2 & -0.10 & 0.08 & -0.02 & -0.08 & 0.05 & -0.05 & -0.01 & -0.02 & -0.06 & -0.06 & 0.05 & 0.07 & 0.09 & -0.08 \\
\hline PE1 & -0.13 & 0.03 & 0.02 & -0.04 & 0.08 & -0.25 & -0.01 & -0.02 & -0.02 & -0.09 & 0.04 & -0.09 & 0.07 & 0.05 \\
\hline PE2 & -0.31 & -0.02 & -0.05 & 0.04 & 0.04 & -0.06 & -0.04 & 0.05 & -0.12 & -0.02 & 0.02 & 0.02 & -0.09 & 0.05 \\
\hline PE3 & $.860(a)$ & -0.14 & -0.03 & 0.06 & -0.27 & -0.07 & 0.07 & 0.04 & 0.10 & 0.01 & -0.03 & 0.01 & 0.03 & -0.10 \\
\hline SB1 & -0.14 & $907(a)$ & -0.34 & -0.28 & -0.06 & -0.11 & -0.16 & 0.21 & -0.03 & 0.03 & 0.13 & 0.01 & -0.12 & -0.11 \\
\hline SB2 & -0.03 & -0.34 & $.931(a)$ & -0.09 & -0.14 & -0.04 & -0.14 & -0.02 & -0.02 & -0.07 & -0.04 & -0.08 & -0.02 & -0.01 \\
\hline SB3 & 0.06 & -0.28 & -0.09 & $.917(a)$ & -0.02 & -0.23 & 0.05 & -0.23 & -0.16 & -0.01 & -0.04 & 0.07 & 0.12 & 0.13 \\
\hline WT1 & -0.27 & -0.06 & -0.14 & -0.02 & $.919(\mathrm{a})$ & -0.10 & -0.25 & 0.06 & -0.06 & 0.01 & 0.08 & -0.04 & -0.02 & 0.12 \\
\hline WT2 & -0.07 & -0.11 & -0.04 & -0.23 & -0.10 & $927(a)$ & -0.02 & -0.22 & 0.03 & 0.07 & -0.04 & 0.00 & -0.02 & 0.03 \\
\hline BA1 & 0.07 & -0.16 & -0.14 & 0.05 & -0.25 & -0.02 & $.851(a)$ & -0.59 & 0.01 & -0.09 & 0.07 & 0.02 & 0.08 & -0.12 \\
\hline BA2 & 0.04 & 0.21 & -0.02 & -0.23 & 0.06 & -0.22 & -0.59 & $.843(a)$ & 0.01 & 0.06 & -0.03 & 0.01 & -0.12 & -0.02 \\
\hline WM1 & 0.10 & -0.03 & -0.02 & -0.16 & -0.06 & 0.03 & 0.01 & 0.01 & $.862(a)$ & -0.27 & -0.07 & -0.0 & -0.17 & -0.03 \\
\hline WM2 & 0.01 & 0.03 & -0.07 & -0.01 & 0.01 & 0.07 & -0.09 & 0.06 & -0.27 & $.892(a)$ & -0.14 & -0. & 0.01 & -0.08 \\
\hline MC1 & -0.03 & 0.13 & -0.04 & -0.04 & 0.08 & -0.04 & 0.07 & -0.03 & -0 . & -0.14 & $.800(a)$ & -0.20 & -0.26 & -0.01 \\
\hline MC2 & 0.01 & 0.01 & -0.08 & 0.07 & -0.04 & 0.00 & 0.02 & 0.01 & -0 . & -0.02 & -0.20 & $.775(a)$ & 0.04 & -0.03 \\
\hline MC3 & 0.03 & -0.12 & -0.02 & 0.12 & -0.02 & -0.02 & 0.08 & -0.12 & -0.17 & 0.01 & -0.26 & 0.04 & $.870(a)$ & -0.02 \\
\hline CL1 & -0.10 & -0.11 & -0.01 & 0.13 & 0.12 & 0.03 & -0.12 & -0.02 & -0.03 & -0.08 & -0.01 & -0.03 & -0.02 & $.874(a)$ \\
\hline CL2 & -0.09 & -0.03 & -0.05 & 0.03 & 0.04 & -0.04 & 0.06 & -0.04 & 0.07 & 0.10 & -0.08 & 0.00 & 0.00 & -0.24 \\
\hline ST1 & 0.00 & 0.10 & -0.11 & 0.04 & -0.06 & -0.07 & 0.13 & -0.04 & 0.06 & -0.13 & 0.00 & -0.08 & 0.08 & -0.04 \\
\hline ST2 & -0.09 & -0.06 & 0.09 & -0.01 & 0.09 & 0.00 & -0.13 & 0.13 & 0.00 & 0.01 & -0.10 & 0.07 & -0.15 & 0.09 \\
\hline DE1 & -0.07 & 0.10 & -0.13 & -0.03 & 0.03 & 0.01 & -0.01 & 0.11 & -0.14 & 0.06 & -0.05 & -0.07 & 0.02 & -0.28 \\
\hline DE2 & -0.03 & 0.03 & 0.15 & -0.06 & 0.01 & -0.03 & -0.08 & 0.08 & 0.10 & -0.06 & 0.01 & -0.09 & -0.18 & -0.12 \\
\hline VM1 & 0.12 & -0.09 & -0.08 & -0.12 & -0.18 & 0.12 & 0.04 & -0.11 & 0.11 & -0.08 & -0.13 & 0.01 & 0.07 & 0.00 \\
\hline VM2 & 0.00 & -0.03 & 0.01 & -0.01 & 0.05 & 0.02 & -0.21 & 0.03 & -0.04 & 0.04 & 0.06 & 0.01 & -0.15 & 0.07 \\
\hline BP1 & 0.07 & -0.03 & 0.02 & -0.03 & -0.02 & -0.14 & -0.01 & -0.03 & -0.01 & 0.04 & -0.04 & -0.07 & 0.01 & -0.18 \\
\hline BP2 & -0.06 & -0.02 & 0.05 & 0.03 & -0.05 & -0.01 & -0.01 & -0.04 & -0.01 & -0.05 & -0.05 & -0.12 & 0.04 & 0.11 \\
\hline
\end{tabular}


Table 5.4: The Anti-Image Correlation Matrix for Goer (Continued)

\begin{tabular}{|c|c|c|c|c|c|c|c|c|c|}
\hline & CL2 & ST1 & ST2 & DE1 & DE2 & VM1 & VM2 & BP1 & BP2 \\
\hline UF1 & -0.04 & -0.08 & -0.03 & -0.05 & -0.08 & -0.06 & 0.04 & -0.01 & -0.07 \\
\hline UF2 & -0.02 & 0.10 & -0.03 & -0.02 & 0.02 & 0.04 & 0.01 & 0.10 & 0.06 \\
\hline MV1 & -0.07 & -0.17 & 0.05 & 0.05 & -0.06 & -0.02 & -0.06 & -0.09 & 0.03 \\
\hline MV2 & 0.19 & 0.05 & -0.02 & 0.05 & -0.07 & 0.03 & -0.15 & 0.01 & -0.06 \\
\hline AP1 & 0.00 & -0.03 & 0.00 & -0.16 & -0.03 & 0.11 & 0.02 & -0.06 & 0.05 \\
\hline AP2 & -0.01 & 0.06 & 0.01 & 0.01 & -0.12 & -0.08 & -0.04 & 0.01 & 0.00 \\
\hline HF1 & -0.02 & 0.04 & -0.04 & 0.09 & 0.01 & -0.03 & -0.14 & 0.06 & -0.03 \\
\hline HF2 & 0.04 & 0.01 & -0.01 & -0.09 & 0.07 & -0.14 & 0.20 & 0.01 & -0.01 \\
\hline FF1 & -0.03 & 0.04 & -0.06 & 0.10 & 0.06 & -0.04 & -0.02 & 0.04 & -0.12 \\
\hline FF2 & 0.08 & 0.03 & -0.13 & 0.05 & 0.03 & -0.02 & -0.02 & -0.11 & -0.06 \\
\hline RF1 & 0.01 & -0.09 & 0.03 & -0.12 & 0.06 & -0.01 & 0.03 & 0.02 & 0.04 \\
\hline RF2 & -0.03 & 0.08 & -0.12 & 0.09 & -0.09 & 0.09 & -0.04 & 0.04 & -0.05 \\
\hline PE1 & -0.17 & 0.05 & -0.05 & 0.03 & 0.02 & 0.06 & -0.01 & -0.06 & 0.12 \\
\hline PE2 & 0.02 & -0.07 & 0.02 & -0.17 & -0.16 & -0.02 & 0.06 & -0.07 & -0.04 \\
\hline PE3 & -0.09 & 0.00 & -0.09 & -0.07 & -0.03 & 0.12 & 0.00 & 0.07 & -0.06 \\
\hline SB1 & -0.03 & 0.10 & -0.06 & 0.10 & 0.03 & -0.09 & -0.03 & -0.03 & -0.02 \\
\hline SB2 & -0.05 & -0.11 & 0.09 & -0.13 & 0.15 & -0.08 & 0.01 & 0.02 & 0.05 \\
\hline SB3 & 0.03 & 0.04 & -0.01 & -0.03 & -0.06 & -0.12 & -0.01 & -0.03 & 0.03 \\
\hline WT1 & 0.04 & -0.06 & 0.09 & 0.03 & 0.01 & -0.18 & 0.05 & -0.02 & -0.05 \\
\hline WT2 & -0.04 & -0.07 & 0.00 & 0.01 & -0.03 & 0.12 & 0.02 & -0.14 & -0.01 \\
\hline BA1 & 0.06 & 0.13 & -0.13 & -0.01 & -0.08 & 0.04 & -0.21 & -0.01 & -0.01 \\
\hline BA2 & -0.04 & -0.04 & 0.13 & 0.11 & 0.08 & -0.11 & 0.03 & -0.03 & -0.04 \\
\hline WM1 & 0.07 & 0.06 & 0.00 & -0.14 & 0.10 & 0.11 & -0.04 & -0.01 & -0.01 \\
\hline WM2 & 0.10 & -0.13 & 0.01 & 0.06 & -0.06 & -0.08 & 0.04 & 0.04 & -0.05 \\
\hline MC1 & -0.08 & 0.00 & -0.10 & -0.05 & 0.01 & -0.13 & 0.06 & -0.04 & -0.05 \\
\hline MC2 & 0.00 & -0.08 & 0.07 & -0.07 & -0.09 & 0.01 & 0.01 & -0.07 & -0.12 \\
\hline MC3 & 0.00 & 0.08 & -0.15 & 0.02 & -0.18 & 0.07 & -0.15 & 0.01 & 0.04 \\
\hline CL1 & -0.24 & -0.04 & 0.09 & -0.28 & -0.12 & 0.00 & 0.07 & -0.18 & 0.11 \\
\hline CL2 & $.911(a)$ & 0.03 & -0.12 & -0.06 & -0.20 & -0.17 & -0.06 & 0.00 & -0.05 \\
\hline ST1 & 0.03 & $.769(a)$ & -0.55 & 0.09 & -0.04 & -0.03 & -0.12 & -0.14 & -0.08 \\
\hline ST2 & -0.12 & -0.55 & $.798(a)$ & -0.06 & -0.03 & -0.04 & 0.11 & 0.04 & -0.12 \\
\hline DE1 & -0.06 & 0.09 & -0.06 & $.884(a)$ & -0.17 & -0.01 & -0.03 & -0.05 & -0.07 \\
\hline DE2 & -0.20 & -0.04 & -0.03 & -0.17 & $.898(a)$ & -0.04 & 0.10 & 0.05 & -0.01 \\
\hline VM1 & -0.17 & -0.03 & -0.04 & -0.01 & -0.04 & $.864(a)$ & -0.46 & 0.08 & 0.04 \\
\hline VM2 & -0.06 & -0.12 & 0.11 & -0.03 & 0.10 & -0.46 & $.846(a)$ & 0.02 & 0.00 \\
\hline BP1 & 0.00 & -0.14 & 0.04 & -0.05 & 0.05 & 0.08 & 0.02 & $.896(a)$ & -0.21 \\
\hline BP2 & -0.05 & -0.08 & -0.12 & -0.07 & -0.01 & 0.04 & 0.00 & -0.21 & $.857(a)$ \\
\hline
\end{tabular}


Table 5.5: Factor Extraction

\begin{tabular}{|c|c|c|c|c|c|c|}
\hline \multirow[b]{2}{*}{ Component } & \multicolumn{3}{|c|}{ Initial Eigenvalues } & \multicolumn{3}{|c|}{$\begin{array}{c}\text { Extraction Sums of Squared } \\
\text { Loadings }\end{array}$} \\
\hline & Total & $\begin{array}{c}\% \text { of } \\
\text { Variance }\end{array}$ & $\begin{array}{c}\text { Cumulative } \\
\%\end{array}$ & Total & $\begin{array}{c}\% \text { of } \\
\text { Variance }\end{array}$ & $\begin{array}{c}\text { Cumulative } \\
\%\end{array}$ \\
\hline 1 & 9.392 & 25.383 & 25.383 & 9.392 & 25.383 & 25.383 \\
\hline 2 & 3.351 & 9.057 & 34.440 & 3.351 & 9.057 & 34.440 \\
\hline 3 & 2.191 & 5.923 & 40.362 & 2.191 & 5.923 & 40.362 \\
\hline 4 & 1.822 & 4.924 & 45.287 & 1.822 & 4.924 & 45.287 \\
\hline 5 & 1.623 & 4.388 & 49.674 & 1.623 & 4.388 & 49.674 \\
\hline 6 & 1.386 & 3.745 & 53.420 & 1.386 & 3.745 & 53.420 \\
\hline 7 & 1.264 & 3.417 & 56.837 & 1.264 & 3.417 & 56.837 \\
\hline 8 & 1.157 & 3.128 & 59.965 & 1.157 & 3.128 & 59.965 \\
\hline 9 & 1.075 & 2.904 & 62.869 & 1.075 & 2.904 & 62.869 \\
\hline 10 & 0.992 & 2.680 & 65.550 & & & \\
\hline 11 & 0.957 & 2.588 & 68.137 & & & \\
\hline 12 & 0.877 & 2.370 & 70.507 & & & \\
\hline 13 & 0.782 & 2.113 & 72.620 & & & \\
\hline 14 & 0.714 & 1.928 & 74.548 & & & \\
\hline 15 & 0.683 & 1.845 & 76.393 & & & \\
\hline 16 & 0.668 & 1.805 & 78.198 & & & \\
\hline 17 & 0.625 & 1.689 & 79.886 & & & \\
\hline 18 & 0.611 & 1.652 & 81.538 & & & \\
\hline 19 & 0.582 & 1.573 & 83.111 & & & \\
\hline 20 & 0.565 & 1.527 & 84.638 & & & \\
\hline 21 & 0.532 & 1.439 & 86.077 & & & \\
\hline 22 & 0.512 & 1.383 & 87.460 & & & \\
\hline 23 & 0.501 & 1.355 & 88.815 & & & \\
\hline 24 & 0.461 & 1.246 & 90.061 & & & \\
\hline 25 & 0.404 & 1.091 & 91.151 & & & \\
\hline 26 & 0.384 & 1.038 & 92.189 & & & \\
\hline 27 & 0.368 & 0.996 & 93.185 & & & \\
\hline 28 & 0.344 & 0.930 & 94.115 & & & \\
\hline 29 & 0.319 & 0.863 & 94.978 & & & \\
\hline 30 & 0.311 & 0.840 & 95.818 & & & \\
\hline 31 & 0.281 & 0.760 & 96.578 & & & \\
\hline 32 & 0.272 & 0.734 & 97.312 & & & \\
\hline 33 & 0.239 & 0.647 & 97.959 & & & \\
\hline 34 & 0.226 & 0.612 & 98.571 & & & \\
\hline 35 & 0.216 & 0.583 & 99.154 & & & \\
\hline 36 & 0.166 & 0.449 & 99.603 & & & \\
\hline 37 & 0.147 & 0.397 & 100.000 & & & \\
\hline
\end{tabular}

Extraction Method: Principal Component Analysis.

a. Choice of Upscale Ethnic Restaurant = Goer 
Table 5.6: VARIMAX Rotation Results (Goer)

\begin{tabular}{|c|c|c|c|c|c|c|c|c|c|}
\hline & \multicolumn{9}{|c|}{ Component } \\
\hline & 1 & 2 & 3 & 4 & 5 & 6 & 7 & 8 & 9 \\
\hline BA1 & 0.826 & & & & & & & & \\
\hline SB2 & 0.767 & & & & & & & & \\
\hline SB1 & 0.751 & & & & & & & & \\
\hline BA2 & 0.749 & & & & & & & & \\
\hline SB3 & 0.735 & & & & & & & & \\
\hline WT1 & 0.716 & & & & & & & & \\
\hline WT2 & 0.662 & & & & & & & & \\
\hline VM2 & 0.559 & & & & & & & & 0.536 \\
\hline HF2 & & 0.736 & & & & & & & \\
\hline HF1 & & 0.732 & & & & & & & \\
\hline MV2 & & 0.615 & & & & & & & \\
\hline MV1 & & 0.599 & & & & & & & \\
\hline AP1 & & 0.581 & & & & & & 0.401 & \\
\hline UF2 & & 0.548 & & & & & & & \\
\hline AP2 & & 0.478 & & & & & & & \\
\hline PE3 & & & 0.681 & & & & & & \\
\hline PE2 & & & 0.673 & & & & & & \\
\hline DE1 & & & 0.628 & & & & & & \\
\hline DE2 & & & 0.619 & & & & & & \\
\hline CL1 & & & 0.527 & & & & & & \\
\hline BP2 & & & & 0.699 & & & & & \\
\hline ST1 & & & & 0.698 & & & & & \\
\hline ST2 & & & & 0.583 & & & & & \\
\hline BP1 & & & & 0.554 & & & & & \\
\hline WM1 & & & & & 0.654 & & & & \\
\hline MC1 & & & & & 0.653 & & & & \\
\hline WM2 & & & & & 0.572 & & & & \\
\hline MC3 & & & & & 0.516 & & & & \\
\hline MC2 & & & & & 0.451 & & & & \\
\hline RF1 & & & & & & 0.902 & & & \\
\hline RF2 & & & & & & 0.895 & & & \\
\hline FF2 & & & & & & & 0.725 & & \\
\hline FF1 & & & & & & & 0.707 & & \\
\hline UF1 & & & & & & & -0.452 & & \\
\hline PE1 & & & & & & & & 0.710 & \\
\hline VM1 & 0.547 & & & & & & & & 0.596 \\
\hline CL2 & & & 0.476 & & & & & & 0.477 \\
\hline
\end{tabular}

Extraction Method: Principal Component Analysis.

Rotation Method: Varimax with Kaiser Normalization.
a. Rotation converged in 19 iterations.
b. Choice of Upscale Ethnic Restaurant $=$ Goer 
Table 5.7: OBLIMIN Rotation Results (Goer)

\begin{tabular}{|c|c|c|c|c|c|c|c|c|c|}
\hline & \multicolumn{9}{|c|}{ Component } \\
\hline & 1 & 2 & 3 & 4 & 5 & 6 & 7 & 8 & 9 \\
\hline BA1 & 0.865 & & & & & & & & \\
\hline BA2 & 0.785 & & & & & & & & \\
\hline SB2 & 0.767 & & & & & & & & \\
\hline SB3 & 0.736 & & & & & & & & \\
\hline SB1 & 0.723 & & & & & & & & \\
\hline WT1 & 0.707 & & & & & & & & \\
\hline WT2 & 0.618 & & & & & & & & \\
\hline VM2 & 0.583 & & & & & & & & \\
\hline VM1 & 0.560 & & & & & & & & \\
\hline ST1 & & 0.763 & & & & & & & \\
\hline BP2 & & 0.656 & & & & & & & \\
\hline ST2 & & 0.647 & & & & & & & \\
\hline FF2 & & & 0.785 & & & & & & \\
\hline UF1 & & & -0.577 & & & & & & \\
\hline FF1 & & & 0.570 & & & & & -0.410 & \\
\hline HF2 & & & & 0.790 & & & & & \\
\hline HF1 & & & & 0.750 & & & & & \\
\hline MV2 & & & & 0.611 & & & & & \\
\hline MV1 & & & & 0.605 & & & & & \\
\hline AP1 & & & & 0.551 & & & & & \\
\hline UF2 & & & & 0.508 & & & & & \\
\hline RF1 & & & & & -0.918 & & & & \\
\hline RF2 & & & & & -0.911 & & & & \\
\hline PE3 & & & & & & -0.664 & & & \\
\hline PE2 & & & & & & -0.608 & & & \\
\hline DE1 & & & & & & & & & \\
\hline CL1 & & & & & & & & & \\
\hline WM1 & & & & & & & 0.678 & & \\
\hline MC1 & & & & & & & 0.650 & & \\
\hline MC3 & & & & & & & 0.609 & & \\
\hline WM2 & & & & & & & 0.595 & & \\
\hline $\mathrm{MC} 2$ & & & & & & & & 0.593 & \\
\hline BP1 & & 0.401 & & & & & & 0.446 & \\
\hline PE1 & & & & & & & & & 0.624 \\
\hline CL2 & & & & & & & & & 0.607 \\
\hline AP2 & & & & 0.407 & & & & & 0.461 \\
\hline DE2 & & & & & & & & & 0.427 \\
\hline
\end{tabular}

Extraction Method: Principal Component Analysis.

Rotation Method: Oblimin with Kaiser Normalization.

a. Rotation converged in 37 iterations.

b. Choice of Upscale Ethnic Restaurant $=$ Goer 
Table 5.8: VARIMAX Rotation with Descriptions of Variables

\begin{tabular}{|c|c|c|c|c|c|c|c|c|c|c|}
\hline & & \multicolumn{9}{|c|}{ Component } \\
\hline & Item Name & 1 & 2 & 3 & 4 & 5 & 6 & 7 & 8 & 9 \\
\hline BA1 & Billing accuracy & 0.83 & & & & & & & & \\
\hline SB2 & Competency of staff & 0.77 & & & & & & & & \\
\hline SB1 & $\begin{array}{l}\text { Attentiveness of } \\
\text { staff }\end{array}$ & 0.75 & & & & & & & & \\
\hline BA2 & Billing accuracy & 0.75 & & & & & & & & \\
\hline SB3 & $\begin{array}{l}\text { Interpersonal skills } \\
\text { of staff }\end{array}$ & 0.74 & & & & & & & & \\
\hline WT1 & Service promptness & 0.72 & & & & & & & & \\
\hline WT2 & Seating order & 0.66 & & & & & & & & \\
\hline VM2 & Value for money & 0.56 & & & & & & & & 0.54 \\
\hline HF2 & Healthy food & & 0.74 & & & & & & & \\
\hline HF1 & Healthy food & & 0.73 & & & & & & & \\
\hline MV2 & Menu variety & & 0.61 & & & & & & & \\
\hline MV1 & Menu variety & & 0.60 & & & & & & & \\
\hline AP1 & Food presentation & & 0.58 & & & & & & 0.40 & \\
\hline UF2 & Unique food tastes & & 0.55 & & & & & & & \\
\hline AP2 & Food appearance & & 0.48 & & & & & & & \\
\hline PE3 & $\begin{array}{l}\text { Authentic } \\
\text { restaurant design }\end{array}$ & & & 0.68 & & & & & & \\
\hline PE2 & $\begin{array}{l}\text { Restaurant } \\
\text { atmosphere }\end{array}$ & & & 0.67 & & & & & & \\
\hline DE1 & $\begin{array}{l}\text { Different } \\
\text { experience }\end{array}$ & & & 0.63 & & & & & & \\
\hline DE2 & $\begin{array}{l}\text { Different } \\
\text { experience }\end{array}$ & & & 0.62 & & & & & & \\
\hline CL1 & Cultural learning & & & 0.53 & & & & & & \\
\hline BP2 & $\begin{array}{l}\text { Beverage } \\
\text { preference }\end{array}$ & & & & 0.70 & & & & & \\
\hline ST1 & Social status & & & & 0.70 & & & & & \\
\hline ST2 & Social status & & & & 0.58 & & & & & \\
\hline BP1 & $\begin{array}{l}\text { Beverage } \\
\text { preference }\end{array}$ & & & & 0.55 & & & & & \\
\hline WM1 & Word of mouth & & & & & 0.65 & & & & \\
\hline MC1 & Advertising & & & & & 0.65 & & & & \\
\hline WM2 & Word of mouth & & & & & 0.57 & & & & \\
\hline MC3 & Publicity & & & & & 0.52 & & & & \\
\hline MC2 & Sales promotion & & & & & 0.45 & & & & \\
\hline RF1 & Religious food & & & & & & 0.90 & & & \\
\hline RF2 & Religious food & & & & & & 0.90 & & & \\
\hline FF2 & Familiar food & & & & & & & 0.73 & & \\
\hline FF1 & Familiar food & & & & & & & 0.71 & & \\
\hline UF1 & Unique food tastes & & & & & & & -0.45 & & \\
\hline PE1 & Restaurant décor & & & & & & & & 0.71 & \\
\hline VM1 & Value for money & 0.55 & & & & & & & & 0.60 \\
\hline CL2 & Cultural learning & & & 0.48 & & & & & & 0.48 \\
\hline
\end{tabular}

Extraction Method: Principal Component Analysis.

Rotation Method: Varimax with Kaiser Normalization. 
Table 5.9: The Reliability Test for the Upscale Ethnic Restaurant Goer

\begin{tabular}{|c|c|c|}
\hline Constructs & Items & Cronbach's Alpha \\
\hline Service Quality & $\begin{array}{l}\text { 22. An upscale ethnic restaurant has attentive staff that } \\
\text { pay attention to my personal needs. } \\
\text { 20. Restaurant service staff at an upscale ethnic restaurant } \\
\text { are competent and have a good knowledge of the } \\
\text { menu. } \\
\text { 15. The service staff at an upscale ethnic restaurant are } \\
\text { polite and have good interpersonal skills. } \\
\text { 18. An upscale ethnic restaurant provides a prompt service } \\
\text { and does not keep me waiting for a long time. } \\
\text { 16. An upscale ethnic restaurant has a well allocated } \\
\text { seating order. } \\
\text { 21. An upscale ethnic restaurant charges me accurately. } \\
\text { 14. The invoices at an upscale ethnic restaurant are } \\
\text { accurate. }\end{array}$ & 0.901 \\
\hline Food Quality & $\begin{array}{l}\text { 7. The food served at an upscale ethnic restaurant is } \\
\text { made of authentic ingredients and has unique taste of } \\
\text { the cuisine. } \\
\text { 9. I go to an upscale ethnic restaurant because there is a } \\
\text { wide variety of food on the menu. } \\
\text { 3. An upscale ethnic restaurant offers several interesting } \\
\text { food choices on the menu. } \\
\text { 5. The food served at an upscale ethnic restaurant is } \\
\text { nicely presented. } \\
\text { 11. I like the appearance of the food at an upscale ethnic } \\
\text { restaurant. } \\
\text { 6. The food served at an upscale ethnic restaurant is } \\
\text { healthy. } \\
\text { 4. I like how an upscale ethnic restaurant offers nutritious } \\
\text { food choices. }\end{array}$ & 0.824 \\
\hline Dining Experience & $\begin{array}{l}\text { 19. The atmosphere in an upscale ethnic restaurant } \\
\text { influences my decision when selecting a restaurant. } \\
\text { 17. The authentic design of an upscale ethnic restaurant is } \\
\text { important. } \\
\text { 25. I go to an upscale ethnic restaurant because it offers } \\
\text { me a unique experience. } \\
\text { 35. I go to an upscale ethnic restaurant when I want to try } \\
\text { a different dining experience. } \\
\text { 28. Going to an upscale ethnic restaurant is a great way to } \\
\text { experience a different culture. } \\
\text { 34. The cultural experience I get from dining at an upscale } \\
\text { ethnic restaurant gives me the impression that I am in } \\
\text { that particular country. }\end{array}$ & 0.802 \\
\hline Social Status & $\begin{array}{l}\text { 31. I go to an upscale ethnic restaurant because it is } \\
\text { patronised by people of a similar class to mine. } \\
\text { 37. I choose an upscale ethnic restaurant whose image } \\
\text { reflects my self-image. } \\
\text { 29. An upscale ethnic restaurant offers a wide assortment } \\
\text { of beverages. } \\
\text { 24. I go to an upscale ethnic restaurant that sells the } \\
\text { beverages that I normally drink. }\end{array}$ & 0.711 \\
\hline
\end{tabular}




\begin{tabular}{|c|c|c|}
\hline Constructs & \begin{tabular}{|c|} 
Items \\
\end{tabular} & Cronbach's Alpha \\
\hline $\begin{array}{l}\text { Marketing } \\
\text { Communications }\end{array}$ & $\begin{array}{l}\text { 23. When my friends/family recommend an upscale ethnic } \\
\text { restaurant to me, I try it. } \\
\text { 30. I go to an upscale ethnic restaurant because my } \\
\text { friends/family like to go there. } \\
\text { 32. I choose an upscale ethnic restaurant that I have heard } \\
\text { about through advertising. } \\
\text { 26. I choose an upscale ethnic restaurant where I can get a } \\
\text { discount (e.g. from vouchers, loyalty card). } \\
\text { 36. Positive comments about an upscale ethnic restaurant } \\
\text { from publicity encourage me to dine at one. }\end{array}$ & 0.636 \\
\hline Religious Food & $\begin{array}{l}\text { 10. I go to an upscale ethnic restaurant that serves food } \\
\text { that is in accordance with my religious beliefs. } \\
\text { 2. An upscale ethnic restaurant offers food choices that } \\
\text { are prepared according to the requirements of my } \\
\text { religion. }\end{array}$ & 0.870 \\
\hline Familiar Food & $\begin{array}{l}\text { 8. An upscale ethnic restaurant serves food that I am } \\
\text { familiar with. } \\
\text { 12. The food served at an upscale ethnic restaurant is } \\
\text { similar to the food that I normally eat. }\end{array}$ & 0.556 \\
\hline Restaurant Décor & $\begin{array}{l}\text { 13. An upscale ethnic restaurant has visually appealing } \\
\text { décor. }\end{array}$ & N/A \\
\hline Value for Money & $\begin{array}{l}\text { 33. I get good value for the amount of money I pay when } \\
\text { dining at an upscale ethnic restaurant. } \\
\text { 27. I am satisfied with the price I pay for a meal at an } \\
\text { upscale ethnic restaurant. }\end{array}$ & 0.786 \\
\hline
\end{tabular}


Table 5.10: The Reliability Test for the Upscale Ethnic Restaurant Non-goer

\begin{tabular}{|c|c|c|}
\hline Constructs & Items & Cronbach's Alpha \\
\hline Service Quality & $\begin{array}{l}\text { 22. I assume an upscale ethnic restaurant does not have } \\
\text { attentive staff that pay attention to my personal needs. } \\
\text { 20. I believe the restaurant service staff at an upscale ethnic } \\
\text { restaurant are not competent and do not have a good } \\
\text { knowledge of the menu. } \\
\text { 15. I assume the service staff at an upscale ethnic restaurant } \\
\text { are not polite and do not have good interpersonal skills. } \\
\text { 18. I assume an upscale ethnic restaurant will not provide a } \\
\text { prompt service and will keep me waiting for a long time. } \\
\text { 16. I believe an upscale ethnic restaurant has a poorly } \\
\text { allocated seating order. } \\
\text { 21. I think an upscale ethnic restaurant will charge me } \\
\text { inaccurately. } \\
\text { 14. I assume the invoices at an upscale ethnic restaurant are } \\
\text { inaccurate. }\end{array}$ & 0.931 \\
\hline Food Quality & $\begin{array}{l}\text { 7. I assume an upscale ethnic restaurant does not offer food } \\
\text { with authentic tastes and ingredients. } \\
\text { 9. I assume an upscale ethnic restaurant has limited food } \\
\text { choices on the menu. } \\
\text { 3. I assume an upscale ethnic restaurant does not offer } \\
\text { several interesting food choices on the menu. } \\
\text { 5. I think the food at an upscale ethnic restaurant is not } \\
\text { well-presented. } \\
\text { 11. I assume the appearance of the food at an upscale ethnic } \\
\text { restaurant is not appealing. } \\
\text { 6. I believe the food served at an upscale ethnic restaurant } \\
\text { is unhealthy. } \\
\text { 4. I assume an upscale ethnic restaurant does not offer food } \\
\text { choices with high nutritional value. }\end{array}$ & 0.923 \\
\hline \begin{tabular}{|l|} 
Dining \\
Experience
\end{tabular} & $\begin{array}{l}\text { 19. The atmosphere in an upscale ethnic restaurant does not } \\
\text { influence my decision to dine at one. } \\
\text { 17. I assume I will not like the authentic design of an } \\
\text { upscale ethnic restaurant. } \\
\text { 25. I do not believe an upscale ethnic restaurant will offer } \\
\text { me a unique experience. } \\
\text { 35. I do not think dining at an upscale ethnic restaurant will } \\
\text { give me a different dining experience. } \\
\text { 28. I do not think I can experience a different culture by } \\
\text { going to an upscale ethnic restaurant. } \\
\text { 34. I believe an upscale ethnic restaurant will not give me } \\
\text { the cultural experience or the impression that I am in that } \\
\text { particular country. }\end{array}$ & 0.664 \\
\hline Social Status & $\begin{array}{l}\text { 31. I do not take social status into account when choosing a } \\
\text { restaurant. } \\
\text { 37. I do not think the image of an upscale ethnic restaurant } \\
\text { reflects my self-image. } \\
\text { 29. I assume an upscale ethnic restaurant does not offer a } \\
\text { wide assortment of beverages. } \\
\text { 24. I believe that an upscale ethnic restaurant does not sell } \\
\text { the beverages that I normally drink. }\end{array}$ & 0.446 \\
\hline
\end{tabular}




\begin{tabular}{|c|c|c|}
\hline Constructs & Items & Cronbach's Alpha \\
\hline $\begin{array}{l}\text { Marketing } \\
\text { Communications }\end{array}$ & $\begin{array}{l}\text { 23. My friends'/family's recommendation about an upscale } \\
\text { ethnic restaurant does not encourage me to try it. } \\
\text { 30. I do not choose an upscale ethnic restaurant on a basis } \\
\text { that my friends/family like to go there. } \\
\text { 32. An advertisement does not influence me to dine at an } \\
\text { upscale ethnic restaurant. } \\
\text { 26. A discount (e.g. from coupons/loyalty card) does not } \\
\text { influence me to dine at an upscale ethnic restaurant. } \\
\text { 36. Positive comments about an upscale ethnic restaurant } \\
\text { from publicity do not encourage me to dine at one. }\end{array}$ & 0.659 \\
\hline Religious Food & $\begin{array}{l}\text { 10. I believe the food served at an upscale ethnic restaurant } \\
\text { is not in accordance with my religious beliefs. } \\
\text { 2. I assume an upscale ethnic restaurant does not offer food } \\
\text { choices that are prepared according to the requirements } \\
\text { of my religion. }\end{array}$ & 0.865 \\
\hline Familiar Food & $\begin{array}{l}\text { 8. I am not familiar with the food at an upscale ethnic } \\
\text { restaurant. } \\
\text { 12. I think the food served at an upscale ethnic restaurant is } \\
\text { different from the food that I normally eat. }\end{array}$ & 0.088 \\
\hline $\begin{array}{l}\text { Restaurant } \\
\text { Décor }\end{array}$ & $\begin{array}{l}\text { 13. I assume an upscale ethnic restaurant does not have } \\
\text { visually appealing décor. }\end{array}$ & N/A \\
\hline Value for Money & $\begin{array}{l}\text { 33. I believe dining at an upscale ethnic restaurant will be } \\
\text { too expensive. } \\
\text { 27. I am unwilling to pay the price they charge for a meal at } \\
\text { an upscale ethnic restaurant. }\end{array}$ & 0.717 \\
\hline
\end{tabular}


Table 5.11: Pearson Correlation Matrix (Goer)

\begin{tabular}{|c|c|c|c|c|c|c|c|c|c|}
\hline & & $\begin{array}{l}\text { Service } \\
\text { Quality }\end{array}$ & $\begin{array}{c}\text { Food } \\
\text { Quality }\end{array}$ & $\begin{array}{c}\text { Dining } \\
\text { Experience }\end{array}$ & $\begin{array}{l}\text { Social } \\
\text { Status }\end{array}$ & $\begin{array}{c}\text { Marketing } \\
\text { Communications }\end{array}$ & $\begin{array}{l}\text { Religious } \\
\text { Food } \\
\end{array}$ & $\begin{array}{l}\text { Restaurant } \\
\text { Décor }\end{array}$ & $\begin{array}{c}\text { Value for } \\
\text { Money }\end{array}$ \\
\hline \multirow[t]{3}{*}{ Service Quality } & Pearson Correlation & 1 & $.555(* *)$ & $.407(* *)$ & $.235(* *)$ & $.283(* *)$ & $.121(*)$ & $.422(* *)$ & $.589(* *)$ \\
\hline & Sig. (2-tailed) & & 0.000 & 0.000 & 0.000 & 0.000 & 0.029 & 0.000 & 0.000 \\
\hline & $\mathrm{N}$ & 325 & 325 & 325 & 325 & 325 & 325 & 325 & 325 \\
\hline \multirow[t]{3}{*}{ Food Quality } & Pearson Correlation & $.555(* *)$ & 1 & $.450(* *)$ & $.251(* *)$ & $.328(* *)$ & $.164(* *)$ & $.408(* *)$ & $.420(* *)$ \\
\hline & Sig. (2-tailed) & 0.000 & & 0.000 & 0.000 & 0.000 & 0.003 & 0.000 & 0.000 \\
\hline & $\mathrm{N}$ & 325 & 325 & 325 & 325 & 325 & 325 & 325 & 325 \\
\hline Dining & Pearson Correlation & $.407(* *)$ & $.450(* *)$ & 1 & $.461(* *)$ & $.482(* *)$ & $.217(* *)$ & $.407(* *)$ & $.232(* *)$ \\
\hline \multirow[t]{2}{*}{ Experience } & Sig. (2-tailed) & 0.000 & 0.000 & & 0.000 & 0.000 & 0.000 & 0.000 & 0.000 \\
\hline & $\mathrm{N}$ & 325 & 325 & 325 & 325 & 325 & 325 & 325 & 325 \\
\hline \multirow[t]{3}{*}{ Social Status } & Pearson Correlation & $.235(* *)$ & $.251(* *)$ & $.461(* *)$ & 1 & $.413(* *)$ & $.276(* *)$ & $.247(* *)$ & $.143(* *)$ \\
\hline & Sig. (2-tailed) & 0.000 & 0.000 & 0.000 & & 0.000 & 0.000 & 0.000 & 0.010 \\
\hline & $\mathrm{N}$ & 325 & 325 & 325 & 325 & 325 & 325 & 325 & 325 \\
\hline Marketing & Pearson Correlation & $.283(* *)$ & $.328(* *)$ & $.482(* *)$ & $.413(* *)$ & 1 & $.139(*)$ & $.244(* *)$ & $.221(* *)$ \\
\hline \multirow[t]{2}{*}{ Communications } & Sig. (2-tailed) & 0.000 & 0.000 & 0.000 & 0.000 & & 0.012 & 0.000 & 0.000 \\
\hline & $\mathrm{N}$ & 325 & 325 & 325 & 325 & 325 & 325 & 325 & 325 \\
\hline \multirow[t]{3}{*}{ Religious Food } & Pearson Correlation & $.121(*)$ & $.164(* *)$ & $.217(* *)$ & $.276(* *)$ & $.139(*)$ & 1 & $.201(* *)$ & 0.003 \\
\hline & Sig. (2-tailed) & 0.029 & 0.003 & 0.000 & 0.000 & 0.012 & & 0.000 & 0.951 \\
\hline & $\mathrm{N}$ & 325 & 325 & 325 & 325 & 325 & 325 & 325 & 325 \\
\hline Restaurant & Pearson Correlation & $.422(* *)$ & $.408(* *)$ & $.407(* *)$ & $.247(* *)$ & $.244(* *)$ & $.201(* *)$ & 1 & $.162(* *)$ \\
\hline \multirow[t]{2}{*}{ Décor } & Sig. (2-tailed) & 0.000 & 0.000 & 0.000 & 0.000 & 0.000 & 0.000 & & 0.003 \\
\hline & $\mathrm{N}$ & 325 & 325 & 325 & 325 & 325 & 325 & 325 & 325 \\
\hline Value for & Pearson Correlation & $.589(* *)$ & $.420(* *)$ & $.232(* *)$ & $.143(* *)$ & $.221(* *)$ & 0.003 & $.162(* *)$ & \\
\hline \multirow[t]{2}{*}{ Money } & Sig. (2-tailed) & 0.000 & 0.000 & 0.000 & 0.010 & 0.000 & 0.951 & 0.003 & \\
\hline & $\mathrm{N}$ & 325 & 325 & 325 & 325 & 325 & 325 & 325 & 325 \\
\hline
\end{tabular}

** Correlation is significant at the 0.01 level (2-tailed)

* Correlation is significant at the 0.05 level (2-tailed) 
Table 5.12: Chi-square Tests for Demographic Characteristics and a Choice of an Upscale Ethnic Restaurant

\begin{tabular}{|l|c|l|c|l|}
\hline $\begin{array}{c}\text { Demographic } \\
\text { Characteristics }\end{array}$ & $\begin{array}{c}\text { No. of } \\
\text { Original } \\
\text { Groups }\end{array}$ & $\begin{array}{c}\text { Chi-square } \\
\text { Tests }\end{array}$ & $\begin{array}{c}\text { No. of } \\
\text { New } \\
\text { Groups }\end{array}$ & $\begin{array}{c}\text { Chi-square } \\
\text { Tests }\end{array}$ \\
\hline Gender & 2 & 0.648 & 2 & 0.648 \\
\hline Age & 6 & $\mathbf{0 . 0 0 2} *$ & 3 & $\mathbf{0 . 0 1 4}$ \\
\hline Ethnicity & 8 & 0.156 & 2 & 0.507 \\
\hline Qualification & 7 & 0.382 & 3 & 0.076 \\
\hline Occupation & 12 & $\mathbf{0 . 0 4 7}$ & 3 & $\mathbf{0 . 0 0 0 *}$ \\
\hline Household Composition & 9 & 0.121 & 3 & $\mathbf{0 . 0 4 0 *}$ \\
\hline Household Income & 9 & $\mathbf{0 . 0 0 1} *$ & 3 & $\mathbf{0 . 0 0 0 *}$ \\
\hline
\end{tabular}

* Significant at .05 level 
Table 5.13: Cross-tabulation of Gender

\begin{tabular}{|c|c|c|c|c|c|}
\hline & \multicolumn{2}{|c|}{ Gender } & \multirow[b]{2}{*}{ Total } \\
\hline & & & Male & Female & \\
\hline \multirow{10}{*}{$\begin{array}{l}\text { Choice of an } \\
\text { Upscale } \\
\text { Ethnic } \\
\text { Restaurant }\end{array}$} & \multirow[t]{5}{*}{ Goer } & Count & 151 & 174 & 325 \\
\hline & & Expected Count & 152.8 & 172.2 & 325.0 \\
\hline & & $\%$ within Choice of an & $46.5 \%$ & $53.5 \%$ & $100.0 \%$ \\
\hline & & $\begin{array}{l}\text { Upscale Ethnic Restaurant } \\
\% \text { within Gender }\end{array}$ & $79.9 \%$ & $81.7 \%$ & $80.8 \%$ \\
\hline & & $\%$ of Total & $37.6 \%$ & $43.3 \%$ & $80.8 \%$ \\
\hline & \multirow[t]{5}{*}{ Non-goer } & Count & 38 & 39 & 77 \\
\hline & & Expected Count & 36.2 & 40.8 & 77.0 \\
\hline & & $\begin{array}{l}\% \text { within Choice of an } \\
\text { Unscale Ethnic Restaurant }\end{array}$ & $49.4 \%$ & $50.6 \%$ & $100.0 \%$ \\
\hline & & $\%$ within Gender & $20.1 \%$ & $18.3 \%$ & $19.2 \%$ \\
\hline & & $\%$ of Total & $9.5 \%$ & $9.7 \%$ & $19.2 \%$ \\
\hline \multirow{5}{*}{\multicolumn{2}{|c|}{ Total }} & Count & 189 & 213 & 402 \\
\hline & & Expected Count & 189.0 & 213.0 & 402.0 \\
\hline & & $\begin{array}{l}\% \text { within Choice of an } \\
\text { Upscale Ethnic Restaurant }\end{array}$ & $47.0 \%$ & $53.0 \%$ & $100.0 \%$ \\
\hline & & $\%$ within Gender & $100.0 \%$ & $100.0 \%$ & $100.0 \%$ \\
\hline & & $\%$ of Total & $47.0 \%$ & $53.0 \%$ & $100.0 \%$ \\
\hline
\end{tabular}


Table 5.14: Cross-tabulation of Age

\begin{tabular}{|c|c|c|c|c|c|c|}
\hline & & & & Age & & \\
\hline & & & $\begin{array}{l}\text { Young- } \\
\text { age }\end{array}$ & $\begin{array}{l}\text { Middle- } \\
\text { age }\end{array}$ & $\begin{array}{l}\text { Old- } \\
\text { age }\end{array}$ & Total \\
\hline Choice of an & Goer & Count & 40 & 146 & 139 & 325 \\
\hline Upscale & & Expected Count & 40.4 & 135.0 & 149.6 & 325.0 \\
\hline $\begin{array}{l}\text { Ethnic } \\
\text { Restaurant }\end{array}$ & & $\begin{array}{l}\% \text { within Choice of } \\
\text { an Upscale Ethnic }\end{array}$ & $12.3 \%$ & $44.9 \%$ & $42.8 \%$ & $100.0 \%$ \\
\hline & & $\begin{array}{l}\text { Restaurant } \\
\text { within Age }\end{array}$ & $800 \%$ & $874 \%$ & $751 \%$ & $808 \%$ \\
\hline & & $\%$ of Total & $10.0 \%$ & $36.3 \%$ & $34.6 \%$ & $80.8 \%$ \\
\hline & Non-goer & Count & 10 & 21 & 46 & 77 \\
\hline & & Expected Count & 9.6 & 32.0 & 35.4 & 77.0 \\
\hline & & $\begin{array}{l}\text { an Upscale Ethnic } \\
\text { Restaurant }\end{array}$ & $13.0 \%$ & $27.3 \%$ & $59.7 \%$ & $100.0 \%$ \\
\hline & & $\%$ within Age & $20.0 \%$ & $12.6 \%$ & $24.9 \%$ & $19.2 \%$ \\
\hline & & $\%$ of Total & $2.5 \%$ & $5.2 \%$ & $11.4 \%$ & $19.2 \%$ \\
\hline Total & & Count & 50 & 167 & 185 & 402 \\
\hline & & Expected Count & 50.0 & 167.0 & 185.0 & 402.0 \\
\hline & & $\begin{array}{l}\text { \% within Choice of } \\
\text { an Upscale Ethnic }\end{array}$ & $12.4 \%$ & $41.5 \%$ & $46.0 \%$ & $100.0 \%$ \\
\hline & & $\%$ within Age & $100.0 \%$ & $100.0 \%$ & $100.0 \%$ & $100.0 \%$ \\
\hline & & $\%$ of Total & $12.4 \%$ & $41.5 \%$ & $46.0 \%$ & $100.0 \%$ \\
\hline
\end{tabular}


Table 5.15: Cross-tabulation of Ethnicity

\begin{tabular}{|c|c|c|c|c|c|}
\hline & & & Ethn & & \\
\hline & & & $\begin{array}{c}\text { NZ } \\
\text { European }\end{array}$ & Others & Total \\
\hline Choice of an & Goer & Count & 268 & 57 & 325 \\
\hline Upscale & & Expected Count & 266.0 & 59.0 & 325.0 \\
\hline $\begin{array}{l}\text { Ethnic } \\
\text { Restaurant }\end{array}$ & & $\%$ within Choice of an & $82.5 \%$ & $17.5 \%$ & $100.0 \%$ \\
\hline & & $\%$ within Ethnicity & $81.5 \%$ & $78.1 \%$ & $80.8 \%$ \\
\hline & & $\%$ of Total & $66.7 \%$ & $14.2 \%$ & $80.8 \%$ \\
\hline & Non-goer & Count & 61 & 16 & 77 \\
\hline & & Expected Count & 63.0 & 14.0 & 77.0 \\
\hline & & $\begin{array}{l}\% \text { within Choice of an } \\
\text { Upscale Ethnic Restaurant }\end{array}$ & $79.2 \%$ & $20.8 \%$ & $100.0 \%$ \\
\hline & & $\%$ within Ethnicity & $18.5 \%$ & $21.9 \%$ & $19.2 \%$ \\
\hline & & $\%$ of Total & $15.2 \%$ & $4.0 \%$ & $19.2 \%$ \\
\hline Total & & Count & 329 & 73 & 402 \\
\hline & & Expected Count & 329.0 & 73.0 & 402.0 \\
\hline & & $\begin{array}{l}\% \text { within Choice of an } \\
\text { Upscale Ethnic Restaurant }\end{array}$ & $81.8 \%$ & $18.2 \%$ & $100.0 \%$ \\
\hline & & $\%$ within Ethnicity & $100.0 \%$ & $100.0 \%$ & $100.0 \%$ \\
\hline & & $\%$ of Total & $81.8 \%$ & $18.2 \%$ & $100.0 \%$ \\
\hline
\end{tabular}


Table 5.16: Cross-tabulation of Qualification

\begin{tabular}{|c|c|c|c|c|c|c|}
\hline & & & & ualificatio & & \\
\hline & & & $\begin{array}{l}\text { Low- } \\
\text { level }\end{array}$ & $\begin{array}{c}\text { Medium- } \\
\text { level }\end{array}$ & $\begin{array}{l}\text { High- } \\
\text { level }\end{array}$ & Total \\
\hline Choice of an & Goer & Count & 97 & 110 & 113 & 320 \\
\hline Upscale & & Expected Count & 104.8 & 108.8 & 106.4 & 320.0 \\
\hline $\begin{array}{l}\text { Ethnic } \\
\text { Restaurant }\end{array}$ & & $\begin{array}{l}\% \text { within Choice of an } \\
\text { Unscale Ethnic }\end{array}$ & $30.3 \%$ & $34.4 \%$ & $35.3 \%$ & $100.0 \%$ \\
\hline & & Restaurant & & & & \\
\hline & & $\%$ within Qualification & $74.6 \%$ & $81.5 \%$ & $85.6 \%$ & $80.6 \%$ \\
\hline & & $\%$ of Total & $24.4 \%$ & $27.7 \%$ & $28.5 \%$ & $80.6 \%$ \\
\hline & Non-goer & Count & 33 & 25 & 19 & 77 \\
\hline & & Expected Count & 25.2 & 26.2 & 25.6 & 77.0 \\
\hline & & $\begin{array}{l}\text { Upscale Ethnic } \\
\text { Restaurant }\end{array}$ & $42.9 \%$ & $32.5 \%$ & $24.7 \%$ & $100.0 \%$ \\
\hline & & $\%$ within Qualification & $25.4 \%$ & $18.5 \%$ & $14.4 \%$ & $19.4 \%$ \\
\hline & & $\%$ of Total & $8.3 \%$ & $6.3 \%$ & $4.8 \%$ & $19.4 \%$ \\
\hline Total & & Count & 130 & 135 & 132 & 397 \\
\hline & & Expected Count & 130.0 & 135.0 & 132.0 & 397.0 \\
\hline & & $\begin{array}{l}\text { \% within Choice of an } \\
\text { Upscale Ethnic }\end{array}$ & $32.7 \%$ & $34.0 \%$ & $33.2 \%$ & $100.0 \%$ \\
\hline & & $\%$ within Qualification & $100.0 \%$ & $100.0 \%$ & $100.0 \%$ & $100.0 \%$ \\
\hline & & $\%$ of Total & $32.7 \%$ & $34.0 \%$ & $33.2 \%$ & $100.0 \%$ \\
\hline
\end{tabular}


Table 5.17: Cross-tabulation of Occupation

\begin{tabular}{|c|c|c|c|c|c|c|}
\hline & & & & ccupation & & \\
\hline & & & $\begin{array}{l}\text { White- } \\
\text { collar }\end{array}$ & Retired & Others & Total \\
\hline Choice of an & Goer & Count & 236 & 52 & 35 & 323 \\
\hline Upscale & & Expected Count & 222.9 & 63.8 & 36.3 & 323.0 \\
\hline $\begin{array}{l}\text { Ethnic } \\
\text { Restaurant }\end{array}$ & & $\begin{array}{l}\% \text { within Choice of } \\
\text { an Upscale Ethnic }\end{array}$ & $73.1 \%$ & $16.1 \%$ & $10.8 \%$ & $100.0 \%$ \\
\hline & & Restaurant & & & & \\
\hline & & $\%$ within Occupation & $85.5 \%$ & $65.8 \%$ & $77.8 \%$ & $80.8 \%$ \\
\hline & & $\%$ of Total & $59.0 \%$ & $13.0 \%$ & $8.8 \%$ & $80.8 \%$ \\
\hline & Non-goer & Count & 40 & 27 & 10 & 77 \\
\hline & & Expected Count & 53.1 & 15.2 & 8.7 & 77.0 \\
\hline & & $\begin{array}{l}\text { an Upscale Ethnic } \\
\text { Restaurant }\end{array}$ & $51.9 \%$ & $35.1 \%$ & $13.0 \%$ & $100.0 \%$ \\
\hline & & $\%$ within Occupation & $14.5 \%$ & $34.2 \%$ & $22.2 \%$ & $19.3 \%$ \\
\hline & & $\%$ of Total & $10.0 \%$ & $6.8 \%$ & $2.5 \%$ & $19.3 \%$ \\
\hline Total & & Count & 276 & 79 & 45 & 400 \\
\hline & & Expected Count & 276.0 & 79.0 & 45.0 & 400.0 \\
\hline & & $\begin{array}{l}\% \text { within Choice of } \\
\text { an Upscale Ethnic } \\
\text { Restaurant }\end{array}$ & $69.0 \%$ & $19.8 \%$ & $11.3 \%$ & $100.0 \%$ \\
\hline & & $\%$ within Occupation & $100.0 \%$ & $100.0 \%$ & $100.0 \%$ & $100.0 \%$ \\
\hline & & $\%$ of Total & $69.0 \%$ & $19.8 \%$ & $11.3 \%$ & $100.0 \%$ \\
\hline
\end{tabular}


Table 5.18: Cross-tabulation of Household Composition

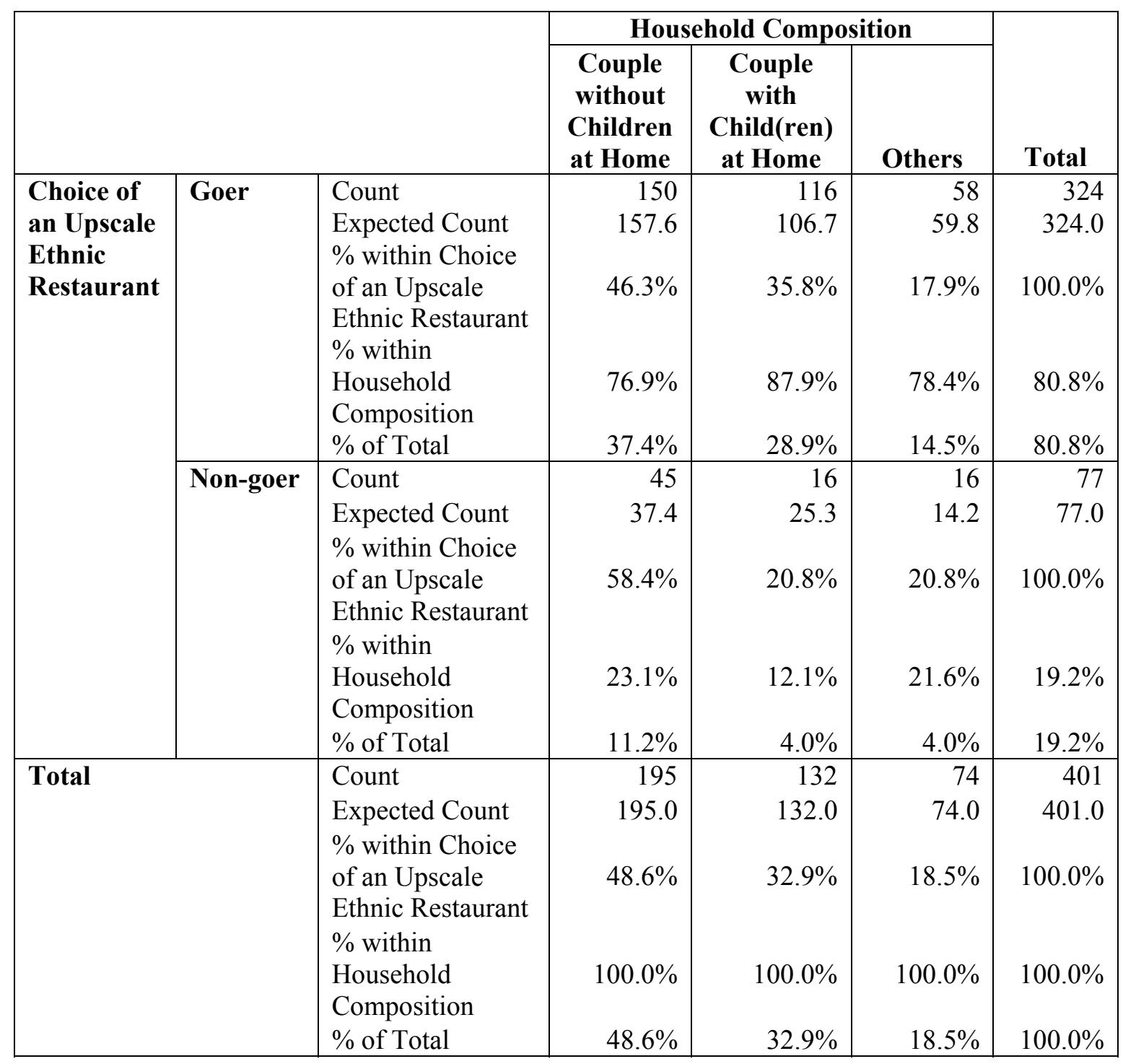


Table 5.19: Cross-tabulation of Household Income

\begin{tabular}{|c|c|c|c|c|c|c|}
\hline & & & Ho & sehold In & me & \\
\hline & & & $\begin{array}{c}\text { Low } \\
\text { Income }\end{array}$ & $\begin{array}{l}\text { Middle } \\
\text { Income }\end{array}$ & $\begin{array}{l}\text { High } \\
\text { Income }\end{array}$ & Total \\
\hline Choice of an & Goer & Count & 80 & 129 & 107 & 316 \\
\hline Upscale & & Expected Count & 96.1 & 123.8 & 96.1 & 316.0 \\
\hline $\begin{array}{l}\text { Ethnic } \\
\text { Restaurant }\end{array}$ & & $\begin{array}{l}\% \text { within Choice of } \\
\text { an Upscale Ethnic } \\
\text { Restaurant }\end{array}$ & $25.3 \%$ & $40.8 \%$ & $33.9 \%$ & $100.0 \%$ \\
\hline & & $\begin{array}{l}\% \text { within Household } \\
\text { Income }\end{array}$ & $67.8 \%$ & $84.9 \%$ & $90.7 \%$ & $81.4 \%$ \\
\hline & & $\%$ of Total & $20.6 \%$ & $33.2 \%$ & $27.6 \%$ & $81.4 \%$ \\
\hline & Non-goer & Count & 38 & 23 & 11 & 72 \\
\hline & & Expected Count & 21.9 & 28.2 & 21.9 & 72.0 \\
\hline & & $\begin{array}{l}\text { an Upscale Ethnic } \\
\text { Restaurant }\end{array}$ & $52.8 \%$ & $31.9 \%$ & $15.3 \%$ & $100.0 \%$ \\
\hline & & $\begin{array}{l}\% \text { within Household } \\
\text { Income }\end{array}$ & $32.2 \%$ & $15.1 \%$ & $9.3 \%$ & $18.6 \%$ \\
\hline & & $\%$ of Total & $9.8 \%$ & $5.9 \%$ & $2.8 \%$ & $18.6 \%$ \\
\hline Total & & Count & 118 & 152 & 118 & 388 \\
\hline & & Expected Count & 118.0 & 152.0 & 118.0 & 388.0 \\
\hline & & $\begin{array}{l}\text { an Upscale Ethnic } \\
\text { Restaurant }\end{array}$ & $30.4 \%$ & $39.2 \%$ & $30.4 \%$ & $100.0 \%$ \\
\hline & & $\begin{array}{l}\text { \% within Household } \\
\text { Income }\end{array}$ & $100.0 \%$ & $100.0 \%$ & $100.0 \%$ & $100.0 \%$ \\
\hline & & $\%$ of Total & $30.4 \%$ & $39.2 \%$ & $30.4 \%$ & $100.0 \%$ \\
\hline
\end{tabular}


Table 5.24: T-tests Results Relating to Gender

\begin{tabular}{|l|l|r|r|r|c|}
\hline \multicolumn{1}{|c|}{ Factor } & \multicolumn{1}{|c|}{ Gender } & $\begin{array}{c}\text { No. of } \\
\text { Respondents }\end{array}$ & Mean & t & Sig. \\
\hline Marketing & Male & 189 & 3.653 & 3.142 & $0.002 *$ \\
Communications & Female & 213 & 3.332 & & \\
\hline
\end{tabular}

* Significant at $\mathbf{. 0 5}$ level

Table 5.25: T-tests Results Relating to Ethnicity

\begin{tabular}{|l|l|r|r|r|r|}
\hline \multicolumn{1}{|c|}{ Factors } & \multicolumn{1}{c|}{ Ethnicity } & $\begin{array}{c}\text { No. of } \\
\text { Respondents }\end{array}$ & Mean & t & Sig. \\
\hline Dining & NZ European & 329 & 3.295 & 1.694 & $0.091^{* *}$ \\
Experience & Others & 73 & 3.018 & & \\
\hline Religious Food & NZ European & 329 & 6.040 & 3.442 & $0.001^{*}$ \\
& Others & 73 & 5.390 & & \\
\hline Restaurant & NZ European & 329 & 4.137 & 3.415 & $0.001^{*}$ \\
Décor & Others & 73 & 3.452 & & \\
\hline
\end{tabular}

* Significant at $\mathbf{. 0 5}$ level

** Significant at .10 level 
Table 5.26: ANOVA (F-tests) Results Relating to Age

\begin{tabular}{|l|l|r|r|r|c|}
\hline \multicolumn{1}{|c|}{ Factors } & \multicolumn{1}{c|}{ Age } & $\begin{array}{c}\text { No. of } \\
\text { Respondents }\end{array}$ & Mean & F & Sig. \\
\hline Service Quality & Young-age & 50 & 3.071 & 2.364 & $0.095^{* *}$ \\
& Middle-age & 167 & 3.281 & & \\
& Old-age & 185 & 3.537 & & \\
\hline Marketing & Young-age & 50 & 3.048 & 7.455 & $0.001^{*}$ \\
Communications & Middle-age & 167 & 3.423 & & \\
& Old-age & 185 & 3.654 & & \\
\hline Religious Food & Young-age & 50 & 5.490 & 2.895 & $0.056^{* *}$ \\
& Middle-age & 167 & 6.060 & & \\
& Old-age & 185 & 5.914 & & \\
\hline Restaurant Décor & Young-age & 50 & 3.300 & 7.102 & $0.001^{*}$ \\
& Middle-age & 167 & 3.988 & & \\
& Old-age & 185 & 4.227 & & \\
\hline
\end{tabular}

* Significant at .05 level

** Significant at .10 level 
Table 5.27: ANOVA (F-tests) Results Relating to Qualification

\begin{tabular}{|l|l|r|r|r|c|}
\hline \multicolumn{1}{|c|}{ Factors } & Qualification & $\begin{array}{c}\text { No. of } \\
\text { Respondents }\end{array}$ & Mean & F & Sig. \\
\hline Dining & Low-level & 130 & 3.469 & 2.934 & $0.054^{* *}$ \\
Experience & Medium-level & 135 & 3.111 & & \\
& High-level & 132 & 3.191 & & \\
\hline Social Status & Low-level & 130 & 4.417 & 2.930 & $0.055^{* *}$ \\
& Medium-level & 135 & 4.231 & & \\
& High-level & 132 & 4.551 & & \\
\hline
\end{tabular}

** Significant at .10 level 
Table 5.28: ANOVA (F-tests) Results Relating to Occupation

\begin{tabular}{|l|l|r|r|r|r|}
\hline \multicolumn{1}{|c|}{ Factors } & Occupation & $\begin{array}{c}\text { No. of } \\
\text { Respondents }\end{array}$ & Mean & F & Sig. \\
\hline Service Quality & White-collar & 276 & 3.303 & 3.623 & $0.028^{*}$ \\
& Retired & 79 & 3.769 & & \\
& Others & 45 & 3.117 & & \\
\hline Food Quality & White-collar & 276 & 3.134 & 5.049 & $0.007^{*}$ \\
& Retired & 79 & 3.727 & & \\
& Others & 45 & 3.092 & & \\
\hline Dining & White-collar & 276 & 3.168 & 6.648 & $0.001^{*}$ \\
Experience & Retired & 79 & 3.690 & & \\
& Others & 45 & 2.970 & & \\
\hline Marketing & White-collar & 276 & 3.397 & 10.485 & $0.000^{*}$ \\
Communications & Retired & 79 & 3.939 & & \\
& Others & 45 & 3.227 & & \\
\hline Religious Food & White-collar & 276 & 5.957 & 2.864 & $0.058^{* *}$ \\
& Retired & 79 & 6.108 & & \\
& Others & 45 & 5.467 & & \\
\hline Restaurant & White-collar & 276 & 4.043 & 7.739 & $0.001^{*}$ \\
Décor & Retired & 79 & 4.367 & & \\
& Others & 45 & 3.244 & & \\
\hline
\end{tabular}

* Significant at .05 level

** Significant at .10 level 
Table 5.29: ANOVA (F-tests) Results Relating to Household Composition

\begin{tabular}{|c|c|c|c|c|c|}
\hline Factors & $\begin{array}{l}\text { Household } \\
\text { Composition }\end{array}$ & $\begin{array}{c}\text { No. of } \\
\text { Respondents }\end{array}$ & Mean & $\mathbf{F}$ & Sig. \\
\hline $\begin{array}{l}\text { Dining } \\
\text { Experience }\end{array}$ & $\begin{array}{l}\text { Couple without } \\
\text { Children at Home } \\
\text { Couple with } \\
\text { Child(ren) at Home } \\
\text { Others }\end{array}$ & $\begin{array}{r}195 \\
\\
132 \\
74\end{array}$ & $\begin{array}{l}3.397 \\
3.100 \\
3.097\end{array}$ & 2.814 & $0.061 * *$ \\
\hline $\begin{array}{l}\text { Marketing } \\
\text { Communications }\end{array}$ & $\begin{array}{l}\text { Couple without } \\
\text { Children at Home } \\
\text { Couple with } \\
\text { Child(ren) at Home } \\
\text { Others }\end{array}$ & $\begin{array}{r}195 \\
\\
132 \\
74\end{array}$ & $\begin{array}{l}3.658 \\
3.371 \\
3.211\end{array}$ & 6.278 & $0.002 *$ \\
\hline
\end{tabular}

* Significant at .05 level

$* *$ Significant at .10 level 
Table 5.30: ANOVA (F-tests) Results Relating to Household Income

\begin{tabular}{|l|l|r|r|r|l|}
\hline \multicolumn{1}{|c|}{ Factors } & \multicolumn{1}{|c|}{$\begin{array}{c}\text { Household } \\
\text { Income }\end{array}$} & $\begin{array}{c}\text { No. of } \\
\text { Respondents }\end{array}$ & Mean & F & Sig. \\
\hline Service Quality & Low Income & 118 & 3.738 & 5.163 & $0.006^{*}$ \\
& Middle Income & 152 & 3.225 & & \\
& High Income & 118 & 3.178 & & \\
\hline Food Quality & Low Income & 118 & 3.616 & 5.645 & $0.004^{*}$ \\
& Middle Income & 152 & 3.100 & & \\
& High Income & 118 & 3.019 & & \\
\hline
\end{tabular}

* Significant at .05 level 
Table 5.31: The Scheffe Output for Age

\begin{tabular}{|l|l|l|c|c|c|}
\hline & & & $\begin{array}{c}\text { Marketing } \\
\text { Communications }\end{array}$ & $\begin{array}{c}\text { Religious } \\
\text { Food }\end{array}$ & $\begin{array}{c}\text { Restaurant } \\
\text { Décor }\end{array}$ \\
\hline Scheffe & (I) Age & (J) Age & Sig. & Sig. & Sig. \\
& Young-age & Middle-age & $0.075^{* *}$ & $0.057^{* *}$ & $0.023^{*}$ \\
& & $0.001^{*}$ & 0.197 & $0.001^{*}$ \\
& Old-age & $0.075^{* *}$ & $0.057^{* *}$ & $0.023^{*}$ \\
& Middle-age & Young-age & 0.106 & 0.648 & 0.352 \\
& & Old-age & $0.001^{*}$ & 0.197 & $0.001^{*}$ \\
& Old-age & Young-age & 0.106 & 0.648 & 0.352 \\
\hline
\end{tabular}

* Significant at $\mathbf{0 5}$ level

** Significant at .10 level 
Table 5.32: The Scheffe Output for Qualification

\begin{tabular}{|l|l|l|c|c|}
\hline & & & $\begin{array}{c}\text { Dining } \\
\text { Experience }\end{array}$ & $\begin{array}{c}\text { Social } \\
\text { Status }\end{array}$ \\
\hline Scheffe & (I) Qualification & (J) Qualification & Sig. & Sig. \\
& Low-level & Medium-level & $0.070^{* *}$ & 0.379 \\
& & High-level & 0.203 & 0.608 \\
& Medium-level & Low-level & $0.070^{* *}$ & 0.379 \\
& & High-level & 0.875 & $0.056^{* *}$ \\
& High-level & Low-level & 0.203 & 0.608 \\
& & Medium-level & 0.875 & $0.056^{* *}$ \\
\hline
\end{tabular}

** Significant at .10 level 
Table 5.33: The Scheffe Output for Occupation

\begin{tabular}{|l|l|l|c|c|c|}
\hline & & & $\begin{array}{c}\text { Service } \\
\text { Quality }\end{array}$ & $\begin{array}{c}\text { Food } \\
\text { Quality }\end{array}$ & $\begin{array}{c}\text { Dining } \\
\text { Experience }\end{array}$ \\
\hline Scheffe & (I) Occupation & (J) Occupation & Sig. & Sig. & Sig. \\
& White-collar & Retired & $0.056^{* *}$ & $0.009^{*}$ & $0.005^{*}$ \\
& & 0.749 & 0.985 & 0.614 \\
& Others & $0.056^{* *}$ & $0.009^{*}$ & $0.005^{*}$ \\
& Retired & White-collar & $0.072^{* *}$ & $0.079^{* *}$ & $0.009^{*}$ \\
& Others & 0.749 & 0.985 & 0.614 \\
& Others & White-collar & $0.072^{* *}$ & $0.079 * *$ & $0.009^{*}$ \\
\hline
\end{tabular}

* Significant at $\mathbf{0 5}$ level

** Significant at .10 level

Table 5.33: The Scheffe Output for Occupation (Continued)

\begin{tabular}{|l|l|l|c|c|c|}
\hline & & & $\begin{array}{c}\text { Marketing } \\
\text { Communications }\end{array}$ & $\begin{array}{c}\text { Religious } \\
\text { Food }\end{array}$ & $\begin{array}{c}\text { Restaurant } \\
\text { Décor }\end{array}$ \\
\hline Scheffe & (I) Occupation & (J) Occupation & Sig. & Sig. & Sig. \\
& White-collar & Retired & $0.000^{*}$ & 0.723 & 0.259 \\
& & Others & 0.578 & 0.117 & $0.006^{*}$ \\
& Retired & White-collar & $0.000^{*}$ & 0.723 & 0.259 \\
& Others & $0.001^{*}$ & $0.066^{* *}$ & $0.001^{*}$ \\
& Others & White-collar & 0.578 & 0.117 & $0.006^{*}$ \\
& & Retired & $0.001^{*}$ & $0.066^{* *}$ & $0.001^{*}$ \\
\hline
\end{tabular}

* Significant at .05 level

** Significant at .10 level 
Table 5.34: The Scheffe Output for Household Composition

\begin{tabular}{|c|c|c|c|}
\hline & & & $\begin{array}{c}\text { Marketing } \\
\text { Communications }\end{array}$ \\
\hline Scheffe & $\begin{array}{l}\text { (I) Household } \\
\text { Composition } \\
\text { Couple without } \\
\text { Children at Home } \\
\text { Couple with } \\
\text { Child(ren) at Home } \\
\text { Others }\end{array}$ & $\begin{array}{l}\quad \text { (J) Household } \\
\quad \text { Composition } \\
\text { Couple with } \\
\text { Child(ren) at Home } \\
\text { Others } \\
\text { Couple without } \\
\text { Children at Home } \\
\text { Others } \\
\text { Couple without } \\
\text { Children at Home } \\
\text { Couple with } \\
\text { Child(ren) at Home }\end{array}$ & $\begin{array}{l}\text { Sig. } \\
0.046^{*} \\
0.006^{*} \\
0.046^{*} \\
0.559 \\
0.006^{*} \\
0.559\end{array}$ \\
\hline
\end{tabular}

* Significant at .05 level 
Table 5.35: The Scheffe Output for Household Income

\begin{tabular}{|l|l|l|c|c|}
\hline & & & $\begin{array}{c}\text { Service } \\
\text { Quality }\end{array}$ & $\begin{array}{c}\text { Food } \\
\text { Quality }\end{array}$ \\
\hline Scheffe & (I) Household & (I) Household & & Income \\
& Income & Sig. & Sig. \\
& Low Income & Middle Income & $0.022^{*}$ & $0.020^{*}$ \\
& & High Income & $0.018^{*}$ & $0.010^{*}$ \\
& Middle Income & Low Income & $0.022^{*}$ & $0.020^{*}$ \\
& & High Income & 0.969 & 0.909 \\
& \multirow{2}{*}{ High Income } & Low Income & $0.018^{*}$ & $0.010^{*}$ \\
& & Middle Income & 0.969 & 0.909 \\
\hline
\end{tabular}

* Significant at .05 level 


\section{APPENDICES}

\section{Appendix A: Cover Letter}

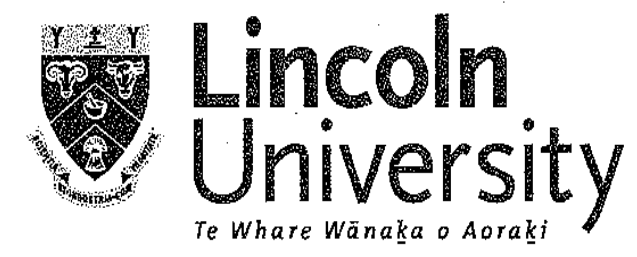

Commerce Division

PO Box 84, Lincoln University, Canterbury 7647, New Zealand

Telephone $643325-2811$ Facsimile $643325-3847$

www.lincoln,ac.nz

Dear Sir/Madam,

You are invited to participate in a survey that constitutes a part of Master of Commerce and Management thesis at Lincoln University. The survey is to identify and prioritise factors that influence consumers' decision to dine at an upscale ethnic restaurant.

You have been randomly selected to participate in this research. Your participation is very important to this research if the results are to be accurate. Attached is a brief questionnaire, which should only take about 10 to 15 minutes to complete. Your answers will be completely anonymous and confidential. No personal details will be reported in the thesis or any resulting publications.

If you are 18 years old or above and have dined out in a restaurant in the past twelve months, I would be extremely grateful if you would spend a few minutes to complete the questionnaire and return it in the pre-paid, self-addressed envelope attached herewith. Please respond within 15 days after receiving this letter. This research is completely voluntary and returning a completed questionnaire implies consent to participate in the survey. This research project has been reviewed and approved by the Lincoln University Human Ethics Committee.

I will be pleased to discuss any concerns you may have about your participation in the research. I can be contacted at (03) 3253838 ext 8972 or by email at sriwonc2@lincoln.ac.nz. You can also contact my research supervisors, Mr Michael D. Clemes at (03) 3253838 ext 8292, clemes@lincoln.ac.nz, or Dr Zhaohua Li at (03) 3253838 ext 8254, liz2b@lincoln.ac.nz.

Your assistance will contribute greatly to the success of my research. Each and every response is important and I appreciate your willingness to help. Thank you very much.

Yours sincerely,

Chirawan (Mee) Sriwongrat

Master of Commerce and Management Student

Lincoln University 


\section{Appendix B: Questionnaire}

\section{A SURVEY OF CONSUMERS' CHOICE FACTORS OF AN UPSCALE ETHNIC RESTAURANT}

\section{PLEASE NOTE:}

In this study, an upscale ethnic restaurant refers to a full-service restaurant serving food of foreign origin rather than typical New Zealand food (e.g. traditional New Zealand or British-influenced meals such as roasted meat and three vegetables). Examples of ethnic restaurants operating in New Zealand are: Chinese, Greek, Italian, Indian, Japanese, Thai, Mexican, Spanish, etc. A full-service restaurant provides table service where customers give their orders to a server and their food is then brought to them at their tables.

If you come from a country whose cuisine is considered ethnic in New Zealand, please refer to other cuisines as your ethnic food. For example, if you are originally from China and do not consider a Chinese restaurant as an ethnic restaurant, you may refer to your experience with another ethnic restaurant such as Indian, Japanese, or Mexican, when filling out this survey.

For the purpose of this study, an upscale ethnic restaurant has an average main meal price of at least $\$ 20.00$. If you have never dined at an ethnic restaurant which has a main meal price of $\$ 20.00$ or over, please fill out SECTION THREE in the survey, rather than SECTION TWO.

This questionnaire consists of four sections. Please respond to all of the statements in each section (where applicable). Listed below are a series of statements that relate to your restaurant selection behaviour.

\section{SECTION ONE}

Please TICK the most appropriate box.

1. Have you dined at an upscale ethnic restaurant in the past twelve months?
$\square$ Yes.
Please go to QUESTION TWO
No, never.
Please go to SECTION THREE

2. How often do you normally dine out at an upscale ethnic restaurant?

1-2 times a year.

7-11 times a year.

2-3 times a month.
3-6 times a year.

Once a month.

More than 3 times a month. 
3. What is the main occasion of your dining out at an upscale ethnic restaurant? Please tick ONLY ONE box.

Normal dining out.

Gathering with friends/family.

Dating/Intimate dining.
Business- or work-related

Special occasion and celebration. (e.g. birthday, Christmas day)

\section{SECTION TWO: For Upscale Ethnic Restaurant $\underline{\text { Goers }}$}

Statements 1-37 below represent the factors that may influence your decision to dine at an upscale ethnic restaurant.

Please CIRCLE the number that most accurately reflects how strongly you agree or disagree with each statement on a scale of 1 to 7 . Circle 1 if you strongly agree, 7 if strongly disagree, 4 if neutral.

\begin{tabular}{|c|c|c|c|c|c|c|c|}
\hline & $\begin{array}{l}\text { Strongly } \\
\text { Agree }\end{array}$ & & & tral & & & $\begin{array}{l}\text { gly } \\
\text { ree }\end{array}$ \\
\hline 1. An upscale ethnic restaurant offers food that & & & & & & & \\
\hline I cannot cook at home. & 1 & 2 & 3 & 4 & 5 & 6 & 7 \\
\hline $\begin{array}{l}\text { 2. An upscale ethnic restaurant offers food choices } \\
\text { that are prepared according to the requirements }\end{array}$ & & & & & & & \\
\hline of my religion. & 1 & 2 & 3 & 4 & 5 & 6 & 7 \\
\hline $\begin{array}{l}\text { 3. An upscale ethnic restaurant offers several } \\
\text { interesting food choices on the menu. }\end{array}$ & 1 & 2 & 3 & 4 & 5 & 6 & 7 \\
\hline $\begin{array}{l}\text { 4. I like how an upscale ethnic restaurant offers } \\
\text { nutritious food choices. }\end{array}$ & 1 & 2 & 3 & 4 & 5 & 6 & 7 \\
\hline $\begin{array}{l}\text { 5. The food served at an upscale ethnic restaurant } \\
\text { is nicely presented. }\end{array}$ & 1 & 2 & 3 & 4 & 5 & 6 & 7 \\
\hline $\begin{array}{l}\text { 6. The food served at an upscale ethnic restaurant } \\
\text { is healthy. }\end{array}$ & 1 & 2 & 3 & 4 & 5 & 6 & 7 \\
\hline $\begin{array}{l}\text { 7. The food served at an upscale ethnic restaurant } \\
\text { is made of authentic ingredients and has unique } \\
\text { taste of the cuisine. }\end{array}$ & 1 & 2 & 3 & 4 & 5 & 6 & 7 \\
\hline $\begin{array}{l}\text { 8. An upscale ethnic restaurant serves food that I am } \\
\text { familiar with. }\end{array}$ & 1 & 2 & 3 & 4 & 5 & 6 & 7 \\
\hline $\begin{array}{l}\text { 9. I go to an upscale ethnic restaurant because there } \\
\text { is a wide variety of food on the menu. }\end{array}$ & 1 & 2 & 3 & 4 & 5 & 6 & 7 \\
\hline
\end{tabular}




\begin{tabular}{|c|c|c|c|c|c|c|c|}
\hline & \multicolumn{2}{|c|}{$\begin{array}{l}\text { Strongly } \\
\text { Agree }\end{array}$} & \multicolumn{3}{|c|}{ Neutral } & \multicolumn{2}{|c|}{$\begin{array}{l}\text { Strongly } \\
\text { Disagree }\end{array}$} \\
\hline $\begin{array}{l}\text { 10. I go to an upscale ethnic restaurant that serves food } \\
\text { that is in accordance with my religious beliefs. }\end{array}$ & 1 & 2 & 3 & 4 & 5 & 6 & 7 \\
\hline $\begin{array}{l}\text { 11. I like the appearance of the food at an upscale } \\
\text { ethnic restaurant. }\end{array}$ & 1 & 2 & 3 & 4 & 5 & 6 & 7 \\
\hline $\begin{array}{l}\text { 12. The food served at an upscale ethnic restaurant is } \\
\text { similar to the food that I normally eat. }\end{array}$ & 1 & 2 & 3 & 4 & 5 & 6 & 7 \\
\hline $\begin{array}{l}\text { 13. An upscale ethnic restaurant has visually } \\
\text { appealing décor. }\end{array}$ & 1 & 2 & 3 & 4 & 5 & 6 & 7 \\
\hline $\begin{array}{l}\text { 14. The invoices at an upscale ethnic restaurant are } \\
\text { accurate. }\end{array}$ & 1 & 2 & 3 & 4 & 5 & 6 & 7 \\
\hline $\begin{array}{l}\text { 15. The service staff at an upscale ethnic restaurant } \\
\text { are polite and have good interpersonal skills. }\end{array}$ & 1 & 2 & 3 & 4 & 5 & 6 & 7 \\
\hline $\begin{array}{l}\text { 16. An upscale ethnic restaurant has a well allocated } \\
\text { seating order. }\end{array}$ & 1 & 2 & 3 & 4 & 5 & 6 & 7 \\
\hline $\begin{array}{l}\text { 17. The authentic design of an upscale ethnic } \\
\text { restaurant is important. }\end{array}$ & 1 & 2 & 3 & 4 & 5 & 6 & 7 \\
\hline $\begin{array}{l}\text { 18. An upscale ethnic restaurant provides a prompt } \\
\text { service and does not keep me waiting for a long time. }\end{array}$ & 1 & 2 & 3 & 4 & 5 & 6 & 7 \\
\hline $\begin{array}{l}\text { 19. The atmosphere in an upscale ethnic restaurant } \\
\text { influences my decision when selecting a restaurant. }\end{array}$ & 1 & 2 & 3 & 4 & 5 & 6 & 7 \\
\hline $\begin{array}{l}\text { 20. Restaurant service staff at an upscale ethnic restauran } \\
\text { are competent and have a good knowledge of the men }\end{array}$ & it & 2 & 3 & 4 & 5 & 6 & 7 \\
\hline 21. An upscale ethnic restaurant charges me accurately. & 1 & 2 & 3 & 4 & 5 & 6 & 7 \\
\hline $\begin{array}{l}\text { 22. An upscale ethnic restaurant has attentive staff that } \\
\text { pay attention to my personal needs. }\end{array}$ & 1 & 2 & 3 & 4 & 5 & 6 & 7 \\
\hline $\begin{array}{l}\text { 23. When my friends/family recommend an upscale } \\
\text { ethnic restaurant to me, I try it. }\end{array}$ & 1 & 2 & 3 & 4 & 5 & 6 & 7 \\
\hline $\begin{array}{l}\text { 24. I go to an upscale ethnic restaurant that sells the } \\
\text { beverages that I normally drink. }\end{array}$ & 1 & 2 & 3 & 4 & 5 & 6 & 7 \\
\hline $\begin{array}{l}\text { 25. I go to an upscale ethnic restaurant because it offers } \\
\text { me a unique experience. }\end{array}$ & 1 & 2 & 3 & 4 & 5 & 6 & 7 \\
\hline $\begin{array}{l}\text { 26. I choose an upscale ethnic restaurant where I can get } \\
\text { a discount (e.g. from vouchers, loyalty card). }\end{array}$ & 1 & 2 & 3 & 4 & 5 & 6 & 7 \\
\hline $\begin{array}{l}\text { 27. I am satisfied with the price I pay for a meal at an } \\
\text { upscale ethnic restaurant. }\end{array}$ & 1 & 2 & 3 & 4 & 5 & 6 & 7 \\
\hline
\end{tabular}




\begin{tabular}{|c|c|c|c|c|c|c|c|}
\hline & \multicolumn{2}{|c|}{$\begin{array}{l}\text { Strongly } \\
\text { Agree }\end{array}$} & \multicolumn{3}{|c|}{ Neutral } & \multicolumn{2}{|c|}{$\begin{array}{l}\text { Strongly } \\
\text { Disagree }\end{array}$} \\
\hline $\begin{array}{l}\text { 28. Going to an upscale ethnic restaurant is a great } \\
\text { way to experience a different culture. }\end{array}$ & 1 & 2 & 3 & 4 & 5 & 6 & 7 \\
\hline $\begin{array}{l}\text { 29. An upscale ethnic restaurant offers a wide } \\
\text { assortment of beverages. }\end{array}$ & 1 & 2 & 3 & 4 & 5 & 6 & 7 \\
\hline $\begin{array}{l}\text { 30. I go to an upscale ethnic restaurant because my } \\
\text { friends/family like to go there. }\end{array}$ & 1 & 2 & 3 & 4 & 5 & 6 & 7 \\
\hline $\begin{array}{l}\text { 31. I go to an upscale ethnic restaurant because it is } \\
\text { patronised by people of a similar class to mine. }\end{array}$ & 1 & 2 & 3 & 4 & 5 & 6 & 7 \\
\hline $\begin{array}{l}\text { 32. I choose an upscale ethnic restaurant that I have } \\
\text { heard about through advertising. }\end{array}$ & 1 & 2 & 3 & 4 & 5 & 6 & 7 \\
\hline $\begin{array}{l}\text { 33. I get good value for the amount of money I pay } \\
\text { when dining at an upscale ethnic restaurant. }\end{array}$ & 1 & 2 & 3 & 4 & 5 & 6 & 7 \\
\hline $\begin{array}{l}\text { 34. The cultural experience I get from dining at an } \\
\text { upscale ethnic restaurant gives me the impression } \\
\text { that I am in that particular country. }\end{array}$ & 1 & 2 & 3 & 4 & 5 & 6 & 7 \\
\hline $\begin{array}{l}\text { 35. I go to an upscale ethnic restaurant when I want } \\
\text { to try a different dining experience. }\end{array}$ & 1 & 2 & 3 & 4 & 5 & 6 & 7 \\
\hline $\begin{array}{l}\text { 36. Positive comments about an upscale ethnic restaurant } \\
\text { from publicity encourage me to dine at one. }\end{array}$ & it & 2 & 3 & 4 & 5 & 6 & 7 \\
\hline $\begin{array}{l}\text { 37. I choose an upscale ethnic restaurant whose image } \\
\text { reflects my self-image. }\end{array}$ & 1 & 2 & 3 & 4 & 5 & 6 & 7 \\
\hline
\end{tabular}

\section{Please go to SECTION FOUR}




\section{SECTION THREE: For Upscale Ethnic Restaurant Non-goers}

Statements 1-37 below represent the factors that may influence your decision not to dine at an upscale ethnic restaurant.

Please CIRCLE the number that most accurately reflects how strongly you agree or disagree with each statement on a scale of 1 to 7 . Circle 1 if you strongly agree, 7 if strongly disagree, 4 if neutral.

\begin{tabular}{|c|c|c|c|c|c|c|c|}
\hline & \multicolumn{2}{|c|}{$\begin{array}{l}\text { Strongly } \\
\text { Agree }\end{array}$} & \multicolumn{3}{|c|}{ Neutral } & \multicolumn{2}{|c|}{$\begin{array}{l}\text { Strongly } \\
\text { Disagree }\end{array}$} \\
\hline $\begin{array}{l}\text { 1. I believe an upscale ethnic restaurant offers food } \\
\text { that I can cook at home. }\end{array}$ & 1 & 2 & 3 & 4 & 5 & 6 & 7 \\
\hline $\begin{array}{l}\text { 2. I assume an upscale ethnic restaurant does not } \\
\text { offer food choices that are prepared according to } \\
\text { the requirements of my religion. }\end{array}$ & 1 & 2 & 3 & 4 & 5 & 6 & 7 \\
\hline $\begin{array}{l}\text { 3. I assume an upscale ethnic restaurant does not offer } \\
\text { several interesting food choices on the menu. }\end{array}$ & 1 & 2 & 3 & 4 & 5 & 6 & 7 \\
\hline $\begin{array}{l}\text { 4. I assume an upscale ethnic restaurant does not offer } \\
\text { food choices that are high in nutritional value. }\end{array}$ & 1 & 2 & 3 & 4 & 5 & 6 & 7 \\
\hline $\begin{array}{l}\text { 5. I think the food at an upscale ethnic restaurant is } \\
\text { not well-presented. }\end{array}$ & 1 & 2 & 3 & 4 & 5 & 6 & 7 \\
\hline $\begin{array}{l}\text { 6. I believe the food served at an upscale ethnic } \\
\text { restaurant is unhealthy. }\end{array}$ & 1 & 2 & 3 & 4 & 5 & 6 & 7 \\
\hline $\begin{array}{l}\text { 7. I assume an upscale ethnic restaurant does not } \\
\text { offer food with authentic tastes and ingredients. }\end{array}$ & 1 & 2 & 3 & 4 & 5 & 6 & 7 \\
\hline $\begin{array}{l}\text { 8. I am not familiar with the food at an upscale } \\
\text { ethnic restaurant. }\end{array}$ & 1 & 2 & 3 & 4 & 5 & 6 & 7 \\
\hline $\begin{array}{l}\text { 9. I assume an upscale ethnic restaurant has limited } \\
\text { food choices on the menu. }\end{array}$ & 1 & 2 & 3 & 4 & 5 & 6 & 7 \\
\hline $\begin{array}{l}\text { 10. I believe the food served at an upscale ethnic } \\
\text { restaurant is not in accordance with my religious } \\
\text { beliefs. }\end{array}$ & 1 & 2 & 3 & 4 & 5 & 6 & 7 \\
\hline $\begin{array}{l}\text { 11. I assume the appearance of the food at an upscale } \\
\text { ethnic restaurant is not appealing. }\end{array}$ & 1 & 2 & 3 & 4 & 5 & 6 & 7 \\
\hline $\begin{array}{l}\text { 12. I think the food served at an upscale ethnic restauran } \\
\text { is different from the food that I normally eat. }\end{array}$ & nt & 2 & 3 & 4 & 5 & 6 & 7 \\
\hline $\begin{array}{l}\text { 13. I assume an upscale ethnic restaurant does not have } \\
\text { visually appealing décor. }\end{array}$ & 1 & 2 & 3 & 4 & 5 & 6 & 7 \\
\hline $\begin{array}{l}\text { 14. I assume the invoices at an upscale ethnic } \\
\text { restaurant are inaccurate. }\end{array}$ & 1 & 2 & 3 & 4 & 5 & 6 & 7 \\
\hline
\end{tabular}




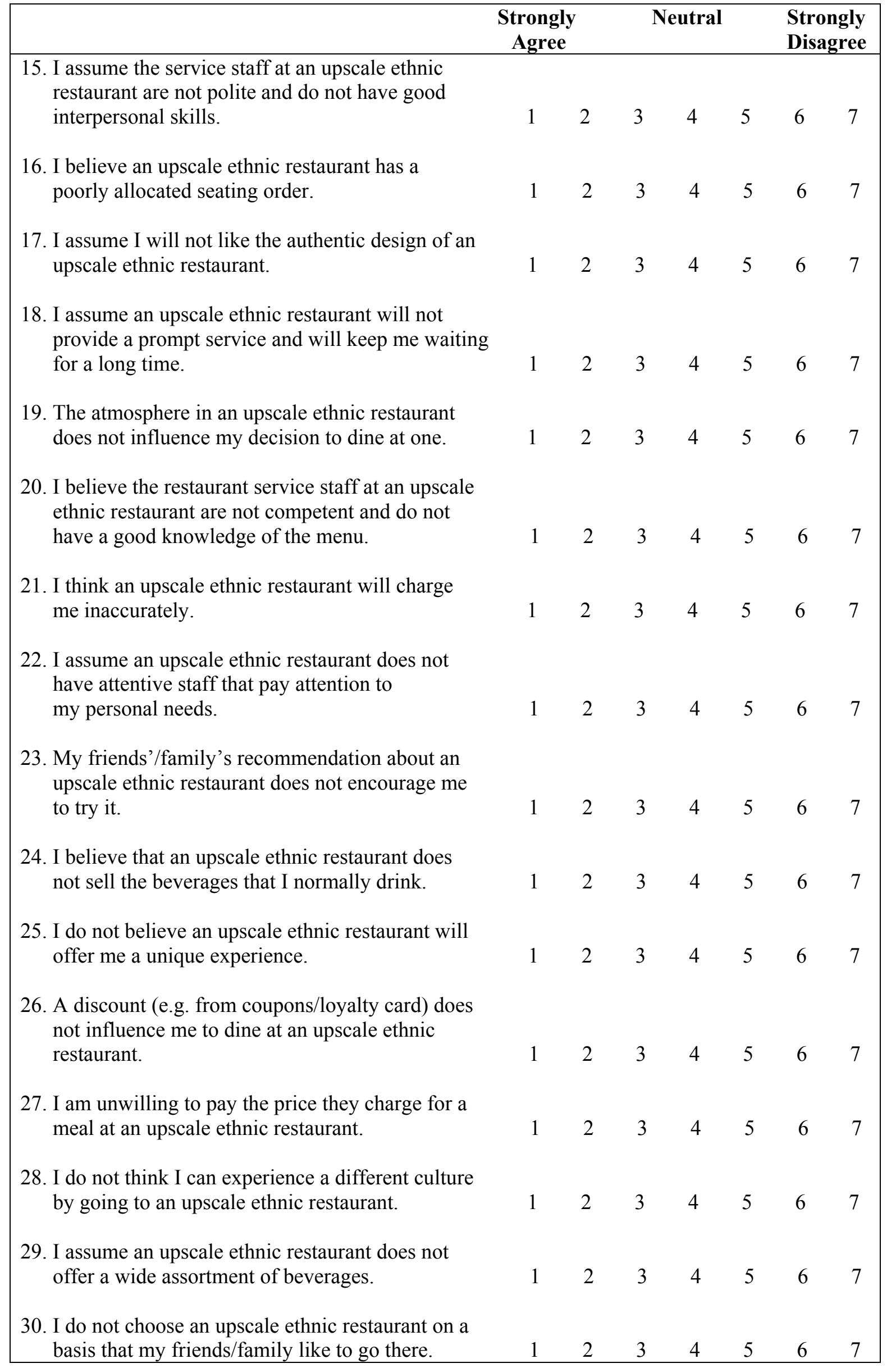




\begin{tabular}{|c|c|c|c|c|c|c|c|}
\hline & \multicolumn{2}{|l|}{$\begin{array}{l}\text { Strongly } \\
\text { Agree }\end{array}$} & \multicolumn{3}{|c|}{ Neutral } & \multicolumn{2}{|c|}{$\begin{array}{l}\text { Strongly } \\
\text { Disagree }\end{array}$} \\
\hline $\begin{array}{l}\text { 31. I do not take social status into account when } \\
\text { choosing a restaurant. }\end{array}$ & 1 & 2 & 3 & 4 & 5 & 6 & 7 \\
\hline $\begin{array}{l}\text { 32. An advertisement does not influence me to dine } \\
\text { at an upscale ethnic restaurant. }\end{array}$ & 1 & 2 & 3 & 4 & 5 & 6 & 7 \\
\hline $\begin{array}{l}\text { 33. I believe dining at an upscale ethnic restaurant } \\
\text { will be too expensive. }\end{array}$ & 1 & 2 & 3 & 4 & 5 & 6 & 7 \\
\hline $\begin{array}{l}\text { 34. I believe an upscale ethnic restaurant will not give } \\
\text { me the cultural experience or the impression that } \\
\text { I am in that particular country. }\end{array}$ & 1 & 2 & 3 & 4 & 5 & 6 & 7 \\
\hline $\begin{array}{l}\text { 35. I do not think dining at an upscale ethnic restaurant } \\
\text { will give me a different dining experience. }\end{array}$ & 1 & 2 & 3 & 4 & 5 & 6 & 7 \\
\hline $\begin{array}{l}\text { 36. Positive comments about an upscale ethnic } \\
\text { restaurant from publicity do not encourage me } \\
\text { to dine at one. }\end{array}$ & 1 & 2 & 3 & 4 & 5 & 6 & 7 \\
\hline $\begin{array}{l}\text { 37. I do not think the image of an upscale ethnic } \\
\text { restaurant reflects my self-image. }\end{array}$ & 1 & 2 & 3 & 4 & 5 & 6 & 7 \\
\hline
\end{tabular}

\section{Please go to SECTION FOUR}




\section{SECTION FOUR}

Please TICK the most appropriate box.

1. What is your gender?

Male

Female

2. Which is your age group?

$18-25$

46-55
26-35

56-65
$36-45$

$66+$

3. What is your ethnicity?
$\square$ NZ European
$\square$ NZ Maori
$\square$ European
$\square$ Asian
Pacific Islander
North American
Other
Australian

4. What is your highest educational or professional qualification?
Up to high school certificate
Seventh form certificate
Bachelors degree
Diploma
Trade qualification
Other
Postgraduate degree

5. What is your occupation?

$\begin{array}{llll}\square \text { Professional } & \square \text { Tradesperson } & \square \text { Student } & \square \text { Clerical } \\ \square \text { Labourer } & \square \text { Farmer } & \square \text { Sales/Service } & \square \text { Unemployed } \\ \square \text { Self-employed } & \square \text { Management } & \square \text { Retired } & \square \text { Other }\end{array}$

6. What is your household composition?
Married without children at home
$\square$ Partner without children at home
$\square$ Single-person household
Living with flatmate(s)
$\square$ Married with child(ren)
$\square$ Partner with child(ren)
Single-parent family
Other

7. What is your annual household income before tax?
$\square$ Under $\$ 25,000$
$\$ 75,000-\$ 99,999$

$\$ 150,000-\$ 174,999$

$\$ 25,000-\$ 49,999$

$\$ 100,000-\$ 124,999$

$\square \$ 175,000-\$ 199,999$
$\square \$ 50,000-\$ 74,999$
$\square \$ 125,000-\$ 149,999$
$\square \$ 200,000+$

Thank you very much for your valuable assistance in this research. Please promptly return the survey. A prepaid envelope is provided. 